\title{
RDUS
}

Revue de DROIT

UNIVERSITÉ DE SHERBROOKE

Titre : $\quad$ L'AFFIRMATION DE L'ACTION DIRECTE DU TIERS LÉSÉ EN ASSURANCE DE RESPONSABILITÉ

Auteur(s): $\quad$ Annick GUÉRARD-KERHULU

Revue : $\quad$ RDUS, 1996-1997, volume 27, numéro 1-2

Pages: $\quad 171-306$

ISSN : $\quad 0317-9656$

Éditeur : $\quad$ Université de Sherbrooke. Faculté de droit.

URI : $\quad$ http://hdl.handle.net/11143/12851

DOI : https://doi.org/10.17118/11143/12851 
Page vide laissée intentionnellement. 


\title{
ARTICLE
}

\section{L'AFFIRMATION DE L'ACTION DIRECTE DU TIERS LÉSÉ EN ASSURANCE DE RESPONSABILITÉ}

\author{
par Annick GUÉRARD-KERHULU**
}

L'action directe du tiers lésé n'est plus un droit de procédure. En procédant à l'analyse de la nature de l'action directe du tiers lésé, nous établirons que les droits des tiers lésés sont diminués par les clauses d'assurance qui limitent la garantie selon les réclamations des victimes, d'où l'intérêt de s'interroger sur la validité de telles clauses d'assurance.

Nous verrons également que l'autonomie de l'action directe du tiers lésé a pour conséquence de modifier les droits que détient un assureur subrogé pour se faire rembourser l'indemnité qu'il a versée. Les conséquences de l'autonomie de l'action directe du tiers lésé nous conduiront à vérifier l'applicabilité des exceptions au droit de subrogation lorsque l'assureur entend recouvrer le montant de l'indemnité contre l'assureur d'une personne de la maison de l'assuré.

A direct action brought by an injured third party is no longer a mere procedural right. Through an analysis of the actual nature of the direct action, rights of injured third parties may be curtailed by clauses which, according to the nature of the claims, actually limit guarantees. The importance of examining the validity of these insurance clauses thus becomes evident.

Moreover, the autonomy of the direct action by an injured third party may also affect the rights of a subrogated insurer to obtain reimbursement of the indemnity paid. The repercussions flowing from the autonomous nature of the action of an injured third party require an examination of the law governing exceptions to the right of subrogation in cases where an insurer, having disbursed an indemnity, seeks to recover the amount disbursed from the insurer of a member of the insured's household.

\footnotetext{
* $\quad$ Ce texte est tiré d'un mémoire présenté à la Faculté des études supérieures de l'Université Laval pour l'obtention du grade de maître en droit (LL.M.).

**. Associée nominale de l'étude Langlois \& Boulay, avocats. L'auteure est bachelière en science politique et en droit de l'Université Laval.
} 


\section{SOMMAIRE}

\section{CHAPITRE PRÉLIMINAIRE :}

LA GENÈSE DE L'ACTION DIRECTE DU TIERS LÉSÉ EN ASSURANCE DE RESPONSABILITÉ $\ldots \ldots \ldots \ldots \ldots 179$

Section 1. Le droit antérieur à $1974 \ldots \ldots \ldots \ldots \ldots$

$\S 1 . \quad$ La fragilité du recours direct de la victime avant $1974 \ldots$. . . . . 179

§2. La création d'un véritable recours direct en matière d'accidents d'automobile ...................... 184

Section 2. La réforme de $1974 \ldots \ldots \ldots \ldots \ldots \ldots \ldots \ldots$

$\S 1$ La création de l'action directe en faveur du tiers lésé . . . . . . 187

§2. L'interprétation restrictive de l'action directe du tiers lésé . . . . 188

A. La thèse du raccourci procédural $\ldots \ldots \ldots \ldots \ldots \ldots 188$

B. Le rejet du cumul $\ldots \ldots \ldots \ldots \ldots \ldots \ldots \ldots \ldots \ldots \ldots$

C. Le débat portant sur l'inopposabilité des exceptions postérieures

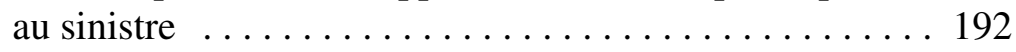

a) La nature du débat $\ldots \ldots \ldots \ldots \ldots \ldots \ldots \ldots \ldots$

b) L'affaire Aetna ................ 193

Section 3. Le code civil de $1994 \ldots \ldots \ldots \ldots \ldots \ldots$

§1. L'adoption du cumul en faveur du tiers lésé . . . . . . . . . 196

§2. La consécration de l'inopposabilité des exceptions postérieures au sinistre
A. L'influence du droit français 
B. L'étendue de la protection des droits des tiers lésés .... 201

\section{CHAPITRE 1 :}

LA NATURE HYBRIDE DE L'ACTION DIRECTE DU TIERS LÉSÉ ................................. 205

Section 1. La notion de sinistre et la période de garantie . . . . 206

§1. La naissance de la dette de responsabilité de l'assuré . . . . . . 207

A. La datation du sinistre en assurance de responsabilité

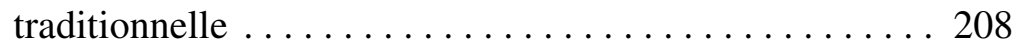

a) L'interprétation des principes issus du Code civil $d u$ Québec ...................... 208

i) L'existence d'un fait dommageable . . . 208

ii) L'existence d'une dette de responsabilité 209

b) Les enseignements de la Cour suprême du Canada 210

c) Le sinistre en droit français . . . . . . . . 213

i) La détermination $\mathrm{du}$ sinistre selon la jurisprudence .............. 213

ii) La détermination du sinistre selon la doctrine

d) Les clauses des polices d'assurance déterminant le sinistre . . . . . . . . . . . . . 219

i) La notion d' «accident» .......... 219

ii) La notion d' «événement» ......... 220

iii) La notion de «réclamation de la victime» 222

B. La datation du sinistre dans les assurances à base de réclamation

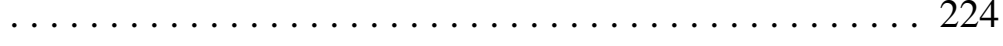

a) Les contrats «sur la base des réclamations» . . . . 224

b) Le déclenchement de la garantie des polices hybrides ....................... 226

i) La survenance du sinistre . . . . . . 226

ii) La déclaration de la réclamation à l'assureur 228

c) L'arrêt Reid Crowther Ltd. : les considérations de la Cour suprême du Canada concernant les contrats à base de réclamation .................. 229 
i) La création de trous de garantie ..... 230

ii) Les effets des trous de garantie sur la couverture d'assurance ................ 231

iii) Les conditions de validité des polices à base de réclamation vis-à-vis l'assuré . . . . . . . . 232

d) Les clauses destinées à pallier les trous de garantie233

i) La «reprise du passé inconnu» ....... 234

ii) La «garantie subséquente» ......... 236

§2. Le caractère prépondérant de l'action directe du tiers lésé sur les clauses à base de réclamation . . . . . . . . . . . . 240

A. La protection de l'action directe en réparation du tiers lésé . . . . . . . . . . . . . . . . . . . . 240

a) La consécration du droit direct .............. 240

b) L'autonomie du droit direct ................ 241

B. La critique des clauses à base de réclamation . . . . . 242

a) La perte du bénéfice de la prescription ...... 243

b) La dérogation à l'ordre public .......... 244

§3. Le caractère impératif des droits des tiers lésés en droit français . 246

a) Le premier courant prononçant l'inopposabilité des clauses basées sur les réclamations ........ 247

b) Le renversement jurisprudentiel déclarant la nullité des clauses dites «claims-made» ............ 249

\section{Section 2. Les conditions d'exercice de l'action directe du tiers lésé}

$\S 1$ Les personnes pouvant exercer l'action directe . . . . . . . 255

§2. La preuve de la dette de responsabilité de l'assuré ........ 256

A. La mise en cause de l'assuré ............. 256

B. La preuve de la responsabilité de l'assuré au moyen de l'«exception de la chose jugée»............... 259

§3. La preuve du contrat d'assurance . . . . . . . . . . . . 262

A. L'existence du contrat d'assurance $\ldots \ldots \ldots \ldots \ldots 263$ 
B. La preuve de la garantie d'assurance au moyen de l'«exception de la chose jugée» . . . . . . . . . . . . . . . . . 265

a) L'application de l' «exception de la chose jugée» aux fins de prouver le sinistre ............ 265

b) L'application de l' «exception de la chose jugée» à l'action directe du tiers lésé . . . . . . . . . . . 267

\section{CHAPITRE 2 :}

\section{LES CONSÉQUENCES DE L'AUTONOMIE DE L'ACTION DIRECTE DU TIERS LÉSÉ

§1. Le caractère autonome de l'action directe en réparation

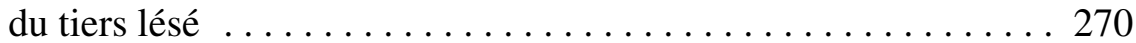

A. Le recours subrogatoire de l'assureur . . . . . . . 270

a) Le principe de la subrogation . . . . . . . 271

b) La subrogation de la créance de réparation directe du

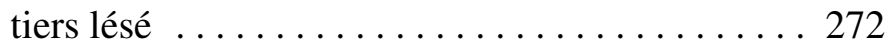

B. Les exceptions au recours subrogatoire de l'assureur . . . 275

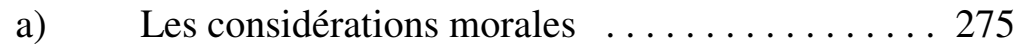

b) Les raisons juridiques ............ 278

§2. Le caractère prédominant de l'action directe du tiers lésé sur les exceptions à la subrogation de l'article 2474 C.c.Q. . . . . . . . . 280

A. L'inapplication des fondements de l'interdiction de subrogation

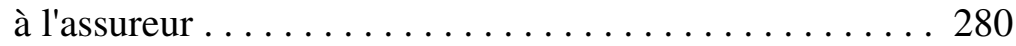

a) L'absence de liens moraux entre assureurs ... . . 280

b) L'absence de raison juridique .......... 282

B. Le recours direct de l'assureur contre l'assureur du responsable faisant partie de la maison de l'assuré . . . . . . . . . 284

a) L'état de la question selon la jurisprudence de la SaintMaurice ..................... 285

b) L'état de la question selon la doctrine québécoise 285

i) La thèse fondée sur la subrogation . . . . 286

ii) La thèse fondée sur l'assurance de responsabilité

c) Les hésitations de la jurisprudence française ... . 288 
i) Le premier courant rejetant le recours subrogatoire de l'assureur . . . . . . . 288

ii) Le revirement de la jurisprudence française à l'égard des Caisses de Sécurité sociale . . 289

iii) Le retour au premier courant . . ...... 291

iv) La jurisprudence française change encore d'optique .................. 292

d) La solution française s'appuyant sur le caractère d'exception de l'interdiction de subrogation . . . . 293

e) L'applicabilité de la solution française au Québec 295

§3. Le caractère autonome de l'extinction de l'action directe du tiers lésé . . . . . . . . . . . . . . . . . . . . . . . . . . . . . 298

A. La prescription de l'action directe du tiers lésé . . . . . . 299

B. Les modes d'extinction de l'action directe du tiers lésé . . 300

C. L'autonomie de la prescription du recours direct du tiers lésé .............................. 302

a) L'absence d'interruption de prescription ...... 302

b) L'étendue de la prescription de l'action directe du tiers lésé ............................... 304

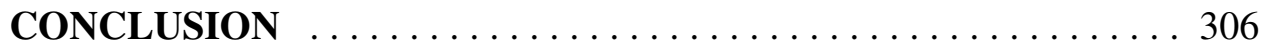




\section{INTRODUCTION}

Depuis l'adoption du Code civil du Québec, la protection des droits des tiers lésés est devenue une finalité de l'assurance de responsabilité. Le souci du législateur d'assurer une plus grande protection aux victimes se traduit par l'institution d'un régime de protection d'ordre public et par la reconnaissance du caractère substantiel de l'action directe du tiers lésé.

La transformation de l'action directe du tiers lésé en un droit propre et autonome établit un nouveau rapport de droit entre la victime et l'assureur de responsabilité de l'auteur du préjudice. Pour démontrer ce nouveau rapport de droit, il convient de mettre en lumière l'essentiel de la théorie classique de l'action directe qui s'est développée en France au début des années trente. En effet, la présentation des fondements théoriques du droit direct du tiers lésé nous permet de mieux comprendre la notion d'action directe, sa nature et ses effets. C'est pourquoi nous avons cru opportun de rappeler, dans un chapitre préliminaire, l'évolution des droits des tiers lésés dans le domaine de l'assurance de responsabilité au Québec.

Dans la présentation des liens juridiques unissant la victime à l'assureur de l'auteur du préjudice, nous ferons valoir le caractère substantiel du droit direct du tiers lésé. Avec le remarquable essor de l'autonomie de l'action directe, consécutif à l'adoption d'un régime d'ordre public qui assure la protection des droits des tiers lésés en assurance de responsabilité, nous constaterons que l'action directe n'a plus la même portée depuis l'adoption du nouveau Code civil.

À cet égard, nous aborderons deux aspects majeurs découlant de l'affirmation de l'action directe du tiers lésé selon le droit moderne. L'un d'eux 
consiste à analyser la nature autonome du droit direct du tiers lésé pour arriver à déterminer l'étendue de ce même droit. Incidemment, nous verrons que l'affirmation du caractère autonome du recours direct du tiers lésé implique une remise en question des clauses d'assurance qui exigent que les réclamations des victimes soient présentées à l'assureur pendant que le contrat est en vigueur. Le second aspect traite des conséquences de l'autonomie de l'action directe du tiers lésé. Nous allons démontrer notamment l'impact de l'affirmation du droit direct du tiers lésé sur les droits que possède un assureur subrogé contre les personnes de qui il peut recouvrer le montant de l'indemnité qu'il a versée. L'analyse de la nature de l'action directe du tiers lésé s'avère toutefois un préalable à l'étude de ces deux aspects importants qui découlent de la consécration de l'autonomie du droit direct du tiers lésé.

Il est certain que l'affirmation du caractère substantiel et autonome du droit direct du tiers lésé a transformé la nature de l'action directe. Aussi, avonsnous jugé à propos d'entreprendre, dans un premier chapitre, l'examen de la nature hybride de l'action directe du tiers lésé qui suppose à la fois l'existence de la créance de responsabilité de la victime et l'application du contrat d'assurance.

L'étude de la nature hybride du droit direct du tiers lésé nous permettra de soulever les difficultés propres à la détermination de la naissance de la dette de réparation du tiers lésé et à l'identification du point de départ de la garantie d'assurance. Étant donné la subordination de l'action directe à l'application du contrat d'assurance, nous établirons que, dans certains domaines de l'assurance de responsabilité, spécialement en matières commerciale et professionnelle, les droits des tiers lésés sont diminués par les polices d'assurance qui limitent la garantie en fonction des réclamations des victimes.

L'affirmation du droit direct du tiers lésé engendre d'importantes conséquences sur les droits de l'assureur subrogé lorsque cet assureur désire se faire rembourser par des tierces personnes, le montant de l'indemnité qu'il a payée. C'est ce qui explique pourquoi nous consacrerons l'essentiel du second chapitre aux effets de l'affirmation de l'action directe sur les droits dont dispose un assureur subrogé pour recouvrer contre des tiers le montant représentant l'indemnité versée. Nous déterminerons en quoi le caractère autonome du droit direct du tiers lésé implique une remise en question des limites imposées au 
recours subrogatoire de l'assureur dans le domaine de l'assurance de responsabilité, particulièrement lorsque la personne contre laquelle l'assureur peut se faire rembourser est l'assureur d'un tiers responsable faisant partie de la maison de l'assuré.

Chemin faisant, l'ensemble de notre mémoire permettra de constater la transformation de l'assurance de responsabilité depuis l'adoption du Code civil du Québec. Par notre contribution, nous espérons faire valoir cette réalité et pouvoir alimenter les discussions portant sur le rôle de plus en plus marqué de l'assurance de responsabilité de veiller à la protection des droits des tiers lésés.

\section{CHAPITRE PRÉLIMINAIRE :}

\section{LA GENÈSE DE L'ACTION DIRECTE DU TIERS LÉSÉ EN ASSURANCE DE RESPONSABILITÉ}

\section{Section 1. Le droit antérieur à 1974}

Jusqu'à l'introduction, en 1961, de l'article 6 de la Loi de l'indemnisation des victimes d'accidents d'automobile, ${ }^{1}$ ni le Code civil du Bas-Canada, pas plus que la Loi des assurances ${ }^{2}$ n'instituaient de lien de droit entre la victime et l'assureur du responsable. À moins d'être bénéficiaire d'une stipulation pour autrui, la victime devait poursuivre l'auteur du préjudice ou exercer une action oblique auquel cas la victime pouvait s'adresser directement à l'assureur en subissant toutefois le concours des autres créanciers du responsable.

\section{§1. La fragilité du recours direct de la victime avant 1974}

Hormis le cas particulier de la responsabilité découlant d'un accident d'automobile, seuls l'auteur du préjudice et la victime sont liés par les fondements de la responsabilité civile avant la réforme du droit des assurances

1. Loi de l'indemnisation des victimes d'accidents d'automobile, S.Q. 1961, c. 65.

2. $\quad$ Loi des assurances, S.R.Q. 1964, c. 295. 
en $1974 .^{3}$ C'est pourquoi la réparation de toute victime passe d'abord par la poursuite du responsable et celui-ci peut appeler son assureur en garantie. Si l'assuré refuse ou néglige d'exercer ses droits contractuels contre son assureur, le tiers lésé peut alors agir par le truchement de l'action oblique ${ }^{4}$ afin de recouvrer l'indemnité à laquelle il a droit.

Une apparence de droit suffit au tiers lésé qui entend exercer l'action oblique envers l'assureur du responsable. ${ }^{5}$ En réalité, le tiers lésé exerce les droits contractuels de l'assuré comme s'il était son représentant. C'est ce qui explique pourquoi le montant de l'assurance tombe dans le patrimoine de l'auteur du préjudice; la victime n'ayant aucun droit de gestion du patrimoine de ce dernier. ${ }^{6}$ Une fois le montant des dommages établis par règlement ou par jugement, ${ }^{7}$ la victime peut saisir-arrêter le montant de sa réparation entre les mains de l'assureur du responsable. ${ }^{8}$

Cette procédure implique que l'indemnité qui tombe dans le patrimoine de l'auteur du préjudice est susceptible de saisie par l'ensemble des créanciers de ce dernier. La victime pourra également se faire opposer tous les moyens que l'assureur est en droit d'invoquer contre l'assuré puisque son action est fondée sur les droits du cocontractant. ${ }^{9}$ L'on comprendra que le recours de la victime puisse s'avérer vain parce que la créance de réparation de cette même victime vient en concurrence avec celle des autres créanciers de l'auteur du préjudice. Somme toute, avant la réforme du droit des assurances en 1974, une victime

3. Le droit à la réparation de la victime trouvait sa justification dans les règles de droit des articles 1053-1056 C.c.B.-C. (maintenant 1457-1469 C.c.Q.) qui font de la faute d'une personne la condition première de la responsabilité civile. Il s'agit d'une théorie subjective de la responsabilité où la faute, le préjudice et le lien de causalité en conditionnent l'existence. Voir M. Tancelin, Des obligations : L'acte illégitime et les modes d'exécution, vol. 2, Montréal, Wilson \& Lafleur, 1993 aux pp. 16-20, $\mathrm{n}^{\text {os }} 411-416$.

4. $\quad$ Art. 1627 C.c.Q., anciennement art. 1031 C.c.B.-C.

5. M. Tancelin, supra note 3 aux pp. 164-166, $\mathrm{n}^{\text {os }}$ 646-649.

6. J.-L. Baudouin, Les obligations, $4^{\mathrm{e}}$ éd., Cowansville, Yvon Blais, 1993 à la p. 357, $\mathrm{n}^{0} 649$.

7. I. Mignault, «Assurance-responsabilité : Rapports juridiques entre tiers réclamant et assureur», (1955) 15 R. du B. 126 aux pp. 133-134.

8. $\quad$ Art. 625 et s. C.p.c.

9. La Prévoyance, compagnie d'assurances c. Dulude, [1965] B.R. 573. 
devait espérer que l'auteur de son préjudice soit solvable ${ }^{10}$ ou assuré afin de bénéficier d'une réparation satisfaisante.

L'objet de l'assurance de responsabilité a toujours été de garantir l'assuré contre les conséquences pécuniaires découlant de sa responsabilité civile. ${ }^{11} \mathrm{Au}$ moyen de l'assurance, l'auteur du préjudice peut se libérer de sa dette de responsabilité sans réellement subir de perte patrimoniale. Il lui suffit d'appeler son assureur en garantie pour forcer ce dernier à exécuter son obligation d'assurance car "[l'] assuré n'a pas besoin, c'est évident, de justifier du moindre paiement de ses deniers à la victime». ${ }^{12}$ La fonction indemnitaire de l'assurance de responsabilité s'est vite adaptée à cette réalité. Le marché de l'assurance a alors prévu que le versement de l'indemnité d'assurance pourrait s'effectuer au profit de la victime, pour le compte de l'assuré.

En effet, dès la première moitié du vingtième siècle, les assureurs offraient à leur clientèle les polices d' «indemnisation» et les polices dites «payer pour». ${ }^{13}$ Les premières avaient pour objectif d'indemniser l'assuré par le transfert d'une somme d'argent du patrimoine de l'assureur à celui de son assuré. Les secondes présentaient une stipulation pour autrui en vertu de laquelle l'assureur s'engageait à verser l'indemnité à la victime, au nom de l'assuré. ${ }^{14}$ Il s'agissait ici d'une exception au principe de droit romain «alteri stipulari nemo potest» selon lequel les contrats n'ont d'effets qu'entre les parties contractantes.

10. Parfois, même la solvabilité de l'auteur du préjudice n'est pas un critère suffisant pour que la victime fasse valoir son droit à la réparation contre le débiteur puisque «[d]ans de nombreux pays, ceux qui sont solvables bénéficient d'une situation sociale telle que le citoyen ordinaire n'ose pas les poursuivre devant un tribunal ou n'a pas les moyens d'agir à leur encontre.» A. Tunc, La responsabilité civile, $2^{\mathrm{e}}$ éd., Paris, Economica, 1989 à la p. 8, $\mathrm{n}^{\mathrm{o}} 2$.

11. Voir la version de 1866 de l'article 2475 C.c.B.-C., al. 2, celle de 1994 de l'article 2396 C.c.Q. ainsi que l'article 16 du Règlement d'application de la Loi sur les assurances, R.R.Q. 1981, c. A-32, r. 1.

12. Juris-classeur responsabilité civile, fasc. 511-5, par P. Veaux-Fournerie et D. Veaux, $n^{\circ} 83$ [ci-après J.-cl. resp. civ.].

13. Voir I. Mignault, supra note 7 aux pp. 126-135, pour une analyse des polices d' «indemnisation» et des polices «payer pour».

14. Union québécoise, mutuelle d'assurance contre l'incendie c. Mutuelle des Bois-Francs, [1984] C.A. 473 aux pp. 475-476, M. le juge Mayrand [ci-après Mutuelle des Bois-Francs]. 
Dans le cas des polices «payer pour», l'assuré est avantagé par la stipulation puisqu'il a intérêt à ce que l'assureur (le promettant) s'exécute au profit du tiers pour éteindre sa dette de responsabilité. ${ }^{15}$ Moyennant le consentement de l'assuré, l'assureur pouvait payer directement la victime et éliminer la dette de responsabilité de l'auteur du préjudice. Selon la jurisprudence de La Mutuelle des Bois-Francs, les polices «payer pour» attribuaient «(...) au tiers (la victime) une action directe contre l'assureur avant même que l'article 2603 C.C. n'ait été adopté». ${ }^{16}$

En interprétant une clause omnibus en matière d'assurance automobile, la Cour suprême du Canada a reconnu que la stipulation pour autrui conférait un droit propre en faveur du bénéficiaire, vis-à-vis l'assureur de l'auteur du préjudice. ${ }^{17}$ Ainsi, lorsqu'un contrat d'assurance exigeait que l'indemnité soit versée aux victimes d'accidents d'automobile pour le compte de l'assuré, un lien de droit était créé entre l'assureur et les victimes. ${ }^{18}$ Les bénéficiaires de la stipulation pour autrui devaient être indemnisés de la même manière et aux mêmes conditions que celles auxquelles l'assuré était soumis. Ces bénéficiaires pouvaient donc poursuivre directement l'assureur après jugement final exécutoire contre l'assuré ou une fois la responsabilité de l'assuré établie par règlement.

En assurance de responsabilité, la victime qui bénéficiait d'une stipulation pour autrui avait donc l'avantage de ne pas faire entrer sa créance de

15. J.-L Baudouin, supra note 6 à la p. 275, $\mathrm{n}^{\circ}$ 483. Pour une application plus récente des distinctions entre les polices «payer pour» et les polices d' «indemnisation» voir: Henry John Generas c. Hartford Accident and Indemnity Company, [1978] C.A. 1; Société d'assurance des Caisses populaires c. Maryland Casualty Company, [1977] C.S. 3; Union canadienne, compagnie d'assurances c. Saint-Maurice, compagnie d'assurances (23 janvier 1995), Québec 200-05-002396-898 à la p. 7, M. le juge Moisan [ci-après Union canadienne].

16. Union, Mutuelle d'assurance contre l'incendie c. Mutuelle des Bois-Francs (La), supra note 14 aux pp. 475-476, M. le juge Mayrand; Union canadienne, supra note 15.

17. Hallé c. Canadian Indemnity Ins. Company, [1937] R.C.S. 368 à la p. 377, M. le juge Rinfret. La Cour utilise l'expression «an independent right» pour désigner le droit de la victime vis-à vis l'assureur.

18. Ibid. La Cour suprême précise que les principes de droit qui justifient l'adaptation de la stipulation pour autrui aux contrats d'assurance ont été préalablement reconnus par cette même Cour dans l'arrêt Employer's Liability Assurance Company c. Lefaivre, [1930] R.C.S. 1. 
réparation dans le patrimoine de l'auteur du préjudice. ${ }^{19}$ Cependant, pour que la victime touche l'indemnité, encore fallait-il que l'assureur soit tenu d'exécuter son obligation de garantie. Puisque l'auteur du préjudice demeurait le véritable créancier du promettant, l'assureur pouvait opposer à la victime «(...) tous les moyens résultant du contrat principal passé avec le stipulant lui-même (par exemple les vices de consentement, les vices cachés affectant la chose, etc.)». ${ }^{20}$ La stipulation pour autrui faisait donc naître un droit direct et personnel ${ }^{21}$ au profit du tiers lésé, sans que ce dernier soit pour autant à l'abri des moyens de défense que pouvait soulever l'assureur du responsable. ${ }^{22}$

Le bénéficiaire d'une stipulation pour autrui (la victime) était peut-être directement lié avec le promettant (l'assureur du responsable), mais ce lien de droit demeurait bien fragile. En réalité, il ne s'agissait que d'un accommodement offert par l'assureur à son assuré qui se voyait confirmer le paiement de l'indemnité à la victime. En ayant recours à la stipulation pour autrui, les assurés pouvaient donc être sécurisés par leur assureur qui leur garantissait que la victime avait obtenu réparation.

Malgré les avantages de la stipulation pour autrui, le droit à la réparation de la victime se trouvait trop souvent subordonné aux rapports contractuels unissant l'assureur de responsabilité à l'auteur du préjudice. Comme résultat, l'indemnisation des tiers lésés était rarement effective, même s'il s'agissait d'un objectif fondamental de la responsabilité civile au $\mathrm{XX}^{\mathrm{e}}$ siècle. ${ }^{23}$ Cependant, avec l'influence du développement du recours direct de la victime en matière d'accidents d'automobile et l'essor du marché de l'assurance, la protection des droits des tiers lésés s'est peu à peu affirmée.

19. «Le bénéfice de la stipulation ne tombant à aucun moment dans le patrimoine du stipulant, les créanciers de celui-ci ne peuvent donc jamais entrer en concurrence avec ceux du bénéficiaire, hormis le cas de fraude.» J.-L. Baudouin, supra note 6 à la p. 278, $\mathrm{n}^{\circ} 489$.

20. I. Mignault, supra note 7 à la p. 126; J.-L. Baudouin, supra note 6 aux pp. 279-280, no 491.

21. Supra note 17.

22. Generas c. Hartford Accident \& Indemnity Company, supra note 15. Aussi : J.-G. Bergeron, «L'opposabilité des exceptions à différents intéressés dans un contrat d'assurance», (1987) 47 R. du B. 933 aux pp. 970-971.

23. A. Tunc, supra note 10 aux pp. 142-145, $\mathrm{n}^{\text {os }} 170-173$. 


\section{\$2. La création d'un véritable recours direct en matière d'accidents d'automobile}

En Ontario, au début des années trente, le Highway Traffic $A c t^{24}$ accordait déjà à la victime d'un accident d'automobile le droit de poursuivre directement l'assureur du responsable. La législation ontarienne prévoyait aussi que cette même victime détenait «(...) le privilège exclusif, légitimé par l'art. 104 de la Loi fédérale concernant la faillite, de toucher l'indemnité due sous la police et enlève même à l'assureur le droit d'opposer à la victime les causes de déchéance qu'il pourrait soulever à l'encontre de son assuré». ${ }^{25}$

À la différence du Québec, l'Ontario offrait une plus grande protection à la victime d'un accident d'automobile en lui assurant un dédommagement, indépendamment du comportement de l'assurée ${ }^{26}$ ou de sa déconfiture. D'après la législation ontarienne en matière d'accidents d'automobile, le tiers lésé détenait une créance de réparation directe lui étant exclusive. La victime d'un accident d'automobile disposait donc d'un droit propre sur l'indemnité d'assurance, laquelle était générée par la création légale du droit direct et par le privilège exclusif issu de la Loi sur la faillite.

À compter de 1961, la province de Québec a suivi l'Ontario sur le terrain de l'assurance automobile en adoptant la Loi de l'indemnisation des victimes d'accidents d'automobile. ${ }^{27}$ D'abord, la loi de 1961 venait modifier celles de $1907^{28}$ et de $1912^{29}$ en remplaçant la présomption simple de faute par une présomption de responsabilité opposable au propriétaire d'une automobile. ${ }^{30}$

24. Highway Traffic Act, S.O. 1930, c. 48, art. 10. Aussi : C. Brown et E. Cummins Seto, NoFault Automobile Insurance in Canada, Toronto, Carswell, 1988 aux pp. 5-9.

25. I. Mignault, supra note 7 aux pp. 128-129.

26. En assurance de responsabilité en général, les contrats d'assurance des provinces de Common Law comprennent, la plupart du temps, une clause-type selon laquelle la cour décide, en fonction de l'équité, d'opposer ou non aux tiers lésés les déchéances de l'assuré lorsque l'assureur subit un préjudice. Voir C. Brown et E. Cummins Seto, supra, note 24 aux pp. 1-167.

27. $\quad$ Loi de l'indemnisation des victimes d'accidents d'automobile, supra note 1.

28. Loi de l'indemnisation des victimes d'accidents d'automobile, (1907) 6 Ed. VII, c. 13.

29. Loi de l'indemnisation des victimes d'accidents d'automobile, (1912) 3 Geo. V, c. 19.

30. $\quad$ Loi de l'indemnisation des victimes d'accidents d'automobile, supra note 1, art. 3-4. 
L'innovation majeure de cette loi consistait à instituer un lien de droit direct entre la victime et l'assureur de l'auteur du préjudice. ${ }^{31}$

La responsabilité, encore subjective, n'apportait rien de plus à la protection des droits de la victime. Par contre, au cas d'inexécution de l'assuré, la victime avait le net avantage d'exécuter directement contre l'assureur le jugement qu'elle avait préalablement obtenu contre l'auteur du préjudice. Le droit direct, institué par l'article 6 de la loi de 1961, s'énonçait ainsi :

«Sous réserve des conditions de son contrat et jusqu'à concurrence du montant stipulé, l'assureur est directement responsable envers les tiers d'un dommage faisant l'objet d'assurance-responsabilité.

De plus, jusqu'à concurrence pour chaque automobile du montant prescrit à l'article 14, il ne peut leur opposer les causes de nullité ou de déchéance susceptibles d'être invoquées contre l'assuré.

Il ne peut être poursuivi par les tiers avant jugement final exécutoire contre l'assuré. ${ }^{32}$

Tout compte fait, les premières décisions relatives au recours direct en matière d'accidents d'automobile ne favorisaient pas l'indemnisation des tiers lésés malgré le nombre grandissant d'accidentés de la route. ${ }^{33}$ Les victimes avaient encore le lourd fardeau d'établir le caractère répréhensible ou négligent de la conduite de l'automobiliste responsable, une fois que ce dernier eut renversé la présomption de responsabilité qui pesait sur lui. Compte tenu de la fréquence et de la gravité des accidents d'automobiles, le Comité d'étude sur l'assurance automobile a proposé, dans le Rapport Gauvin, que l'indemnisation des

31. Ibid. art. 6.

32. À l'époque, l'article 14 de la Loi de l'indemnisation des victimes d'accidents d'automobile supra note 1, établissait le montant minimum de l'assurance obligatoire à $35000 \$$ et depuis la réforme Payette, l'article 87 de la nouvelle Loi sur l'assurance automobile, L.R.Q. c. A25 , chiffre ce minimum à $50000 \$$.

33. Selon le Rapport du Comité d'étude sur l'assurance automobile, «(...) environ $28 \%$ des victimes blessées n'ont droit à aucune indemnisation, alors qu'approximativement $6 \%$ n'ont droit qu'à une indemnisation partielle.» Québec, Rapport du Comité d'étude relatifà l'assurance automobile, Québec, Éditeur officiel, 1974 à la p. 183 [ci-après «Rapport Gauvin»]. 
dommages corporels des victimes soit prise en charge en vertu d'un régime d'assurance obligatoire sans égard à la faute d'autrui. ${ }^{34}$

Le législateur a décidé que la victime d'un dommage corporel n'avait plus accès à aucun recours civil et que le recouvrement des indemnités pour les dommages corporels s'effectuerait auprès de la Société de l'assurance automobile. ${ }^{35}$ En ce qui a trait aux dommages matériels, le législateur a repris le principe du recours direct de l'article 6 de la loi de 1961 en instituant les articles 108 et 119 de la Loi sur l'assurance automobile. ${ }^{36}$ La victime de dommages matériels peut alors poursuivre directement l'assureur sans attendre la condamnation de l'assuré. Cependant, l'assureur de l'auteur du dommage ne peut opposer au tiers lésé aucune nullité, déchéance ou exception qu'il peut soulever contre l'assuré. L'indemnisation des victimes d'accidents d'automobile a donc été nettement favorisée par la réforme de l'assurance automobile proposée par le Rapport Gauvin.

Outre le droit direct institué par la Loi sur l'assurance automobile, la victime qui désirait poursuivre directement l'assureur de responsabilité de l'auteur de son préjudice devait se contenter de l'action oblique ou espérer être bénéficiaire d'une stipulation pour autrui. Ces alternatives demeuraient peu avantageuses. $^{37}$ En assurance de responsabilité en général, le tiers lésé ne possédait donc pas de recours direct et exclusif sur l'indemnité d'assurance, semblable à celui que possédait la victime d'un accident d'automobile.

34. Ces principes furent consacrés par l'adoption de la Loi sur l'assurance automobile, L.Q. 1974, c. 70. Pour une étude détaillée de la nouvelle loi : Voir L. Perret, «La nouvelle loi sur l'assurance automobile du Québec» (1978) 9 R.G.D. 8.

35. Loi sur l'assurance automobile, supra note 34 art. 5-7.

36. Les extraits pertinents des articles 108 et 119 de la Loi sur l'assurance automobile, supra note 34, se lisent comme suit : Art. $108:$ :...) l'assureur est directement responsable envers la victime du paiement de l'indemnité qui pourrait lui être due, jusqu'à concurrence du montant de l'assurance souscrite.» Art. 119: «L'assureur d'une personne (...) [responsable] ne peut, jusqu'à concurrence du montant obligatoire d'assurance de responsabilité, opposer au tiers aucune nullité, déchéance ou exception susceptibles d'être invoquées contre l'assuré; (...).»

37. Supra, Chapitre préliminaire, section $1, \S 1$. 
Loin de nous l'idée de mesurer l'impact qu'a pu avoir le développement du recours direct en assurance automobile sur la création de l'action directe du tiers lésé en assurance de responsabilité. Néanmoins, nous sommes forts de constater que la création du recours direct de la victime d'un accident d'automobile a ouvert la voie à une plus grande sollicitude du législateur en vue d'assurer une indemnisation aux tiers lésés en assurance de responsabilité.

En 1974, la réforme du droit des assurances est venue modifier le secteur du droit des assurances terrestres par l'adoption de la Loi sur les assurances ${ }^{38}$ et par l'introduction des articles 2468 à 2605 du Code civil du Bas-Canada. ${ }^{39}$ Cette réforme présente d'importantes innovations concernant les droits des tiers lésés.

\section{Section 2. La réforme de 1974}

À la différence du recours direct qui prévalait encore au 20 octobre 1976 en matière d'assurance automobile, ${ }^{40}$ le législateur innove en créant un droit direct immédiat sans qu'il soit nécessaire que le tiers attende la condamnation du responsable pour poursuivre l'assureur.

\section{\$1. La création de l'action directe en faveur du tiers lésé}

Avec l'entrée en vigueur de la Loi sur les assurances, ${ }^{41}$ le 20 octobre 1976, le législateur a institué un lien de droit entre l'assureur du responsable et le tiers lésé, selon les termes de l'article 2603 C.c.B.-C. Ce lien s'énonce ainsi : «Le tiers lésé peut faire valoir son droit d'action contre l'assuré ou directement contre l'assureur.» L'action directe du tiers lésé existe donc distinctement du recours que peut instituer la victime contre le responsable.

38. Loi sur les assurances, L.Q. 1974, c. 70. La loi a été sanctionnée le 24 décembre 1974 et est entrée en vigueur le 20 octobre 1976.

39. R. Bout, Le contrat d'assurance en droit comparé français et québécois, Montréal, Centre de recherche en droit privé et comparé du Québec, Université McGill, 1988 à la p. 8.

40. L'article 6 de la Loi de l'indemnisation des victimes d'accidents d'automobile, supra note 1, n'a été remplacé que le 1er mars 1978 lors de l'entrée en vigueur de la réforme Payette. Les victimes d'accidents d'automobiles devaient donc attendre le jugement final exécutoire contre l'assuré avant d'exercer leur droit direct.

41. $\quad$ Loi sur les assurances, supra note 38. 
À l'instar de l'indemnisation directe des victimes en assurance automobile, la création du recours direct en assurance de responsabilité avait pour objectif de faciliter l'indemnisation des victimes en accélérant les procédures. En effet, les victimes n'avaient pas à attendre la condamnation de l'auteur de leur préjudice pour être indemnisées. Le droit direct du tiers lésé permettait aussi de réserver ${ }^{42}$ l'indemnité d'assurance de façon à ce que ce même tiers n'ait plus à subir le concours des autres créanciers de l'auteur du préjudice. Le droit direct assurait également un créancier solvable au tiers lésé.

La réforme de 1974 a non seulement consacré le lien de droit entre le tiers lésé et l'assureur, elle a aussi permis au législateur de spécifier que «[1]e montant de l'assurance est affecté exclusivement au paiement des tiers lésés». ${ }^{43}$ Mais cela n'a pas suffi pour que la jurisprudence reconnaisse le caractère substantiel du droit direct du tiers lésé.

\section{§2. L'interprétation restrictive de l'action directe du tiers lésé}

La création de l'action directe du tiers lésé aura permis à la victime d'échapper au concours des créanciers de l'auteur du préjudice. Toutefois, les tribunaux ont favorisé l'interprétation restrictive de l'action directe du tiers lésé. Le caractère substantiel du recours direct du tiers lésé n'a donc pas été reconnu.

\section{A. La thèse du raccourci procédural}

Les articles 2602 et 2603 C.c.B.-C., en vertu desquels le tiers lésé peut poursuivre directement l'assureur pour toucher le montant de l'assurance, sont inspirés du droit français. ${ }^{44}$ Le droit français a d'abord institué un privilège au bénéfice du tiers lésé aux termes de l'article 53 de la Loi des Assurances du 13

42. A. Létourneau, «De l'assurance de dommages sous la nouvelle loi sur les assurances», dans La nouvelle loi sur les assurances : profonds changements au C.c. et aux lois connexes, C.F.P.B.Q. , 1975-1976, 106 aux pp. 154-155.

43. Art. 2602 C.c.B.-C.

44. Québec, ministère de la Justice, Commentaires du ministre de la Justice, t. 2, Québec, Publications du Québec, 1993 à la p. 1568. 
juillet $1930 .{ }^{45}$ Selon ce texte de loi, l'assureur doit désintéresser la victime avant tout autre créancier, jusqu'à concurrence du montant de l'assurance. ${ }^{46}$ Par la suite, à partir du principe de l'immobilisation de la créance, la jurisprudence française a déduit l'existence d'un droit propre. ${ }^{47} \mathrm{Ce}$ droit est autonome par sa forme et substantiel quant à son fond. ${ }^{48}$

Au Québec, le Code civil du Bas-Canada a fait plus qu'établir un privilège en faveur de la victime. Il a d'abord expressément consacré le recours direct du tiers lésé, puis il a prévu que l'indemnité d'assurance serait affectée exclusivement au paiement de ce même tiers. Malgré cette importante distinction avec le droit français au sujet de la codification du droit direct, la

45. L'article 53 de la Loi des assurances du 13 juillet 1930 se lit ainsi : «L'assureur ne peut payer à un autre que le tiers lésé tout ou partie de la somme due par lui, tant que ce tiers n'a pas été désintéressé, jusqu'à concurrence de ladite somme, des conséquences pécuniaires du fait dommageable ayant entraîné la responsabilité de l'assuré.» Cet article correspond maintenant à l'article L.124-3 du Code des assurances français.

46. Les premières manifestations de l'action directe sont apparues en France relativement au risque d'incendie causé par un locataire et dans le domaine des accidents du travail (lois de 1889 et de 1913). Par la suite, on a étendu l'application de l'article 53 de la Loi des assurances de 1930 en faveur de toute victime en assurance de responsabilité en général. Voir M. Picard et A. Besson, Traité général des assurances terrestres en droit français : Assurances de choses - Assurances de responsabilité, t. $3^{\text {e }}$, Paris, L.G.D.J., 1943 aux pp. 532 à 672.

47. L'action directe a connu un développement jurisprudentiel très important en France depuis un célèbre arrêt de la Cour de cassation daté du 14 juin 1926. Il s'agissait d'une victime d'un accident d'automobile qui désirait mettre en cause simultanément l'assureur de responsabilité et l'auteur de l'accident afin que le tribunal puisse fixer contradictoirement la validité du recours direct en lui-même, le montant de l'indemnité et le quantum des dommages. Les intimés niaient l'action directe en invoquant l'atteinte au principe de la relativité des conventions et le fait de prêter au législateur une intention qui n'apparaît nulle part dans les textes de loi. La Cour précise que le droit du tiers est un droit qui naît de la loi et non pas du contrat. En conséquence, les parties ne peuvent y faire obstacle par convention. La Cour conclut que l'affectation exclusive de l'indemnité, au bénéfice de la victime, justifie l'action directe du tiers lésé contre l'assureur. Cass. civ. $1^{\text {re }}, 14$ juin 1926, D.P. 1927.1.57 (note L. Josserand), S. 1927.1.25 (note P. Esmein).

48. «En immobilisant cette créance d'indemnité pour en faire bénéficier la victime à l'exclusion de qui que ce soit, la loi a implicitement, mais nécessairement accordé à la victime une action directe pour son recouvrement contre l'assureur.» É. Beaudonnat, Des clauses de non-responsabilité et de l'assurance des fautes, Paris, Librairie de jurisprudence ancienne et moderne, 1927 à la p. 157. 
jurisprudence québécoise n'accordait pas au recours de la victime une aussi grande importance que la jurisprudence française.

Par exemple, les tribunaux québécois ont jugé que le recours direct du tiers lésé relevait de la procédure. Ils ont considéré qu'il s'agissait d'une exception au principe de la relativité des contrats et qu'en conséquence, le droit du tiers lésé ne pouvait être interprété que de façon restrictive, c'est-à-dire comme un raccourci procédural servant à simplifier les procédures de réclamation de la victime. ${ }^{49}$

Dans la mesure où la jurisprudence a refusé de considérer le caractère substantiel du recours direct du tiers lésé, les tribunaux ont fait de l'action directe, une procédure permettant au tiers d'être payé plus rapidement en évitant d'avoir à poursuivre l'auteur de son préjudice. Le recours direct ne procurait donc aucune protection particulière au tiers lésé, ne serait-ce que de lui éviter d'être en concurrence avec les créanciers du responsable.

49. Union québécoise, mutuelle d'assurance contre l'incendie c. Mutuelle des Bois-Francs, supra note 14 à la p. 473; Aetna Casualty and Surety Company et autres c. Groupe Estrie, mutuelle d'assurance contre l'incendie et une autre, [1989] R.J.Q. 1251 (C.S.), conf. par [1990] R.J.Q. 1792 (C.A.), MM. les juges Kaufman, LeBel et Brossard [ci-après Aetna avec renvois au jugement de]; Commercial Union Assurance Company c. Northumberland General Insurance Company (28 juin 1990), Montréal 500-09-001035-856 (C.A.), MM. les juges Kaufman, Brossard et Lebel; Guardian du Canada, compagnie d'assurances c. StMaurice, compagnie d'assurances, [1990] R.R.A. 700 (C.A.) [ci-après St-Maurice]. Voir la doctrine suivante : A. Létourneau, «The Direct Action Against the Insurer» (1978) Mer. Mem. L. 51; A.T. Hewitt, «The Direct Action against the Insurer : Comments and Comparison with the Law of Ontario» (1978) Mer. Mem. L. 63; P. A. Melançon et F. C. Meagher, «La face cachée de l'article 2603 C.c.» (1986) 46 R. du B. 453; B. Faribault, «Du papillon à la chrysalide ou l'étrange métamorphose de l'assurance de responsabilité» (1987) 55 Assurances 300. 


\section{B. Le rejet du cumul}

Même si le Code civil du Bas-Canada offre au tiers le choix d'exercer son action directe ou son action en responsabilité auprès de l'assureur, la Cour d'appel a décidé, en 1984, que ces deux actions étaient mutuellement exclusives; elles ne peuvent coexister simultanément. ${ }^{50}$ La victime doit donc opter en faveur de l'une ou de l'autre action et éviter ainsi le cumul.

La Cour justifie principalement sa décision selon le principe que le droit du tiers est une exception à l'effet relatif des conventions. D'après la Cour d'appel, le recours direct «(...) est plus restreint que celui accordé par l'article 53 de la loi française du 13 juillet 1930». ${ }^{51}$ La Cour entend par là que le droit direct du tiers lésé n'est qu'une voie de procédure accélérée.

En faisant de l'action directe une simple procédure, à prendre ou à laisser, la Cour d'appel faisait dépendre l'existence du recours direct de celle de l'action en responsabilité. La Cour évitait ainsi d'avoir à attribuer à ce recours toutes les conséquences juridiques rattachées à un droit substantiel, ${ }^{52}$ contrairement à ce qu'avait décidé la Cour de cassation en France. Le refus de la Cour d'appel de considérer le cumul de l'action directe et de l'action en responsabilité avait fermé la porte à la reconnaissance d'un droit substantiel au profit du tiers lésé et confirmait plutôt la thèse du raccourci procédural. Cependant, la nature de l'action directe du tiers lésé demeurait obscure parce que les tribunaux n'avaient pas encore analysé le fondement même de l'action directe.

50. $\quad$ Mutuelle des Bois-Francs, supra note 14 à la p. 473.

51. Ibid. à la p. 476, M. le juge Mayrand).

52. Selon le professeur Bergeron, «(...) refuser le cumul amène à privilégier la technicalité procédurale». J.-G. Bergeron, Les contrats d'assurance : lignes et entre-lignes, t. 2, Sherbrooke, SEM, 1992 à la p. 397. 


\section{Le débat portant sur l'inopposabilité des exceptions postérieures au sinistre}

Il y eut un long débat sur la nature du droit direct du tiers lésé et sur les conséquences qui devaient s'y rattacher. D'une part, on affirmait qu'il s'agissait d'un droit substantiel, tandis que les opposants arguaient que le droit direct du tiers lésé n'était qu'un droit de «faire valoir» plus rapidement l'affectation exclusive du paiement, autrement versé à l'assuré. Toutefois, on reconnaissait que la France octroyait un droit direct à la victime, en vertu de l'article 53 de la Loi des Assurances du 13 Juillet 1930. ${ }^{53}$

\section{a) La nature du débat}

Le droit québécois était hésitant à reconnaître l'influence du droit français sur l'interprétation de l'article 2603 C.c.B.-C. En effet, en dépit d'une similitude importante entre l'article 53 du Code des assurances français et l'article 2603 du Code civil du Bas-Canada, de nombreux juristes québécois refusaient d'attribuer au recours direct les conséquences d'un droit propre et autonome. ${ }^{54}$ Les défenseurs du statut procédural de l'action directe prétendaient que toutes les exceptions, qui pouvaient être opposées à l'assuré, étaient tout autant opposables à la victime.

En l'absence d'un texte clair et exprès sur l'inopposabilité des exceptions, la jurisprudence québécoise demeurait divisée. Elle prétendait, d'une part, que le droit québécois ne permettait à la victime que de faire valoir le droit de l'assuré auprès de l'assureur. Selon ce courant, ${ }^{55}$ il était logique que toutes les exceptions soient opposables au tiers lésé. D'autre part, on était d'avis que le législateur, en 1974, connaissait le développement du recours direct du tiers lésé

53. Supra note 45.

54. Les juristes qui favorisaient l'interprétation restrictive du recours direct du tiers lésé étaient d'avis que le droit à l'exclusivité du paiement, décrété à l'article 2602 C.c.B.-C., était seulement un droit de procédure que le tiers lésé pouvait opposer à l'assureur du responsable : «Article 2603 does not create, against the insurer, a right similar to the one created by the act or omission that made the insured liable to the third person; it merely creates the right to invoke directly against the insurer the above-mentioned right.» A. Létourneau, supra note 49 à la p. 53.

55. Supra note 49. 
en France. Il était donc clair que la réforme de 1974 avait eu pour effet d'introduire en droit québécois des principes de droit similaires à ceux de la France, avec les conséquences juridiques s'y rattachant. ${ }^{56}$ La Cour d'appel a tranché le débat le 28 juin 1990 dans l'affaire Aetna Casualty and Surety Company c. Groupe Estrie, mutuelle d'assurance contre l'incendie ${ }^{57}$ (ci-après citée Aetna).

\section{b) L'affaire Aetna}

Outre l'affaire de la Mutuelle des Bois-Francs,${ }^{5}$ en vertu de laquelle la Cour d'appel a eu à se prononcer sur la possibilité de cumuler ou non l'action directe avec l'action en responsabilité, l'affaire Aetna a été la première occasion pour cette même Cour de statuer sur la nature et les conditions d'exercice du recours direct de la victime. ${ }^{59}$

Selon le juge Brossard, si le législateur québécois avait voulu adopter une solution similaire à celle que la jurisprudence française a déduite de l'article 53 de la Loi des Assurances, ${ }^{60}$ il l'aurait clairement exprimé. Pour lui, la création d'un droit propre au bénéfice du tiers lésé fait exception au principe de la relativité des contrats et cela lui paraît être un motif additionnel pour interpréter de façon restrictive l'article 2603 C.c.B.-C. Le juge Brossard

56. Les décisions suivantes favorisaient la thèse de l'inopposabilité des exceptions après sinistre : St-Louis Viau c. Restaurant Ville St-Pierre Inc., J.E. 83-484 (C.S.); Hoechst Canada Inc. c. Commercial Union Assurance Company (3 juillet 1985), Montréal 500-05-007012-832 (C.S.), M. le juge Lévesque [ci-après Hoechst]; Boucher c. Economical, compagnie d'assurances mutuelle, [1989] R.J.Q., 1481 (C.S.). Voir la doctrine favorable à cette même thèse : I. Parizeau, «Droit des assurances : L'interprétation de l'article 2603 C.c.» (1985) 45 R. du B. 129; D. Lluelles, Droit des assurances : Aspects contractuels, $2^{\mathrm{e}}$ éd., Montréal, Thémis, 1986 à la p. 255; J.-G. Bergeron, «L'opposabilité des exceptions à différents intéressés dans un contrat d'assurance» (1987) 47 R. du B. 933.

57. Aetna, supra note 49. Dans cette affaire, deux autres appels furent réunis sur la question de l'inopposabilité des exceptions postérieures au sinistre : Hoechst, supra note 56 et StMaurice, supra note 49 à la p. 700.

58. $\quad$ Mutuelle des Bois-Francs, supra note 14 à la p. 473.

59. Dans l'affaire Aetna, la Cour d'appel a peut-être réglé le problème de l'opposabilité de l'avis de sinistre mais au-delà de cette question, la nature de l'action directe demeure ambiguë. Pour les juges Brossard et Kaufman, l'article 2603 C.c.B.-C. crée un droit procédural, tandis que le juge Lebel reconnaît que le tiers lésé possède un droit direct substantiel depuis la réforme de 1974.

60. Supra note 45. 
considère l'action directe du tiers lésé comme une voie de procédure accélérée étant donné le silence du législateur au sujet de l'inopposabilité des exceptions.

Dans le même ordre d'idée, le juge Brossard refuse de conclure que l'article 2603 C.c.B.-C. est inspiré de la Loi des Assurances et de la jurisprudence de la Cour de cassation. ${ }^{61}$ Par conséquent, il ne reconnaît pas l'applicabilité de la solution française en droit québécois. ${ }^{62}$ Le juge va même jusqu'à affirmer, dans un obiter dictum, que dans l'hypothèse où l'action directe du tiers lésé serait d'origine légale, «(...) il n'en demeure pas moins que l'obligation de l'assureur est essentiellement fonction des termes et conditions de la convention d'assurance». ${ }^{63}$

Pour sa part, le juge Lebel se dissocie de l'opinion de ses collègues lorsqu'il reconnaît que la victime possède un «droit propre» à compter du sinistre. ${ }^{64}$ Cela implique que le droit direct du tiers lésé ne doit pas être affecté par le comportement fautif de l'assuré, postérieurement au sinistre. ${ }^{65}$ Le juge fonde son raisonnement sur le principe voulant que ce droit soit né à l'occasion du contrat d'assurance mais est accordé à la victime par la loi. ${ }^{66}$ Il déclare que la victime acquiert son droit d'action au moment du sinistre, mais ce n'est que l'exercice de l'action directe qui a pour effet de cristalliser le droit du tiers dans l'état où il se trouve à ce même moment. ${ }^{67}$

À l'opposé du juge Brossard, le juge Lebel reconnaît l'influence des décisions des cours françaises au sujet de l'inopposabilité des exceptions postérieures au sinistre. ${ }^{68}$ Néanmoins la victime ne peut, selon lui, échapper à

61. Aetna, supra note 49 aux pp. 1798-1799, M. le juge Brossard.

62. Ibid. aux pp. 1798-1800, M. le juge Brossard.

63. Ibid. à la p. 1802, M. le juge Brossard.

64. Ibid. à la p. 1811, M. le juge Lebel.

65. Ibid. aux pp. 1811-1812, M. le juge Lebel.

66. Ibid. à la p.1811, M. le juge Lebel.

67. Ibid.

68. Ibid. aux pp. 1807-1809, M. le juge Lebel. Selon le juge Lebel : «La réforme du droit des assurances de 1974 doit être examinée à son mérite. Il ne s'agit pas d'effectuer ce travail en concluant a priori que le rôle des tribunaux est de stériliser toute réforme législative, de la vider de leur contenu et de privilégier nécessairement les interprétations conformes au statu quo. Dans ce travail, sans que nous soyons liés par les décisions des cours françaises, mêmes celles de la Cour de cassation, rien n'interdit d'évaluer les solutions qu'elle retient 
l'obligation de fournir l'avis de sinistre à l'assureur. Le juge Lebel précise à ce sujet que l'article 2572 C.c.B.-C. permet à tout intéressé de se conformer à cette obligation. D'après lui, l'avis de sinistre est une condition d'exercice préalable à l'action directe du tiers, à défaut d'avoir déjà été fourni par l'assuré.

Selon l'expression du juge Lebel, la nature de l'obligation de déclarer le sinistre à l'assureur n'a pas le «caractère personnel» des obligations de l'assuré à l'égard de son assureur. Par exemple, le juge note que l'obligation de collaboration de l'assuré exige de ce dernier une coopération personnelle. C'est ce qui explique pourquoi le juge Lebel conclut que le tiers lésé doit fournir luimême l'avis de sinistre si l'assuré néglige de le faire, sans quoi il ne pourra pas exercer son droit direct contre l'assureur. ${ }^{69}$

L'affaire Aetna a permis d'établir des distinctions importantes qui ont marqué l'évolution de l'action directe du tiers lésé en assurance de responsabilité. Les juges de la Cour d'appel sont arrivés à la conclusion que la tardiveté de l'avis de sinistre est opposable à la victime mais pour des motifs différents.

Pour le juge Brossard, toutes les déchéances postérieures au sinistre sont opposables à l'assuré. Quant au juge Lebel, il est favorable au principe de l'inopposabilité des exceptions mais il émet une réserve concernant l'avis de sinistre. Il considère que cette obligation peut être remplie par n'importe quel intéressé. Les juges Brossard et Lebel diffèrent également d'opinion sur les fondements du droit direct selon qu'il s'agirait d'un droit substantiel ou d'une voie de procédure accélérée.

Ces différences d'opinions sur la nature du droit direct du tiers lésé n'ont pas suscité longtemps la controverse au sein de la doctrine et de la jurisprudence. En effet, moins d'un an après l'affaire Aetna, l'avant-projet de loi

et d'examiner la légitimité et l'opportunité de leur mise en oeuvre par analogie, en droit québécois.»Ibid. à la p. 1809, M. le juge Lebel.

69. Ibid. aux pp. 1811-1812, M. le juge Lebel. 
portant réforme au Code civil annonçait le choix du législateur qui a consacré par la suite le caractère substantiel du recours direct du tiers lésé. ${ }^{70}$

\section{Section 3. Le code civil de 1994}

En 1994, le législateur a adopté le Code civil du Québec. Les nouveaux textes suppriment les imprécisions qui avaient empêché les tribunaux de reconnaître le caractère substantiel du droit direct du tiers lésé. ${ }^{71}$ D'abord, le législateur a élargi les voies de recours du tiers lésé, puis il a consacré le principe de l'inopposabilité des exceptions postérieures au sinistre.

\section{§1. L'adoption du cumul en faveur du tiers lésé}

Contrairement à ce qu'avait décidé la Cour d'appel dans l'arrêt Union québécoise, mutuelle d'assurance contre l'incendie, ${ }^{72}$ la victime peut désormais, en vertu de l'article 2501 C.c.Q., cumuler son action en responsabilité contre l'auteur du préjudice avec son recours direct contre l'assureur du responsable. ${ }^{73}$ Son choix n'est plus exclusif puisqu'il n'emporte pas renonciation aux autres recours du tiers lésé. ${ }^{74}$ Par contre, il semblerait que l'action oblique et la procédure de saisie-arrêt en mains tierces soient toujours admissibles puisque les liens de droit unissant le responsable à la victime demeurent inchangés. ${ }^{75}$

70. $\quad$ A.-P. L., Loi portant réforme au Code civil du Québec du droit des obligations, ${ }^{\mathrm{re}}$ sess., $33^{\mathrm{e}}$ lég., Québec, 1991, art. 2572, al. 1. Cet article fut sanctionné le 18 décembre 1991. Il a été intégralement repris à l'article 2502 C.c.Q., entré en vigueur le $1^{\text {er }}$ janvier 1994.

71. «Si, en 1974, le législateur n'a pas été assez explicite en proclamant à l'article 2602 l'affectation du montant de l'assurance au paiement des tiers lésés et, à l'assureur, pour que l'on puisse en déduire que celui-ci ne pouvait opposer au tiers lésé les causes de nullité postérieures au sinistre, son intervention cette fois ne laisse place à aucun doute.» $\mathrm{C}$. Belleau, «Le droit nouveau proposé en matière d'assurance terrestre» (1988) 29 C. de D. 1037 à la p. 1060.

72. Mutuelle des Bois-Francs, supra note 14 aux pp. 476-477.

73. L'article 2501 C.c.Q. s'énonce comme suit : «Le tiers lésé peut faire valoir son droit d'action contre l'assuré ou l'assureur ou contre l'un et l'autre. Le choix fait par le tiers lésé à cet égard n'emporte pas renonciation à ses autres recours.»

74. Ibid.

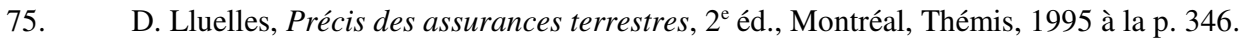


Par cet élargissement des voies d'action du tiers lésé, la loi renforce l'indépendance des recours de la victime, l'un par rapport à l'autre. Le législateur reconnaît ainsi que le recours direct du tiers lésé est plus qu'une voie de procédure; il est aussi un droit distinct et substantiel. En effet, il ne s'agit plus d'un recours de deuxième ordre, subordonné au caractère irréversible de l'option du tiers de poursuivre le responsable,${ }^{76}$ mais d'une action pleinement autonome.

Le caractère autonome du droit direct s'explique par le fait que le tiers lésé fait valoir son propre droit d'action depuis la réforme de 1994. Son recours direct est entièrement détaché de celui que possédait l'auteur du préjudice. La victime pourra donc trouver réparation autant par l'exercice de son action en responsabilité qu'au moyen de son action directe dirigée contre l'assureur de l'auteur du préjudice. Le choix du législateur de multiplier les voies d'action du tiers lésé sans l'obliger à opter entre ses recours consacre l'interprétation élargie du droit direct du tiers lésé contrairement à la position suivie par la Cour d'appel avant $1994 .^{77}$

\section{\$2. La consécration de l'inopposabilité des exceptions postérieures au sinistre}

L'article 2502 C.c.Q. consacre la théorie de l'inopposabilité des exceptions postérieures au sinistre. L'inopposabilité est un principe corollaire à l'action directe du tiers lésé. Ce principe confirme l'autonomie du recours direct par la reconnaissance de la cristallisation des droits des tiers lésés au moment du sinistre. Ainsi, les droits de ces mêmes tiers ne peuvent plus être affectés par les faits et gestes de l'assuré après la réalisation du sinistre.

L'article 2502 C.c.Q., relatif à l'inopposabilité des exceptions, se lit ainsi :

«L'assureur peut opposer au tiers lésé les moyens qu'il aurait pu faire valoir contre l'assuré au jour du sinistre, mais il ne peut opposer ceux qui sont relatifs à des faits survenus postérieurement au sinistre;

76. Mutuelle des Bois-Francs, supra note 14 aux pp. 475-476, M. le juge Mayrand.

77. Ibid. à la p. 473. 
l'assureur dispose, quant à ceux-ci, d'une action récursoire contre l'assuré.»

En même temps qu'il a étendu le principe de l'inopposabilité des exceptions en faveur du tiers lésé, le législateur a confirmé ce principe dans un régime de protection des droits des tiers lésés institué par l'article 2414 C.c.Q., frappant ainsi de nullité toute stipulation qui déroge à la protection des droits des tiers lésés en assurance de responsabilité. ${ }^{78}$ À titre de comparaison avec les victimes d'accidents d'automobile, on peut cependant observer que le principe de l'inopposabilité s'étend aux nullités, déchéances ou exceptions susceptibles d'être invoquées contre l'auteur de l'accident, sans distinction relative à leur antériorité ou à leur postériorité par rapport au sinistre.

Malgré cette distinction avec l'assurance automobile au sujet du principe de l'inopposabilité, la réforme du Code civil du Québec en 1994 a grandement amélioré la protection des victimes en assurance de responsabilité. Le développement du droit direct du tiers lésé en droit français a influé de façon manifeste sur l'intention du législateur québécois d'accroître la protection des droits des tiers lésés.

\section{A. L'influence du droit français}

Dans ses commentaires sur le Code civil du Québec, le ministre de la Justice reconnaît que l'article 2502 C.c.Q., qui institue l'inopposabilité à la victime des moyens postérieurs au sinistre, s'inspire du droit français. ${ }^{79}$ En France, la thèse de l'inopposabilité des déchéances découle du principe selon lequel «(...) le droit de créance de la victime naît au jour du dommage, il ne saurait, à dater de cet événement, être affecté dans son existence, ni dans son objet, par aucune cause de déchéance encourue personnellement par l'assuré pour inobservation des clauses de la police». ${ }^{80}$ Partant du principe que le tiers

78. Art. 2414, al. 2 C.c.Q. : «(...) Est également nulle la stipulation qui déroge aux règles relatives à l'intérêt d'assurance ou, en matière d'assurance de responsabilité, à celles protégeant les droits du tiers lésé.»

79. Québec, ministère de la Justice, supra note 44 à la p. 1568.

80. R. Bout, Le droit des assurances, Paris, P.U.F., 1981 à la p. 74. 
lésé doit être désintéressé le premier, ${ }^{81}$ la jurisprudence française est d'opinion que l'assureur ne peut opposer au tiers lésé les exceptions postérieures au sinistre $^{82}$ telles la tardiveté de l'avis de sinistre, les déclarations mensongères ${ }^{83}$ et la nouvelle déchéance pour «déclaration tardive des aggravations de risques». ${ }^{84}$

Lors de l'étude détaillée de l' Avant-projet de loi portant réforme au Code civil du Québec du droit des obligations, ${ }^{85}$ les intervenants aux débats de l'Assemblée nationale, alors en sous-commission des institutions, ont également constaté que le droit direct du tiers lésé est inspiré du droit français. ${ }^{86}$ Cependant, le Bureau d'assurance du Canada (B.A.C.) a souligné, dans son mémoire, qu'il craignait un encouragement à la collusion entre la victime et le responsable par la consécration de la théorie de l'inopposabilité des exceptions. Par exemple, si la victime surévalue ses pertes avec la complicité du responsable, l'application de l'inopposabilité des exceptions postérieures au sinistre pourrait préjudicier l'assureur.

Mais l'argument du B.A.C. n'a pas suscité de longs commentaires parce que la sous-commission a reconnu que cette possibilité de collusion existait déjà, indépendamment des nouvelles dispositions et que l'assureur a, de toute façon, un recours récursoire contre l'assuré en défaut. ${ }^{87}$ En l'absence d'un véritable débat sur la question, il ressort des commissions parlementaires portant sur l'avant-projet de loi portant réforme au Code civil, que le but de ces mesures législatives était de favoriser l'indemnisation de la victime. ${ }^{88}$

81. Supra note 45

82. Voir la décision de principe du 15 juin 1931 : Cass. civ. $1^{\text {re }}, 15$ juin 1931, D.H. 1931.411.

83. Cass. civ. $1^{\text {re }}, 9$ mai 1956, Bull. civ. 1956.I.147, $\mathrm{n}^{\circ} 181$.

84. Art. L. 113-9, al. 9 C. ass. Mme Lambert-Faivre considère que cette nouvelle déchéance est mal fondée en droit. Y. Lambert-Faivre, Droit des assurances, $8^{\mathrm{e}}$ éd., Paris, Dalloz, 1992 à la p. $223, \mathrm{n}^{\circ} 335$.

85. Loi portant réforme au Code civil du Québec du droit des obligations, supra note 70.

86. $\quad$ Journal des débats : Commissions parlementaires, SCI, $1^{\mathrm{re}}$ session, $34^{\mathrm{e}}$ légi. (Qué.) à la p. 920, nº 23.

87. Ibid.

88. Ibid. 
Même si le ministre de la Justice a identifié formellement la source d'inspiration de l'inopposabilité des exceptions postérieures au sinistre comme étant l'article R. 124-1 du Code des assurances français, ${ }^{89}$ l'on peut cependant observer quelques différences avec la France. Par exemple, l'article RL. 124-1 du Code des assurances ne vise que les déchéances alors qu'en droit québécois, l'inopposabilité est décrétée d'une façon plus générale, en faveur de tous moyens postérieurs au sinistre.

La différence tient au fait que les déchéances sont des sanctions qui découlent obligatoirement du contrat d'assurance, tandis que les «moyens» postérieurs au sinistre comprennent également les sanctions qui se fondent sur les obligations légales de l'assuré. En pratique, la différence n'est pas significative car les obligations légales prévues au Code civil du Québec correspondent respectivement aux déchéances prévues dans les contrats d'assurance de responsabilité en France. ${ }^{90}$

La consécration du principe de l'inopposabilité des exceptions postérieures au sinistre a donc contribué à accroître la protection des droits des tiers lésés en assurance de responsabilité. Mais quelle est l'étendue de cette protection? S'applique-t-elle seulement à l'exercice de l'action directe par le tiers lésé ou s'étend-elle à l'action en responsabilité de la victime?

89. L'article RL.124-1 C. ass. se lit ainsi : «Les polices d'assurances garantissant des risques de responsabilité civile doivent prévoir qu'en ce qui concerne cette garantie aucune déchéance motivée par un manquement de l'assuré à ses obligations commis postérieurement au sinistre ne sera opposable aux personnes lésées ou à leurs ayants droit. Elles ne doivent contenir aucune clause interdisant à l'assuré de mettre en cause son assureur ni de l'appeler en garantie à l'occasion d'un règlement de sinistre. (...)» (Nos caractères gras.)

90. En France, par exemple, le défaut de l'assuré de fournir les pièces nécessaires exigées par l'assureur et le défaut de loger un avis de sinistre à temps ne constituent pas des obligations légales tandis qu'au Québec, ces exigences découlent de la loi. Néanmoins, en France, les assureurs font de ces exigences des déchéances. Y. Lambert-Faivre, supra note 84 aux pp. 306-309, $\mathrm{n}^{\text {os }} 490$ et 495. 


\section{B. L'étendue de la protection des droits des tiers lésés}

L'application du principe de l'inopposabilité des moyens postérieurs au sinistre est-elle propre à l'action directe? Avant 1994, le juge Lebel a abordé cette question lorsqu'il a traité de la cristallisation des droits du tiers lésé dans l'affaire Aetna. ${ }^{91}$ Il a préconisé la théorie de la cristallisation des droits du tiers lésé selon laquelle le tiers acquiert la créance dans l'état où elle se trouve au moment du sinistre, sans être affectée par les déchéances de l'assuré postérieurement à la réalisation du risque. ${ }^{92}$ La théorie de la cristallisation des droits des tiers lésés, telle qu'exposée par le juge Lebel, peut-elle encore prévaloir depuis que le législateur qualifie d'ordre public les droits des tiers lésés en matière d'assurance de responsabilité?

D'après le juge Lebel, le bénéfice de l'inopposabilité ne s'acquiert pas en fonction du seul critère de postériorité par rapport au sinistre; la victime doit aussi exercer son recours direct contre l'assureur de l'auteur du préjudice. Le juge déclare que l'inopposabilité des exceptions postérieures au sinistre ne bénéficie pas à la victime qui choisit de saisir-arrêter le montant de l'indemnité entre les mains de l'assureur. Suivant les conclusions du juge Lebel, le tiers lésé acquiert son droit d'action directe dès le sinistre, mais la cristallisation des droits du tiers lésé ne s'opérera que si ce dernier exerce son action directe. Le juge s'exprime ainsi :

«La situation varierait s'il n'exerçait pas ce recours, se bornait à poursuivre l'assuré et par la suite, tentait de recouvrer l'indemnité par voie de saisie-arrêt. La cristallisation ne se serait pas produite. Il aurait débattu et établi sa créance avec l'assuré. Ensuite, il succéde-

91. Aetna, supra note 49 aux pp. 1809-1811, M. le juge Lebel.

92. La théorie de la cristallisation des droits du tiers lésé est issue d'une jurisprudence audacieuse de la Cour de cassation : Supra note 82; Cass. civ. $1^{\text {re }}, 2$ avril 1974, Bull. civ. 1974.I.90, n 105; R.G.A.T. 1975.76. En vertu de cette théorie, le droit direct du tiers lésé, qui est le droit propre sur l'indemnité d'assurance, naît du sinistre et ne saurait être entaché des faits et gestes de l'assuré postérieurement à cet événement. «On pourrait dire, en schématisant, qu'avant le sinistre, le droit direct de la victime, qui n'est alors qu'en gestation, ne se nourrit que du contrat d'assurance, tandis qu'après le sinistre, qui marque la naissance de ce droit, le "cordon ombilical" est coupé, et le droit direct de la victime vit sa propre vie.» J.-cl. resp. civ., supra note $12, \mathrm{n}^{\mathrm{o}} 18$. 
rait à ses droits contre l'assureur au moment où il les aurait établis. En un sens, le temps et l'exercice de la procédure entraîneront des variations dans les droits substantiels accordés.» ${ }^{93}$

Le professeur Lluelles note que le Code civil du Québec ne spécifie pas si l'article 2502 C.c.Q., relatif à l'inopposabilité, est réservé à l'exercice de l'action directe. Selon lui, ce silence doit être interprété en fonction du respect de la présomption du maintien du droit positif, eu égard particulièrement aux saisies-arrêts. Cela suppose que la victime peut se voir opposer tous moyens par l'assureur lorsqu'elle pratique une saisie-arrêt contre lui. Par contre, cette même victime ne pourrait bénéficier de l'inopposabilité des moyens postérieurs au sinistre que si elle exerce son action directe. ${ }^{94}$

Madame Odette Jobin-Laberge note également cette possibilité d'une dualité de régime selon que la victime intente une poursuite contre l'assuré ou qu'elle exerce son recours direct. ${ }^{95}$ Toutefois, le professeur Lluelles et madame Jobin-Laberge déplorent le fait d'avoir une «(...) opposabilité partielle ou totale selon que la victime a procédé par action directe contre l'assureur ou par action ordinaire contre l'auteur du dommage, sans compter le cas où elle a poursuivi l'un et l'autre». ${ }^{96}$

En France, les déchéances postérieures au sinistre sont inopposables à la victime indistinctement du fait qu'elle exerce son action directe ou son action en responsabilité. Ainsi, l'assureur appelé en garantie qui décide d'assumer la défense de son assuré ou de contester l'application de la garantie dans le cadre de l'action en responsabilité ne peut opposer à la victime les exceptions postérieures au sinistre. En raison du caractère impératif de l'article L. 124-3 du Code des assurances, l'inopposabilité des déchéances à la victime s'applique également à l'exercice de l'action en responsabilité de la victime. ${ }^{97}$

93. Aetna, supra note 49 à la p. 1811, M. le juge Lebel.

94. D. Lluelles, supra note 75 à la p. 346.

95. O. Jobin-Laberge et L. Plamondon, «Les assurances et les rentes», dans La réforme du Code civil : Obligations, contrats nommés, Québec, Presses de l'Université Laval, 1993 à la p. $1093, \mathrm{n}^{\mathrm{o}} 255$.

96. Ibid. Également : D. Lluelles, supra note 75 à la p. 346.

97. Y. Lambert-Faivre, supra note 84 aux pp. 431, 438-439, nos 665 et 677. 
Nous sommes davantage favorables à la thèse qui prévaut en droit français. Nous ne croyons pas qu'il faille interpréter le caractère général du libellé de l'article 2502 C.c.Q. comme l'expression de la volonté du législateur d'appliquer la théorie de l'inopposabilité seulement en faveur de la victime qui exerce son recours direct. Si le législateur avait voulu limiter la protection de la créance du tiers lésé à l'exercice de l'action directe, il l'aurait expressément dit. Il faut garder à l'esprit que l'article 2502 C.c.Q. a comme objet de réformer le droit antérieur, soit d'éliminer les imprécisions de la réforme de 1974 à l'égard des droits des tiers lésés dans le domaine de l'assurance de responsabilité.

Le législateur a posé un nouveau choix social qui s'inscrit dans sa volonté générale d'assurer une plus grande protection aux victimes en créant un régime de protection des droits des tiers lésés et en le décrétant d'ordre public. ${ }^{98}$ Pourquoi faudrait-il comprendre que cette protection n'avantage le tiers lésé qu'au seul cas où il exerce son action directe? Le libellé de l'article 2502 C.c.Q., dont la formulation est générale, succède à l'article 2501 par lequel le Code civil institue le cumul des différentes voies d'action du tiers lésé. N'est-ce pas là une indication que l'inopposabilité des moyens postérieurs au sinistre protège le tiers lésé, quelle que soit la procédure qu'il entend utiliser?

D'ailleurs, l'interprétation que nous favorisons a l'avantage d'éviter une dualité de régimes quant aux moyens opposables au tiers lésé et de parer au risque d'obtenir des jugements contradictoires. Comme nous l'enseigne PierreAndré Côté, il ne faut pas perdre de vue que «(...) la constatation du caractère réformateur de la loi appelle une interprétation déterminée, soit l'interprétation propre à promouvoir la réforme voulue par le législateur». ${ }^{99}$

D'après cette optique découlant de l'interprétation téléologique de la réforme du droit des assurances, nous sommes d'avis que l'inopposabilité des moyens postérieurs au sinistre ne doit pas être circonscrite au seul recours direct du tiers lésé. Nous ne croyons pas davantage que l'article 1608 C.c.Q., qui est

98. Supra note 78.

99. P.-A. Côté, Interprétation des lois, Montréal, Yvon Blais, 1990 à la p. 46. 
relatif au maintien de l'obligation d'un débiteur lorsqu'un tiers paie la victime, puisse être invoqué avec succès au soutien de la dualité de régimes. ${ }^{100}$

$\mathrm{Au}$ contraire, l'obligation du débiteur ne doit pas être modifiée ni atténuée de nouveau parce que l'assureur est poursuivi par son assuré plutôt que par le tiers lésé. En effet, la réforme de 1994 a transformé l'obligation de payer l'indemnité d'assurance en un droit d'ordre public. ${ }^{101}$ Le maintien de la dualité de régime consisterait à transformer le lien de droit unissant le tiers lésé à son débiteur selon qu'il exerce son action en responsabilité ou qu'il choisisse de poursuivre directement l'assureur du responsable.

La protection des victimes n'était sans doute pas aussi affirmée avant la réforme de 1974, mais depuis 1994 le rôle social de l'assurance de responsabilité est nettement accentué. Sa finalité rejoint maintenant celle qui prévaut en France, soit de réaliser «(...) autant la garantie de la créance d'indemnisation des victimes, que celle de la dette de réparation du responsable». ${ }^{102}$ Cet objectif du législateur québécois est d'ailleurs renforcé par le caractère d'ordre public du nouveau régime de protection des droits des tiers lésés en assurance de responsabilité. ${ }^{103}$

Le Code civil du Québec a aussi permis d'éliminer les ambiguïtés relatives à la nature de l'action directe du tiers lésé en lui attribuant un fondement légal incontestable. Nous devons reconnaître au droit direct du tiers lésé tous les attributs d'un droit substantiel afin que se réalise l'intention du législateur qui est de garantir une indemnisation aux victimes en assurance de responsabilité.

Les chapitres 1 et 2 traitent respectivement de la nature de l'action directe du tiers lésé et des conséquences découlant de l'autonomie de cette même

100. Art. 1608 C.c.Q. : «L'obligation du débiteur de payer des dommages-intérêts au créancier n'est ni atténuée ni modifiée par le fait que le créancier reçoive une prestation d'un tiers, par suite du préjudice qu'il a subi, sauf dans la mesure où le tiers est subrogé aux droits du créancier.» Voir O. Jobin-Laberge et L. Plamondon, supra note 95 à la p. 1162, nº 255.

101. Supra note 78.

102. Y. Lambert-Faivre, supra note 84 à la p. 313, $\mathrm{n}^{\circ} 502$.

103. $\quad$ Supra note 78. 
action. Le recours direct du tiers lésé s'analyse d'abord en fonction de la double nature du droit direct : une action fondée à la fois sur la responsabilité civile et sur le contrat d'assurance de l'auteur du préjudice (Chapitre 1).

Une fois la dette de responsabilité de l'assuré établie, l'action directe du tiers lésé devient suffisamment autonome pour avoir des conséquences sur les droits que détient l'assureur subrogé qui a versé l'indemnité. L'autonomie du droit direct se reflète également sur l'extinction de la créance directe du tiers lésé (Chapitre 2).

\section{CHAPITRE 1 :}

\section{LA NATURE HYBRIDE DE L'ACTION DIRECTE DU TIERS LÉSÉ}

L'affirmation de l'autonomie du droit direct du tiers lésé en assurance de responsabilité élargit la portée de l'action directe. En effet, le droit direct du tiers lésé, maintenant doté d'un caractère substantiel, constitue une véritable créance de réparation ayant pour objectif la mise en oeuvre de l'obligation de garantie de l'assureur. On voit tout de suite que l'action directe du tiers lésé possède un double fondement qui suppose, d'une part, l'existence de la créance de responsabilité de la victime et, d'autre part, l'existence du contrat d'assurance de l'auteur du préjudice. De là l'importance d'analyser la nature particulière de l'action directe du tiers lésé en assurance de responsabilité.

Dans la mesure où la double nature de l'action directe du tiers lésé suppose l'application du contrat d'assurance de l'auteur du préjudice, nous verrons que la nature de l'action directe met en cause l'étude du sinistre et la détermination du point de départ de la garantie en assurance de responsabilité. La nature hybride de l'action directe du tiers lésé nous amènera donc à préciser, dans une première section, la naissance du droit à la réparation du tiers lésé et ensuite, la détermination de la mise en oeuvre de l'obligation de garantie de l'assureur dans les assurances de responsabilité traditionnelles.

Une fois ces précisions apportées, nous constaterons les effets de l'affirmation du droit direct sur les droits des tiers lésés qui sont en présence de parties liées par un contrat basé sur la présentation d'une réclamation à l'assureur 
au cours de la période d'assurance. Les conditions d'exercice de l'action directe du tiers lésé seront abordées dans la seconde section.

\section{Section 1. La notion de sinistre et la période de garantie}

Le caractère incertain ${ }^{104} \mathrm{du}$ droit direct du tiers lésé privait souvent ce tiers d'une indemnisation qui lui était pourtant exclusive. Désormais, le droit direct du tiers lésé constitue beaucoup plus qu'une voie de procédure accélérée permettant au tiers lésé de faire valoir son droit à l'indemnité d'assurance. ${ }^{105}$ En effet, le législateur n'a pas retenu le caractère essentiellement procédural du droit direct tel que décrété par la Cour d'appel. ${ }^{106} \mathrm{Il}$ a octroyé au tiers lésé un droit substantiel et d'ordre public. ${ }^{107}$

Si autonome soit-il, le recours direct du tiers lésé est doté d'un caractère hybride. Cela signifie que ce recours «(...) participe à la fois de l'action en responsabilité, puisque sa base directe est le fait dommageable, et de l'action fondée sur un contrat d'assurance, puisque sa base indirecte est la conclusion d'un tel contrat». ${ }^{108}$ Étant donné la double nature de l'action directe, la victime doit d'abord détenir une créance de responsabilité contre l'auteur de son préjudice si elle entend faire valoir son droit à réparation directement contre l'assureur. Sans créance de responsabilité, il n'y a donc aucun lien de droit entre la victime et le responsable, que celui-ci soit assuré ou non. ${ }^{109}$

À elle seule la créance de responsabilité ne permet pas à la victime d'exiger une indemnisation directe de l'assureur de l'auteur du préjudice;

104. R. Moreau, «Chronique juridique» (1991) 4 Assurances, 609.

105. Selon les auteurs Melançon et Meagher, le tiers lésé faisait valoir un «(...) droit d'action qui pourrait être qualifié de la nature d'une action oblique prématurée ayant pour effet de permettre à la victime la possibilité d'atteindre l'assureur le plus rapidement afin d'exercer les droits conférés par l'article 2602 C.c. sans avoir à respecter les exigences imposées pour l'exercice de l'action oblique prévue par l'article 1031 C.c., telles l'inaction et l'insolvabilité.» P. A. Melançon et F. C. Meagher, supra note 49 à la p. 458.

106. Mutuelle des Bois-Francs, supra note 14 aux pp. 475-477, M. le juge Mayrand; Aetna, supra note 49 aux pp. 1800-1802, M. le juge Brossard.

107. Supra note 78 .

108. D. Lluelles, supra note 75 à la p. 342.

109. Y. Lambert-Faivre, supra note 84 à la p. $445, n^{\circ} 687$. 
l'assureur doit aussi être tenu d'exécuter sa garantie. C'est au moment de l'entrée en vigueur du contrat d'assurance que naîtra l'obligation contractuelle de l'assureur, tandis que son obligation de couverture ne sera déclenchée qu'au jour du sinistre. ${ }^{110}$ Ainsi, ce n'est qu'après la réalisation du risque, soit la consécration du sinistre, que le tiers lésé sera en droit d'exiger le montant de l'assurance auprès de l'assureur. Toutefois, ce dernier pourra opposer au tiers lésé les clauses d'exclusion prévues au contrat ainsi que tous moyens antérieurs au sinistre. ${ }^{111}$

La détermination du sinistre est relativement simple lorsque les dommages sont la suite immédiate de la réalisation du risque. Mais nous verrons qu'elle devient fort complexe lorsque les dommages se manifestent longtemps après le fait dommageable, tels les dommages causés à l'environnement ou encore l'apparition de vices en matière de construction. L'identification du jour marquant le déclenchement de la période d'assurance soulève aussi des difficultés, lorsque le contrat d'assurance est basé sur les réclamations des victimes, d'où la nécessité d'analyser la double nature du droit direct du tiers lésé.

\section{§1. La naissance de la dette de responsabilité de l'assuré}

Règle générale, la naissance de la dette de responsabilité de l'assuré constitue le sinistre en assurance de responsabilité traditionnelle. La dette de responsabilité de l'auteur du préjudice sert aussi de fondement pour déterminer le point de départ de la période de garantie de l'assureur. Toutefois, cette règle diffère lorsque les assureurs limitent la garantie d'assurance en fonction de la réclamation de la victime. Cette particularité fait en sorte que les contrats qui sont fondés sur le concept de réclamation présentent des problèmes de couverture qui peuvent affecter le droit d'action directe du tiers lésé.

110. J.-G. Bergeron, supra note 52 aux pp. 328-329.

111. Supra, Chapitre préliminaire, section $3, \S 2$. 


\section{A. La datation du sinistre en assurance de responsabilité traditionnelle}

L'identification du jour du sinistre est de première importance en assurance de responsabilité parce qu'en principe le sinistre marque le déclenchement de l'obligation de garantie de l'assureur. ${ }^{112}$ La loi ne présente aucune définition du sinistre. Cependant, le Code civil du Québec et la jurisprudence de la Cour suprême du Canada fournissent certains éléments qui servent à en préciser la notion.

\section{a) L'interprétation des principes issus du Code civil du Québec}

Aux termes de l'article 2463 C.c.Q., «l'assurance de dommages oblige l'assureur à réparer le préjudice subi au moment du sinistre, mais seulement jusqu'à concurrence du montant de l'assurance». ${ }^{113}$ Deux règles se dégagent de cette disposition : le montant de l'indemnité s'évalue au moment du sinistre et le déclenchement de la couverture naît aussi lors du sinistre. Sur la base de ces principes, nous ferons état des critères que la loi nous dicte pour définir le sinistre en assurance de responsabilité.

\section{i) L'existence d'un fait dommageable}

Bien que la loi ne définisse nulle part le sinistre, le Code civil du Québec établit la portée de ce terme. En effet, il ressort du libellé de l'article 2396 C.c.Q., relatif à l'objet de l'assurance de responsabilité, que le sinistre se réfère au fait dommageable qui entraîne des conséquences pécuniaires pour l'assuré. C'est d'ailleurs pourquoi le Code civil énonce que l'objet de l'assurance de responsabilité est «(...) de garantir les conséquences pécuniaires de l'obligation qui peut lui incomber, en raison d'un fait dommageable, de réparer le préjudice causé à autrui».

Comme le remarque Rémi Moreau, cette définition de l'assurance de responsabilité suppose que l'assureur se préoccupe du fait dommageable

112. Supra note 52 aux pp. 328-329.

113. Nos italiques. 
commis durant la période d'assurance. ${ }^{114}$ Cependant, Rémi Moreau ne considère pas que le fait dommageable réalise le risque prévu au contrat. Selon lui, la notion d'événement ou de risque assuré, en assurance de responsabilité, se réalise par la réclamation d'un tiers plutôt que par le fait dommageable, contrairement à ce qui se passe en assurance de biens. ${ }^{115}$

Le professeur Lluelles diffère d'opinion. Après avoir distingué le risque assurable, soit l'objet de la garantie, du risque assuré, le sinistre, Lluelles identifie le risque assurable comme étant la possibilité de poursuites judiciaires $^{116}$ et spécifie que l'on doit référer au contrat afin de singulariser l'événement pour lequel une protection est accordée. Pour sa part, le professeur Bergeron affirme que lorsqu'on «(...) assure sa responsabilité, on entend assurer l'ensemble des éléments susceptibles d'engager sa responsabilité. Ces éléments sont autant la faute que le dommage». ${ }^{117}$ D'après ces opinions, il demeure difficile de dater le sinistre en assurance de responsabilité.

Chose certaine, le sinistre est consacré par le fait dommageable. Il nous reste à déterminer si ce fait correspond à la faute, à la survenance du préjudice ou à la réclamation. Examinons en quoi le Code civil peut nous aider à préciser ce qui constitue le fait dommageable en assurance de responsabilité.

\section{ii) L'existence d'une dette de responsabilité}

Selon les dispositions du Code civil qui traitent de la déclaration de sinistre et du paiement de l'indemnité, le sinistre est constitué par un événement de nature à mettre en jeu l'obligation indemnitaire de l'assureur. Ces mêmes dispositions nous permettent d'affirmer que le sinistre consacre le risque visé par le contrat d'assurance et constitue ainsi le «risque assuré». Tel que l'observe le

114. R. Moreau, «La notion d'événement en assurance de responsabilité civile » (1987) 21 R.J.T. 419 à la p. 445.

115. Ibid. aux pp. 419 et 422.

116. Didier Lluelles affirme à ce sujet qu'en assurance de responsabilité, il importe peu, d'un point de vue technique, «(...) que l'événement susceptible d'entraîner la responsabilité du preneur se soit réalisé, étant donné que le risque [assurable] est ici la possibilité de poursuites judiciaires». D. Lluelles, supra note 75 à la p. 163.

117. J.-G. Bergeron, Les contrats d'assurance : lignes et entre-lignes, t. 1, Sherbrooke, SEM inc., 1989 à la p. 275. 
professeur Lluelles, le «risque assuré», c'est-à-dire le sinistre, est la réalisation de l'événement circonscrit ${ }^{118}$ par les parties au contrat d'assurance, alors que le «risque assurable» se conçoit selon un événement futur, éventuel et possible. ${ }^{119}$

On se rappellera que l'objet de l'assurance de responsabilité, tel qu'énoncé à l'article 2396 C.c.Q., est de garantir l'assuré contre les conséquences pécuniaires de sa responsabilité civile. Il est clair que l'assuré désire se protéger contre d'éventuelles poursuites en responsabilité. Le professeur Lluelles explique que la possibilité d'être poursuivi représente le risque assurable, soit l'événement redouté par l'assuré, tandis que le sinistre se réfère à l'événement qui cause préjudice à la victime. ${ }^{120}$ Le sinistre pourrait donc se définir par l'événement qui crée la dette de responsabilité civile de l'assuré.

La détermination de l'objet de l'assurance de responsabilité contenue à l'article 2396 C.c.Q. et la définition du risque assuré découlant des dispositions portant sur la déclaration du sinistre (art. 2470 à 2473 C.c.Q.) nous permettent de mieux cerner le sinistre. À cet égard, nous retenons qu'en assurance de responsabilité en général, le sinistre est consacré par la survenance d'un fait dommageable qui crée une dette de responsabilité dans le patrimoine de l'assuré. Par conséquent, nous ne pensons pas que la réclamation de la victime soit créatrice de la dette de responsabilité de l'assuré.

La Cour suprême du Canada a aussi analysé le sinistre dans le domaine de l'assurance en général afin d'identifier l'élément qui déclenche l'obligation de garantie de l'assureur. La Cour suprême apporte donc quelques précisions sur la notion de sinistre.

\section{b) Les enseignements de la Cour suprême du Canada}

La détermination du fait à l'origine du préjudice en assurance de responsabilité est une question qui demeure complexe malgré les précisions

118. D. Lluelles, supra note 75 à la p. 181; Voir Art. 2470 à 2473 C.c.Q.

119. Ibid. aux pp. 163-165.

120. Ibid. aux pp. 163, 200-201. 
apportées par la Cour suprême du Canada sur le sens du mot sinistre. ${ }^{121}$ Au fil du temps, la jurisprudence a rappelé l'importance de se référer aux termes du contrat d'assurance pour déterminer le fait qui déclenche l'obligation de garantie de l'assureur. ${ }^{122}$ Cependant, comme le souligne Mme Odette Jobin-Laberge, il est rare que les parties à un contrat d'assurance définissent clairement le fait qui déterminera le déclenchement de la garantie. ${ }^{123}$ C'est pourquoi nous avons jugé opportun de rappeler l'opinion de la Cour suprême concernant le sens du mot «sinistre» en assurance de responsabilité traditionnelle.

En 1992, la Cour suprême du Canada s'est prononcée sur le sens des mots «risque» et «sinistre» dans l'arrêt Frenette. ${ }^{124}$ La jurisprudence a alors clarifié le moment du déclenchement de la couverture. La Cour a établi des distinctions applicables à l'assurance en général, même si la question en litige concernait une renonciation à la confidentialité des dossiers médicaux de l'assuré lors de la souscription d'une police d'assurance-vie. La juge L'HeureuxDubé a procédé à l'étude des mots «risque» et «sinistre» selon leur sens ordinaire et technique. ${ }^{125}$ Pour étayer son raisonnement, la Cour réitère les distinctions apportées par le juge Malouf, dissident en Cour d'appel. ${ }^{126}$ La juge L'Heureux-Dubé s'exprime ainsi :

«En conséquence, les "risques" constituent l'objet même du contrat d'assurance; la réalisation de ce risque, c'est-à-dire le "sinistre", déclenche l'obligation de l'assureur d'indemniser l'assuré ou son bénéficiaire. Cette interprétation est appuyée davantage par le Code civil qui assimile le terme "sinistre" au terme anglais "loss". Dans

121. Frenette c. Métropolitaine, compagnie d'assurance-vie, [1992] 1 R.C.S. 647 [ci-après Frenette].

122. Canadian Indemnity Company c. Walkem Machinery Equipment Ltd., (1973) 5 W.W.R. 212 à la p. 224 (B.-C.C.A.), conf. par [1976] 1 R.C.S. 309. Aussi J.-G. Bergeron, supra note 117 aux pp. 275-282.

123. O. Jobin-Laberge, «L'affaire Allstate et La Royale : La notion d'événement et les obligations des assureurs excédentaires, une solution propre au droit québécois» (1995) 4 Assurances, 567 à la p. 573.

124. Frenette c. Métropolitaine, compagnie d'assurance-vie, supra note 121 aux pp. 647 et 669 , Mme la juge L'Heureux-Dubé.

125. Ibid.

126. Métropolitaine, compagnie d'assurance-vie c. Frenette, [1990] C.A. 62 aux pp. 68-71, M. le juge Malouf. 
ce contexte, le juge Malouf a parfaitement raison, selon moi, de faire remarquer, à la p. 70 : “(...) le sinistre ne peut avoir lieu qu'au moment de la réalisation du risque. En d'autres termes, c'est la perte ou "loss" qui donne lieu à la réclamation. [...] Autrement dit, le risque est l'événement futur qui est redouté par l'assuré. Ce mot réfère à un événement futur, certain ou incertain, qui peut occasionner la perte. Le mot "sinistre" se réfère à la réalisation de l'événement donnant lieu à la réclamation. En d'autres termes, les expressions "risque" et "sinistre" possèdent une définition différente et une signification distincte." ${ }^{127}$

Ces considérations de la Cour suprême du Canada établissent que le sinistre (risque réalisé) est généralement consacré par la survenance du préjudice ou, en d'autres mots, par la perte qui donne lieu à la réclamation de la victime. Étant donné la récente décision de la Cour supérieure dans l'affaire Allstate c. Royale, on pourrait ajouter à cette définition que le sinistre peut se rapporter à la réalisation d'un événement qui revêt une importance telle qu'un assuré peut s'attendre raisonnablement à recevoir une réclamation. ${ }^{128}$

Compte tenu de ces précisions, nous pensons que la Cour suprême choisit de dater le sinistre selon le jour où survient le préjudice (fait dommageable), plutôt qu'en fonction du jour où survient la cause du préjudice (fait générateur), quoique dans bien des situations la survenance du préjudice soit concomitante au fait qui en est la cause. Par ailleurs, il est intéressant de noter que la définition du sinistre, présentée par la Cour suprême dans l'affaire Frenette, se rapproche de la théorie américaine du Injury-In-Fact servant à déterminer le point de départ de la couverture lorsque le préjudice est progressif et continu. Selon cette théorie, le déclenchement de la garantie des polices commerciales (CGL), qui exigent généralement que l'événement dommageable survienne au cours de la période d'assurance, est daté en fonction du fait même

127. (Nos caractères gras.) Frenette, supra note 121 à la p. 669, Mme la juge L'Heureux-Dubé.

128. Allstate c. Royale, [1994] R.J.Q. 2045 à la p. 2059 (C.S.). Le juge s'exprime en ces mots : "I would therefore conclude that the Insured could reasonably have inferred the possibility of a claim in the course of the month of August 1980. It follows from the foregoing that the only insurance policies which are "triggered" are those which were in force at that time». 
qui réalise le dommage. ${ }^{129}$ Néanmoins, que ce soit le fait dommageable ou le fait générateur que le droit québécois décide de privilégier dans la détermination du moment du déclenchement de la garantie d'assurance, nous pouvons affirmer que la dette de responsabilité de l'assuré ne naît pas de la réclamation de la victime puisque cette même réclamation est toujours postérieure au fait dommageable, quelle que soit la définition retenue pour identifier ce fait.

La question de la datation du sinistre en assurance de responsabilité a fait l'objet de longs débats en France. Malgré les divergences d'opinions qui ressortent de la jurisprudence et de la doctrine, le droit français met de l'avant certains critères servant à identifier le sinistre en assurance de responsabilité.

\section{c) Le sinistre en droit français}

En France, l'interprétation de l'article L.124-1 du Code des assurances a rendu difficile la détermination du sinistre en assurance de responsabilité. D'après cet article, «(...) l'assureur n'est tenu que si, à la suite du fait dommageable prévu au contrat, une réclamation amiable ou judiciaire est faite à l'assuré par le tiers lésé». ${ }^{130}$ Par leur interprétation de l'article L. 124-1 C. ass., la jurisprudence et la doctrine françaises ont tenté de définir le sinistre en assurance de responsabilité.

\section{i) La détermination du sinistre selon la jurisprudence}

La jurisprudence a éprouvé beaucoup de difficultés à identifier le fait à l'origine du déclenchement de la garantie d'assurance, d'autant plus lorsque la manifestation du dommage apparaissait plusieurs années après l'événement dommageable. Par exemple, en avril 1993, la Cour de cassation a retenu que le fait générateur avait déclenché la garantie d'assurance lors de travaux réalisés

129. Infra note 152. Voir G. Hilliker, Liability Insurance Law in Canada, Toronto, Butterworths, 1991 à la p. 134, au sujet des théories américaines relatives à la mise en oeuvre de la garantie de l'assureur.

130. (Nos caractères gras.) Picard et Besson observent que le législateur a codifié la doctrine d'Hémard selon laquelle la réclamation de la victime constitue le dommage qui met en jeu la garantie d'assurance. M. Picard et A. Besson, Les assurances terrestres : Le contrat d'assurance, t. 1, $5^{\mathrm{e}}$ éd., Paris, L.G.D.J., 1982 à la p. 531, nº 357. 
une dizaine d'années précédant l'apparition de vices de construction. ${ }^{131}$ La Cour considère que le fait qui marque le point de départ de la garantie de l'assureur correspond à la réalisation des travaux mal effectués. Toutefois, la Cour ne précise pas davantage la nature du fait générateur. Considérait-elle que la réalisation des travaux mal effectués constituait la cause des dommages, la survenance du dommage en lui-même ou la faute de l'assuré?

Quelques mois plus tard, en octobre 1993, la $1^{\text {re }}$ chambre civile avait, une fois de plus, l'occasion de statuer sur une affaire de vices de construction. Cette fois, la Cour retient que «(...) l'origine des dommages subis par le maître de l'ouvrage résidait dans la faute commise par le fabricant, qui avait fabriqué et livré une production défectueuse (...)». ${ }^{132}$ La Cour refuse de considérer que la révélation du vice peut constituer le fait générateur à l'origine des dommages.

La Cour ne distingue pas le fait générateur, c'est-à-dire la «cause» du dommage, du fait dommageable qui réfère à la survenance du dommage en tant que tel, contrairement aux distinctions qui avaient été développées par une importante doctrine ${ }^{133}$ quelque temps auparavant. La Cour de cassation considère donc que le sinistre se réalise par la faute du fabricant et que la garantie est déclenchée à ce moment précis.

En 1995, la jurisprudence de la Cour de cassation statue sur trois espèces relatives à la détermination du fait à l'origine d'un dommage qui se manifeste longtemps après la faute. Les cours inférieures n'avaient pas retenu la faute du fabricant comme étant le fait à l'origine du dommage, mais plutôt le critère qui avait été préconisé en doctrine selon lequel «(...) c'est la réalisation $d u$ dommage, ou fait dommageable, qui constitue le sinistre constitutif d'une dette d'indemnisation à la charge de l'assuré». ${ }^{134}$ Dans les trois espèces, la Cour de

131. Cass. civ. $1^{\text {re }}, 28$ avr. 1993, Bull. civ. 1993.I.99, $\mathrm{n}^{\circ}$ 148; Resp. civ. et ass. 1993.12.comm.245, obs. S. Bertolaso.

132. Cass. civ. $1^{\text {re }}, 9$ juin 1993, Resp. civ. et assur. 1993.15.comm.326 (note S. Bertolaso).

133. Infra note 142 .

134. Cass. civ. $1^{\text {re }}, 3$ oct. 1995, Resp. civ. et assur. 1996.20.comm.38, cassation de CA Montpellier, $1^{\text {re }}$ ch., D., 11 mars 1993; Cass. civ. $1^{\text {re }}$, 30 oct. 1995, Resp. civ. et assur.1996.20-21.comm.38, cassation de CA Paris, 23 e ch. B, 23 oct. 1995; Cass. civ. $1^{\text {re }}$, 14 nov. 1995, Resp. civ. et assur. 1996.20.comm.38, cassation de CA Versailles, $4^{\mathrm{e}}$ ch., 24 janv. 1992. 
cassation renverse cette position et décide que l'origine des dommages réside dans le fait générateur, c'est-à-dire dans la livraison de produits défectueux.

En choisissant la livraison de produits défectueux plutôt que la date de fabrication comme étant le fait générateur à l'origine du dommage, la jurisprudence de la Cour de cassation se trouve à opter pour un critère qui favorise à la fois les assurés et les victimes. En effet, «(...) moins on fait remonter dans le temps l'origine du dommage, moins elle risque d'être antérieure à la prise d'effet de la police et plus le sinistre a donc de chances d'être garanti». ${ }^{135}$ La jurisprudence française est donc déterminée à faire du fait générateur, le fait à l'origine du dommage qui engage la garantie d'un assureur. $^{136}$

Il est certain que la date de livraison d'un produit défectueux nécessite de remonter moins loin dans le temps que le suppose la date de fabrication. Toujours est-il que si la motivation première de la jurisprudence de la Cour de cassation est d'opter pour le moment qui soit le plus rapproché de la prise d'effet de la police de façon à avantager l'assuré et la victime, pourquoi n'a-t-elle pas choisi le critère du fait dommageable qui implique de remonter moins loin dans le temps que l'exige le critère du fait générateur? En effet, la cause à l'origine du dommage (fait générateur) précède systématiquement le jour de la réalisation du dommage (fait dommageable).

Quelles que soient les motivations rattachées au choix qu'a fait la Cour de cassation dans sa détermination du point de départ de la garantie d'assurance, il est clair qu'elle n'a pas considéré que le sinistre, en assurance de responsabilité, pouvait être daté en fonction de la réclamation de la victime. Nous constaterons ci-après que la détermination du fait à l'origine d'un

135. M.-A. Peano, «Un souci de cohérence dans la jurisprudence relative à l'étendue de la garantie dans le temps» Resp. civ. et assur. 1996.3.chron. 3.

136. La doctrine explique le choix de la Cour de cassation selon le principe qu'en droit français, «(...) c'est la délivrance du produit défectueux, et non sa fabrication, qui engage la responsabilité du fabricant à l'égard du maître de l'ouvrage». Ibid. à la p. 4. Le principe est différent selon le droit québécois car la responsabilité du fabricant peut remonter à la date de fabrication d'un produit. En effet, le fabricant peut engager sa responsabilité au moment de la fabrication puisque le Code civil lui permet de se décharger de sa responsabilité s'il prouve que le défaut ne pouvait être connu lors de la fabrication (art. 1474, al. 2 C.c.Q.). 
dommage a aussi fait l'objet de longues discussions au sein de la doctrine française. On y retrouve d'importantes précisions servant à dater le sinistre en assurance de responsabilité.

\section{ii) La détermination du sinistre selon la doctrine}

D'après Picard et Besson, l'interprétation de l'article L. 124-1 signifie que «[1]e sinistre n'existe que par la réclamation du tiers lésé». ${ }^{137}$ Les auteurs affirment que cette interprétation a l'avantage de prendre en considération le fait que l'assureur couvre les dommages subis par l'assuré plutôt que ceux subis par la victime. Picard et Besson considèrent que le patrimoine de l'assuré «(...) n'est atteint ou menacé de l'être que le jour où le tiers met en jeu la responsabilité de l'assuré en formulant contre lui une réclamation». ${ }^{138}$

Néanmoins, Picard et Besson observent qu'en pratique, la «réclamation» du tiers lésé ne sert pas de référence pour déterminer le déclenchement de la couverture d'assurance. ${ }^{139}$ Selon eux, la mise en jeu de la garantie d'assurance s'explique de la manière suivante :

«(...) normalement, ce qui est couvert, pendant la durée du contrat, c'est-à-dire depuis sa prise d'effet jusqu'à la date de sa cessation, ce sont les fautes dommageables que l'on peut commettre (...). Ce qui est ici habituellement retenu, c'est la cause originaire de la responsabilité de l'assuré, son fait générateur, car, en souscrivant une assurance - par exemple une assurance-automobile - l'assuré envisage les fautes dommageables qu'il peut commettre - dans l'exemple les accidents qu'il peut causer - pendant la période où le contrat sera en vigueur (...).» ${ }^{140}$

Malgré l'interprétation qu'ils font de l'article L.124-1 du Code des assurances, Picard et Besson soulignent que ni les tribunaux, ni la doctrine, ne font de la réclamation du tiers l'élément déclencheur de la garantie d'assurance.

137. Supra à la p. 43 .

138. M. Picard et A. Besson, supra note 130.

139. Cette interprétation fut confirmée par un arrêt de la Cour de cassation du 16 juillet 1970 : Cass. civ. $1^{\text {re }} 16$ juillet 1970, D. 1970.Jur.670, J.C.P. 1971.II.16652 (note A. Besson).

140. M. Picard et A. Besson, supra note 130 aux pp. 532-533, n 358. 
Les auteurs reconnaissent que la garantie est due et «mise en mouvement», selon leur expression, par le «fait générateur» ou par les «fautes dommageables». ${ }^{141}$

À ce sujet, la professeure Yvonne Lambert-Faivre remarque que l' «(...) [o]n confond trop souvent le fait générateur qui se situe en amont du dommage en remontant à sa cause et le fait dommageable qui est le fait même qui réalise le dommage». ${ }^{142}$ Mme Lambert-Faivre est d'avis que le fait dommageable est une conséquence du fait générateur. Selon elle, " [q]uelles que soient les hypothèses de fait, il faut souligner et répéter que la créance d'indemnisation de la victime et, corrélativement, la dette de réparation du responsable naît au jour (ou aux jours) de la réalisation des dommages». ${ }^{143}$

D'après les récentes décisions de la Cour de cassation rendues à la fin de l'année 1995, les distinctions apportées en doctrine par Mme Lambert-Faivre n'ont pas été retenues. La Cour a en effet affirmé «(...) que le fait dommageable se définit comme l'événement, cause génératrice du dommage (...)», ${ }^{144}$ sans toutefois reconnaître qu'il pouvait avoir lieu de distinguer le fait dommageable du fait générateur.

À l'instar de Picard et Besson, madame Lambert-Faivre soulève toute l'ambiguïté pratique qui découle de l'interprétation de l'article L.124-1 du Code des assurances. ${ }^{145}$ Même si elle reconnaît qu'il sera essentiel que la victime soumette préalablement une réclamation amiable ou judiciaire avant d'être indemnisée, la professeure Lambert-Faivre affirme que «(...) jamais la "réclamation de la victime" n'a été érigée en élément constitutif de la dette de responsabilité (créance d'indemnisation); jamais sa date n'a été retenue, ni par la doctrine, ni par la jurisprudence, comme référence de la naissance de la responsabilité ou de l'évaluation des préjudices». ${ }^{146}$

141. Ibid.

142. Y. Lambert-Faivre, «La durée de la garantie dans les assurances de responsabilité : fondement et portée de la nullité des clauses "réclamation de la victime"» D. 1992.Chron.13 à la p. 14.

143. Ibid.

144. M.-A. Peano, supra note 135 à la p. 3 .

145. Y. Lambert-Faivre, supra note 142 aux pp. 13-14.

146. Ibid. à la p. 14. 
De plus, madame Lambert-Faivre considère que la réclamation n'est pas essentielle à la réalisation du sinistre; elle n'en constitue que la révélation. ${ }^{147}$ Toujours selon la professeure, «(...) si la victime ne réclame aucune indemnisation, son droit demeure latent jusqu'à l'arrivée de la prescription qui éteint sa créance : il n'y a rien là de spécifique à l'assurance». ${ }^{148}$

Tout bien considéré, la doctrine française a utilisé plusieurs expressions pour dater le sinistre. La doctrine parlera ainsi de la «faute» ou des «fautes dommageables», de la «cause originaire», du «fait générateur» ou encore du «fait dommageable». Malgré la variété des termes utilisés, la doctrine apporte d'importantes précisions sur la datation du sinistre en assurance de responsabilité lorsqu'elle vient préciser que la réclamation de la victime ne constitue pas le sinistre mais plutôt la révélation de ce même sinistre.

La question de la détermination du fait qui met en oeuvre la garantie de l'assureur n'est sans doute pas épuisée ni en France ni au Québec. Il est en effet complexe de déterminer si ce fait correspond à la survenance du préjudice en luimême, c'est-à-dire la «réalisation du dommage» selon les termes utilisés en droit français, ou si le fait qui déclenche la garantie correspond au fait générateur. Cependant, aussi bien le droit français que le droit québécois évitent de dater le sinistre en fonction de la réclamation de la victime.

Peu à peu conscients des difficultés rattachées à la détermination du sinistre, les assureurs ont développé, au fil du temps, différentes clauses leur permettant de préciser le point de départ de la période de garantie. Les assureurs avaient pour objectif de limiter le déclenchement de la couverture d'assurance de manière à mieux gérer l'indemnisation des dommages apparaissant plusieurs années après la commission de l'événement dommageable.

147. «En effet, si le sinistre est réalisé dès la survenance du dommage, la "réclamation de la victime" joue évidemment un rôle de révélateur nécessaire dans l'assurance de responsabilité comme dans la responsabilité civile elle-même (...).»Ibid. à la p. 16.

148. Y. Lambert-Faivre, supra note 84 à la p. 417, n 646. 


\section{d) Les clauses des polices d'assurance déterminant le sinistre}

Les assureurs ont d'abord identifié le moment de la mise en jeu de la couverture d'assurance en fonction de la notion d' «accident». Par la suite, ils ont privilégié le concept d' «événement», puis le concept de «réclamation de la victime», pour enfin élaborer une police hybride formée à la fois de l' «événement» et de la «réclamation».

\section{i) La notion d' «accident»}

Le sinistre s'est métamorphosé au gré des clauses proposées par le marché de l'assurance. Au milieu des années trente, les assureurs ont choisi de faire de l'accident le concept de base de la définition du sinistre dans les polices d'assurance de responsabilité civile. ${ }^{149}$ Le Bureau d'assurance du Canada, sous l'influence du National Casualty Insurance Rating Bureau, son pendant américain, a alors introduit une police d'assurance de responsabilité multirisque dont le sinistre était défini selon la notion d'accident.

L'accident référait à «(...) un événement soudain, imprévisible et inattendu, involontaire». ${ }^{150}$ Le caractère de soudaineté, essentiel à la qualification du sinistre, avait pour effet d'exclure tous les dommages qui étaient susceptibles de se développer graduellement. Comme le souligne Rémi Moreau, les parties devaient recourir à un avenant relatif aux dommages matériels en vertu duquel on élargissait la définition d'accident pour l'étendre à toute exposition continue ou répétée à des risques essentiellement de même nature. ${ }^{151}$ La notion d'accident était devenue insuffisante en elle-même.

149. R. Moreau, supra note 114 à la p. 417.

150. Ibid. à la p. 434.

151. Ibid. aux pp. 430-431. 


\section{ii) La notion d' «événement»}

Durant les années soixante, les assureurs ont remplacé la notion d'accident par celle d'événement dans les polices multirisques. ${ }^{152}$ Le caractère de soudaineté, associé à la notion d' « accident», a alors complètement disparu pour laisser place au développement graduel et répété d'un risque. Ainsi, les contrats d'assurance offraient l'avantage de déclencher la garantie d'assurance à la date de l'événement. Dans ces circonstances, il se pouvait que le risque se réalise de façon continue et que les dommages surviennent plusieurs années après la réalisation de l'événement. ${ }^{153}$

La substitution de la notion d'événement à celle d'accident n'a pas vraiment aidé à clarifier le moment du déclenchement de la couverture d'assurance. Les assureurs continuaient à définir le sinistre comme étant tout événement générateur de dommages. ${ }^{154}$ Demeurait la question de savoir si le sinistre devait être consacré par la faute commise, par les dommages générés par celle-ci ou par la réclamation d'un tiers lésé.

152. Les polices d'assurance multirisques utilisées dans le domaine commercial sont connues sous l'expression anglaise «Comprehensive General Liability Policy». Ces contrats d'assurance couvrent les risques découlant des services ou des produits issus d'une entreprise commerciale, à l'exception de quinze exclusions standard, tels les risques qui sont propres au roulement des affaires («business risk») d'une compagnie. Voir H. A. Sanderson, The Comprehensive General Liability Policy: The Insuring Intent, Toronto, Butterworths, 1990 aux pp. 9-23.

153. "This revision was designed for at least two purposes : (i) to negate the element of suddenness which has sometimes been associated with "accident", thereby extending coverage to property damage which takes place over a long period of time; and (ii) to ensure that all injury or damage resulting from continuous or repeated exposure to substantially the same general conditions would be considered as arising from one occurence for the purpose of both the deductible provisions and the policy's limits of liability.» G. Hilliker, supra note 129 aux pp. 116-117.

154. Les contrats d'assurance de responsabilité des particuliers présentent une clause-type servant à définir le sinistre selon l'événement générateur de dommages : «Sinistre : tout événement générateur de dommages, étant précisé que tous les dommages ayant la même origine seront imputés à un seul et même sinistre, quel que soit le nombre de tiers lésés.» (Définition tirée d'un contrat d'assurance-habitation des Assurances générales des caisses Desjardins inc. pour la période 1995-1996.) 
Les contrats d'assurance basés sur l'événement sont encore utilisés couramment en assurance-habitation. Ils offrent l'avantage à l'assuré, et incidemment au tiers lésé, de couvrir les réclamations formulées à l'assureur après l'expiration de la police, car c'est la notion d'événement qui aura déclenché la garantie. ${ }^{155}$ Par contre, il se peut que la prévisibilité des sinistres des contrats à base d'événement ne soit pas jugée satisfaisante par les assureurs. Par exemple, lorsque le préjudice apparaît de nombreuses années après l'expiration d'un contrat, il est difficile, voire impossible pour les assureurs de prévoir le nombre d'assurés à indemniser. C'est d'ailleurs ce qui s'est produit au début des années quatre-vingt alors que le marché de l'assurance a subi une importante crise financière.

La définition élargie de la notion d'événement et une série d'autres facteurs sont à l'origine de ce chaos. Plusieurs catastrophes environnementales, tels les désastres chimiques de la l'Union Carbide à Bhopal et l'intoxication des travailleurs de l'amiante, ont conduit à de nombreuses poursuites et entraîné des coûts de défense faramineux pour les compagnies d'assurances. À eux seuls, les dossiers relatifs à la contamination des travailleurs des mines d'amiante ont coûté aux assureurs des billions de dollars en frais de défense. ${ }^{156}$

Vers 1986, les assureurs canadiens ont apporté des modifications aux contrats d'assurance de responsabilité sous l'influence de la plus importante réforme de l'assurance moderne engagée aux États-Unis par l'Insurance Services Office. ${ }^{157}$ La priorité des assureurs consistait à exclure la garantie d'assurance lorsque les dommages apparaissaient plusieurs années après l'événement. Les assureurs ont donc procédé au raffinement de la notion d'événement et ils ont introduit la police basée sur les réclamations des victimes.

155. R. Moreau, supra note 114 à la p. 445.

156. T. R. M. Davis, «The New IBC Standard Form Commercial General (Claims-Made) Liability Policy» (1987) 5 Can. J. Ins. L. 77; H. A. Sanderson, supra note 152 aux pp. 1-8; O. JobinLaberge, supra note 123 aux pp. 567 et 576.

157. R. Moreau, supra note 114 à la p. 446. 


\section{iii) La notion de «réclamation de la victime»}

Les contrats d'assurance basés sur l'événement ne permettaient pas aux assureurs de prévoir le risque avec suffisamment de précision. Les assureurs ont voulu pallier ce problème en insérant la notion de réclamation de la victime dans les polices d'assurance de responsabilité.

Le concept d'événement, adopté par l'industrie de l'assurance en 1973, est substantiellement repris bien qu'on y ajoute des limitations se rapportant au montant de la garantie ainsi que des exclusions particulières. ${ }^{158}$ On a introduit une quinzaine d'exclusions standard afin d'écarter notamment le risque découlant de la responsabilité contractuelle et de la responsabilité professionnelle, le risque de pollution, le risque rattaché à l'utilisation d'un produit, le risque découlant d'un accident nucléaire, etc.

L'innovation majeure marquant la période qui a suivi la crise financière de l'assurance au début des années quatre-vingt demeure l'introduction d'un contrat d'assurance de responsabilité basé sur la réclamation de la victime. Dans la plupart des assurances couvrant les risques commerciaux, le sinistre continuera d'être défini en fonction du fait dommageable (ou du fait générateur selon la thèse privilégiée), tandis qu'en matière d'assurance de responsabilité professionnelle, le sinistre se référera à la réclamation de la victime. Cependant, tant dans les assurances commerciales que professionnelles, la garantie ne sera déclenchée que lorsque la réclamation est logée contre l'assureur pendant la durée du contrat. ${ }^{159}$

Les contrats à base de réclamation sont très utilisés dans le domaine des assurances de construction, des assurances professionnelles, des assurances des commerçants et des fabricants de produits de consommation et dans celui des assurances couvrant le risque de pollution. Le Bureau d'assurance du Canada met également à la disposition des particuliers des polices d'assurance basées sur les réclamations. Mais comme nous l'indique Rémi Moreau, ce genre de contrat

158. Ibid. aux pp. 446-447; T. R. M. Davis, supra note 156 aux pp. 83-84.

159. T. R. M. Davis, supra note 156 à la p. 77. 
ne semble pas connaître la même popularité rencontrée dans le domaine des risques commerciaux ou professionnels. ${ }^{160}$

Tel que le souligne Thomas R. M. Davis, le but recherché par les polices basées sur les réclamations «(...) is to enable insurers to predict current liabilities rather than underwrite unpredictable long-term liabilities (occurence basis)». ${ }^{161}$ À la différence des contrats d'assurance basés sur l'événement, les polices à base de réclamation accroissent donc la prévisibilité du risque en faveur de l'assureur. La Cour suprême du Canada a d'ailleurs reconnu cet avantage pour les assureurs. Par la même occasion, la Cour note certains effets des contrats à base de réclamation sur les droits de l'assuré. À cet égard, la juge McLachlin cite un extrait de Thomas R. M. Davis :

«L'objectif de la formule d'assurance sur la base des réclamations est de permettre aux assureurs de prévoir les responsabilités en cours plutôt que de garantir des responsabilités imprévisibles à long terme (base des événements). Il n'y a pas de doute que cette formule permettra d'atteindre cet objectif, principalement en plaçant sur les épaules de l'assuré une grande partie du risque des responsabilités à long terme imprévisibles.» ${ }^{162}$

Les polices à base de réclamation permettent effectivement aux assureurs de faire une meilleure évaluation du risque. Par exemple, il peut s'avérer qu'un assureur s'engage à garantir la responsabilité découlant d'un produit alors que ce même assureur ignore qu'un tel produit causera des dommages apparaissant à long terme. Selon le nombre, la nature et le montant des réclamations qui peuvent avoir été déclarées à l'assureur pendant la période d'assurance, l'assureur pourra réviser l'évaluation du risque à l'égard de son assuré ou à l'égard d'assurés dont la responsabilité se rapporte à un produit similaire à celui ayant donné lieu à d'importantes réclamations.

160. R. Moreau, «Garanties particulières : L'assurance de responsabilité professionnelle» (1988) 4 Assurances 562 aux pp. 562-563, particulièrement à la note 3 .

161. T. R. M. Davis, supra note 156 à la p. 78.

162. Reid Crowther Ltd. c. Simcoe \& Erie insurance Company, [1993] 1 R.C.S. 266, Mme la juge McLachlin [ci-après Reid Crowther Ltd.]. La citation est une traduction de T. R. M. Davis, supra note 156 à la p. 78. 
Il sera donc avantageux pour l'assureur «(...) d'obtenir des renseignements détaillés sur les réclamations éventuelles avant même d'offrir une garantie (ou son renouvellement) à une personne et, ainsi, d'éviter d'avoir à indemniser des assurés d'une partie importante des réclamations éventuelles qui existent à la date d'effet de la garantie (ou de son renouvellement)». ${ }^{163}$ Considérant cet avantage, l'assureur fixera donc la prime d'un contrat basé sur les réclamations à un moindre coût. ${ }^{164}$

En résumé, l'introduction des contrats à base de réclamation est venue pallier les problèmes de couverture reliés aux polices basées sur l'événement lorsque les dommages se développent graduellement, souvent plusieurs années après l'expiration du contrat. De façon générale, le concept de réclamation augmente la prévisibilité du risque pour l'assureur. Par contre, son utilisation engendre des problèmes de couverture qui peuvent priver l'assuré du bénéfice de l'assurance et empêcher le tiers lésé de faire valoir sa créance directe auprès de l'assureur.

\section{B. La datation du sinistre dans les assurances à base de réclamation}

L'analyse des contrats basés sur les réclamations permet d'illustrer le phénomène des trous de garantie qui caractérise l'ensemble des polices d'assurance fondées sur le concept de réclamation. En raison des trous de garantie inhérents à ce genre de contrats, les clauses liant la garantie à la réclamation de la victime limitent grandement la période de couverture et peuvent diminuer les droits des tiers lésés. Les assureurs ont tenté de minimiser les effets négatifs de ces clauses par la création de mécanismes contractuels mais cela n'élimine pas complètement les trous de garantie.

\section{a) Les contrats «sur la base des réclamations»}

Le marché de l'assurance propose différents contrats faisant de la réclamation de la victime la base du sinistre. On trouve d'abord la «véritable» 
police basée sur les réclamations, ensuite la police basée sur les réclamations présentées et déclarées ${ }^{165}$ et la police dite hybride. ${ }^{166}$ Nous nous intéresserons particulièrement au contrat hybride dont l'utilisation est répandue dans le domaine des assurances commerciales et professionnelles. ${ }^{167}$

Dans une police basée exclusivement sur les réclamations, c'est la réclamation qu'un tiers lésé présente à l'assuré au cours de la période d'assurance qui aura pour effet de mettre en oeuvre l'obligation de garantie de l'assureur. Quant à la police basée sur les réclamations présentées et déclarées, elle exige que la victime présente d'abord sa réclamation à l'assuré pendant la durée du contrat. Par la suite, l'assuré doit déclarer la réclamation à son assureur avant l'expiration de la police.

Les contrats d'assurance à base de réclamation peuvent aussi varier selon qu'ils sont fondés «sur la base de la découverte du sinistre» ou «sur la datation des réclamations». En ce qui a trait aux premiers, c'est la découverte du sinistre qui déclenche la garantie d'assurance. Quant aux contrats basés «sur la datation des réclamations», Rémi Moreau observe que ces contrats exigent habituellement que les dommages se réalisent durant la période d'assurance et que le sinistre soit aussi déclaré à l'assureur à l'intérieur de ce même délai. ${ }^{168}$

La police basée «sur la datation des réclamations», telle que définie par Rémi Moreau, ainsi qu'un bon nombre de polices d'assurance basées sur les réclamations sont dites «hybrides» parce qu'elles intègrent la notion d'événe-

165. La police d'assurance responsabilité professionnelle du Barreau du Québec est basée sur la notion de réclamation présentée et déclarée. Cela signifie qu'en principe, la garantie s'applique aux réclamations que les victimes présentent à l'assuré pendant la période d'assurance, moyennement la déclaration de ces même réclamations à l'assureur pendant la durée du contrat ou de toute prolongation de celui-ci. Voir art. 2.01, 3.01 de la police en vigueur pour la période du $1^{\mathrm{er}}$ janvier 1996 au $1^{\mathrm{er}}$ janvier 1997; R. Langlois, «Le Fonds d'assurance responsabilité professionnelle du Barreau du Québec» (1991) 4 Assurances 569.

166. L'arrêt Reid Crowther Ltd., supra note 162 présente une analyse des différents types de polices basées sur les réclamations.

167. R. Moreau, supra note 160 aux pp. 562-563. L'assurance de responsabilité des particuliers favorise encore l'utilisation de la notion d'événement.

168. R. Moreau, supra note 114 à la p. 449. 
ment ${ }^{169}$ dans la mise en oeuvre de l'obligation de garantie de l'assureur. En effet, l'utilisation de ce genre de police est répandue dans les domaines de l'assurance de responsabilité commerciale et professionnelle, d'où l'intérêt d'examiner les conditions particulières au déclenchement de la garantie des polices hybrides.

\section{b) Le déclenchement de la garantie des polices hybrides}

Le point de départ de la garantie des polices hybrides se distingue de celui des polices à base d'événement et des polices exclusivement basées sur les réclamations en raison de la juxtaposition de la notion d'événement à celle de réclamation. Le déclenchement de la couverture exige la réalisation de deux conditions. L'une d'elles se rapporte à la survenance du sinistre qui se référera au fait dommageable, et l'autre à la date à laquelle est logée la réclamation contre l'assureur.

\section{i) La survenance du sinistre}

En principe, en présence d'un contrat à base de réclamation, l'assureur est tenu d'exécuter sa garantie si la réclamation lui est présentée pendant la durée du contrat. ${ }^{170}$ Cependant, lorsque le contrat est hybride, une condition supplémentaire est habituellement exigée par l'assureur. Cette condition se rapporte à la survenance du sinistre (fait dommageable) et comprend deux éléments essentiels. ${ }^{171}$ D'abord, le sinistre doit survenir pendant que le contrat est en vigueur. Ensuite, le sinistre, ou la possibilité qu'un sinistre se soit réalisé, doit être déclaré à l'assureur pendant la période d'assurance.

La Cour suprême a d'ailleurs fait ressortir les éléments qui permettent de qualifier un contrat d'«hybride» lorsqu'elle a procédé à l'analyse détaillée d'une police d'assurance couvrant le risque professionnel d'une compagnie d'ingénierie.

169. Ibid. aux pp. 446, 449; T. R. M. Davis, supra note 156 aux pp. 83-84.

170. Reid Crowther Ltd., supra note 162 aux pp. 260-261 et 267, Mme la juge McLachlin. Voir T. A. Konopka, «The Advantage of Claims-Made Forms For Insurance Buyers» (1992) 4 Assurances 479 à la p. 481; G. Hilliker, supra note 129 à la p. 135.

171. R. Moreau, supra note 114 à la p. 449. 
En effet, dans l'arrêt Reid Crowther Ltd., ${ }^{172}$ la Cour suprême a qualifié le contrat d' «hybride» vu l'importance qui était accordée à l'acte négligent.

Selon le contrat d'assurance de Reid Crowther Ltd., l'assureur limitait l'application de sa garantie seulement aux réclamations présentées à l'assuré pendant la période d'assurance. Tel que l'observe la Cour suprême, la police de Reid Crowther Ltd. semble donc, à première vue, être une police exclusivement basée sur les réclamations. ${ }^{173}$ Cependant, des limitations supplémentaires transforment le contrat en un contrat hybride.

En effet, une obligation s'ajoutait à celle de déclarer la réclamation à l'assureur au cours du contrat. L'assuré devait aussi aviser l'assureur de ses présumés actes négligents, erreurs ou omissions, aussitôt qu'il avait reçu des renseignements à ce sujet. La Cour note que le libellé des clauses relatives à $l^{\prime}$ «Avis de réclamation ou de poursuite» accorde une importance aux faits donnant lieu à la réclamation, ce qui suppose que les erreurs, omissions ou actes négligents puissent être associés à la réclamation qui déclenche de la couverture d'assurance. ${ }^{174}$ De plus, le contrat excluait les réclamations découlant d'actes antérieurs à la période de validité du contrat, ce qui avait pour conséquence de procurer à l'assureur les avantages liés à une police à base d'événement. La Cour suprême a donc qualifié le contrat d' «hybride» étant donné l'importance accordée aux erreurs, omissions ou actes négligents du professionnel.

Nombreux sont les contrats à base de réclamation qui exigent que le fait dommageable survienne au cours de celui-ci afin que la couverture puisse s'appliquer. Ainsi, la survenance du fait dommageable contribue à déclencher la garantie, en autant que la réclamation soit logée contre l'assureur pendant que le contrat est en vigueur. ${ }^{175}$ Ces contrats devraient recevoir la qualification d'«hybride» en raison de l'importance accordée au moment où surviennent les

172. Reid Crowther Ltd. supra note 162 à la p. 252.

173. Ibid. aux pp. 267-268, Mme la juge McLachlin.

174. Ibid.

175. "The claims-made form respond to claims made during the policy period (and applicable Extended Reporting Period) for bodily injury or property damage which occurs after the Retroactive Date and before the expiry of the policy period.» T. R.M. Davis, supra note 156 à la p. 80. Voir R. Moreau, supra note 114 à la p. 449. 
dommages. L'affaire Reid Crowther Ltd. nous permet de constater que même en assurance de responsabilité professionnelle, ${ }^{176}$ où le concept d'événement est ordinairement absent de la définition du sinistre, le contrat d'assurance peut donc accorder une importance particulière à la notion d'événement.

\section{ii) La déclaration de la réclamation à l'assureur}

L'utilisation du concept de réclamation modifie le rôle du sinistre dans le déclenchement de la couverture d'assurance. En effet, le sinistre ne suffit plus à déclencher la garantie d'assurance. Il est essentiel que l'auteur du préjudice déclare à l'assureur, au cours de la période d'assurance, qu'une victime lui a présenté une réclamation ou qu'une victime est susceptible de lui en présenter une. Cette condition n'est pas particulière aux polices hybrides parce qu'en général l'ensemble des contrats à base de réclamation exige que la réclamation soit déclarée à l'assureur alors que le contrat est en vigueur. ${ }^{177}$

Mais quelle est la nature de la réclamation devant être déclarée à l'assureur? S'agit-il de la simple manifestation du mécontentement d'une victime ou d'une mise en demeure officielle dénonçant la responsabilité de l'assuré? La Cour suprême du Canada s'est interrogée sur le sens d'une réclamation.

En l'absence d'une définition de la «réclamation» dans le contrat (ou encore si la définition est ambiguë), la Cour suprême déduit de l'ensemble de la jurisprudence et de la doctrine que «(...) le tiers doit d'une façon quelconque communiquer à l'assuré l'existence d'une demande d'indemnisation ou d'un autre type de réparation ou encore, il doit tout au moins lui communiquer qu'il a clairement l'intention de tenir l'assuré responsable des dommages en question». ${ }^{178}$ Incidemment, cette affirmation de la Cour suprême du Canada va dans le même

176. Puisque la poursuite de la victime est intentée souvent plusieurs années après la commission de l'acte négligent, le contrat d'assurance basé sur l'événement n'avantagerait pas l'assuré du point de vue de la couverture. C. Tellier, «Le contrat d'assurance-responsabilité professionnelle» dans La responsabilité professionnelle et l'assurance-responsabilité, C.F.P.B.Q., 1976-1977, 134 à la p. 135. Voir R. Moreau, supra note 114 aux pp. 441-443.

177. T. R.M. Davis, supra note 156 à la p. 85; R. Moreau, supra note 114 à la p. 449.

178. Reid Crowther Ltd., supra note 162 à la p. 273, Mme la juge McLachlin. 
sens que la théorie de droit français selon laquelle la réclamation de la victime ne constitue que la révélation du dommage. ${ }^{179}$

Lorsque les assureurs exigent que la réclamation soit déclarée à l'assureur au cours de la période d'assurance, cela fait en sorte que le jour marquant le déclenchement de la couverture ne correspond plus au jour du sinistre. ${ }^{180}$ Ainsi, dans une police hybride, le sinistre se réalisera par la naissance de la dette de responsabilité de l'assuré, mais le déclenchement de la couverture sera retardé jusqu'au jour où l'assuré déclare la réclamation de la victime à son assureur. Nous croyons important d'ajouter que le déclenchement de la garantie d'une police dont le sinistre se réfère à la réclamation de la victime (plutôt qu'au fait dommageable) sera également retardé jusqu'au jour où la réclamation est déclarée à l'assureur.

Selon la professeure Lambert-Faivre, cette particularité des contrats basés sur les réclamations remet en question le principe «(...) d'adéquation de la durée de la garantie à la durée de la responsabilité». ${ }^{181} \mathrm{~L}$ ' «inadéquation» que créent les contrats à base de réclamation entre le jour du sinistre et celui du déclenchement de la garantie d'assurance cause des problèmes de couverture qui limitent grandement la protection de l'assuré et peuvent diminuer les droits des tiers lésés. La Cour suprême du Canada a-t-elle dénoncé les problèmes de couverture particuliers aux contrats d'assurance qui comportent des clauses limitatives de garantie basées sur les réclamations des victimes.

\section{c) L'arrêt Reid Crowther Ltd. : les considérations de la Cour suprême du Canada concernant les contrats à base de réclamation}

Avec l'introduction de la notion de réclamation dans les polices d'assurance de responsabilité, les assureurs ont conçu différentes clauses limitatives de garantie qui fixent le point de départ de la garantie après la réalisation du fait qui est à l'origine du dommage. Ces clauses d'exclusion, qui

179. Supra notes 142-143.

180. Y. Lambert-Faivre, supra note 142 aux pp. 13-14.

181. Y. Lambert-Faivre, supra note 84 à la p. $413, \mathrm{n}^{\circ} 642$. 
ont fait leur apparition dans le marché de l'assurance au milieu des années quatrevingt, comportent des dangers pour les assurés et les tiers lésés.

\section{i) La création de trous de garantie}

Dans un contrat à base de réclamation, la naissance de la dette de responsabilité de l'assuré peut précéder le jour marquant le point de départ de la garantie d'assurance. On se rappellera que la garantie ne sera effective que si le sinistre (fait dommageable ou réclamation de la victime selon la définition retenue) survient au cours de la période d'assurance et si l'assuré avise l'assureur de la réclamation de la victime pendant ce même délai. Seul l'accomplissement de ces deux conditions peut mettre en oeuvre l'obligation de garantie de l'assureur.

Par conséquent, l'assuré peut être privé du bénéfice de la garantie en l'absence de la réalisation de l'une ou l'autre des conditions relatives à la survenance du sinistre et à la déclaration de la réclamation de la victime au cours de la période d'assurance et ce malgré l'existence de la dette de responsabilité de l'assuré. Par exemple, si les dommages surviennent pendant que le contrat est en vigueur et que l'assuré présente une réclamation à son assureur après l'expiration du contrat, la couverture ne sera pas mise en jeu. Si l'assuré a renouvelé son contrat et que la réclamation est logée contre l'assureur durant la période d'assurance ayant fait l'objet du renouvellement, la responsabilité de l'assuré ne sera pas davantage couverte parce que le sinistre est antérieur à la nouvelle période d'assurance et que l'assuré aura eu connaissance du sinistre. Selon cette hypothèse, il y aura création de trous de garantie.

Les trous de garantie affectent également les droits des tiers lésés puisque l'action directe s'exerce en fonction du contrat d'assurance. En effet, comment le tiers lésé peut-il faire valoir sa créance de réparation directe si l'obligation de garantie de l'assureur ne peut pas être mise en oeuvre durant la période d'assurance? Le tiers lésé ne possède donc aucun intérêt juridique à poursuivre directement l'assureur de l'auteur du préjudice s'il s'avère que des trous de garantie privent l'assuré du bénéfice de la couverture d'assurance.

Dans l'arrêt Reid Crowther Ltd., la Cour suprême du Canada a analysé le phénomène des trous de garantie inhérents aux contrats à base de 
réclamation. ${ }^{182}$ La Cour a dénoncé les dangers que comportent de tels contrats pour les droits des assurés. Selon l'expression de la Cour suprême, les assurés couverts par ce genre de police «(...) se retrouvent assis entre deux chaises (...)». ${ }^{183}$ D'un côté, ils ne peuvent être couverts lorsque la victime leur communique une réclamation après l'expiration du contrat. De l'autre côté, même si les assurés ont renouvelé de façon successive leur assurance, ils sont privés du bénéfice de la garantie pour laquelle ils se sont assurés en raison de leur connaissance de l'acte négligent à l'origine de la réclamation.

En somme, le phénomène des trous de garantie résulte du fait que le jour marquant la naissance de la dette de responsabilité de l'assuré n'a plus pour effet de déclencher la garantie d'assurance. Ainsi, l'assuré pourra être privé du bénéfice de l'assurance malgré l'existence de sa dette de responsabilité. Dans de telles situations, l'assuré devra donc assumer les conséquences de sa responsabilité civile même s'il croit être couvert par le contrat d'assurance. Il importe donc d'examiner davantage les conséquences des trous de garantie.

\section{ii) Les effets des trous de garantie sur la couverture d'assurance}

En principe, l'assuré s'attend à ce que sa police d'assurance le couvre dès la réalisation du risque pour lequel il s'est assuré, sous réserve de l'application des exclusions apparaissant clairement dans la police. Or, l'utilisation des contrats à base de réclamation peut s'effectuer au détriment de la théorie des attentes raisonnables de l'assuré. Selon l'arrêt Reid Crowther Ltd., il peut arriver que l'assuré ignore qu'il aura à supporter une part des risques découlant de sa responsabilité civile lorsqu'il achète une police d'assurance à base de réclamation. En effet, «(...) la plupart des assurés achètent une assurance de responsabilité en tenant pour acquis qu'ils sont assurés contre tous les types de responsabilité, sans se rendre compte qu'il peut exister des trous de garantie dans leur assurance». ${ }^{184}$

Le professeur Bergeron observe que très souvent l'assuré associe l'événement à la réclamation et s'attend rarement à ce que la faute ou le dommage

182. Reid Crowther Ltd., supra note 162 à la p. 272, Mme la juge McLachlin.

183. Ibid.

184. Ibid. à la p. 267, Mme la juge McLachlin. 
doivent aussi se produire durant le contrat. Ainsi, l'assuré peut croire qu'il est couvert dès qu'une réclamation est portée à sa connaissance au cours de la période d'assurance, sans même savoir que son contrat exclut les réclamations découlant de l'acte négligent survenu avant l'entrée en vigueur du contrat. ${ }^{185}$

De façon générale, les polices à base de réclamation restreignent grandement la période de couverture en plaçant sur les épaules de l'assuré, souvent à son insu, une part des risques visés au contrat. Certes, la prime est fixée en fonction de ce désavantage, mais encore faut-il que l'assuré soit conscient de l'existence de trous de garantie au moment de la signature du contrat. Dans sa décision Reid Crowther Ltd., la Cour suprême du Canada a d'ailleurs précisé le devoir d'information de l'assureur lorsqu'un assuré souscrit à une police à base de réclamation.

\section{iii) Les conditions de validité des polices à base de réclamation vis-à-vis l'assuré}

Dans l'hypothèse où les assurés sont conscients qu'ils achètent un contrat par lequel l'assureur ne garantit que les réclamations qui surviennent au cours de la période d'assurance, la Cour suprême affirme dans l'arrêt Reid Crowther $L t d$. que la question de l'équité et des attentes raisonnables des parties ne se pose pas. Toutefois, la Cour considère qu'il faut interpréter les polices basées sur les réclamations avec prudence «(...) afin de déterminer si, globalement, elles placent clairement sur les épaules de l'assuré le risque de la responsabilité à long terme». ${ }^{186}$ D'un point de vue plus particulier, la Cour suprême recommande aux tribunaux de ne pas interpréter les contrats à base de réclamation de manière à exclure les réclamations présentées à l'assureur pour un vice de forme. ${ }^{187}$

En analysant les polices à base de réclamation, la juge McLachlin indique clairement qu'un assureur a l'obligation d'informer l'assuré des trous de garantie éventuels. Selon elle, on «(...) doit présumer que les parties ont l'intention soit de fournir, soit d'obtenir, sur une base continue, une garantie relativement à

185. J.-G. Bergeron, supra note 117 à la p. 283

186. Reid Crowther Ltd., supra note 162 à la p. 267, Mme la juge McLachlin.

187. Ibid. 
toutes les réclamations légitimes, que ce soit par le renouvellement d'une police avec le même assureur ou la conclusion d'un nouveau contrat d'assurance avec un assureur différent». ${ }^{188}$

Du moment que des trous de garantie existent, la Cour suprême déclare que l'assuré ne doit pas être privé du bénéfice de la garantie si son assureur ne l'a pas informé des problèmes de couverture propres aux contrats basés sur les réclamations. Nous croyons important de noter que le professeur Bergeron considère aussi que l'assureur doit clairement indiquer les limites de la garantie et préciser à l'assuré si l'événement qui donne lieu à la réclamation peut lui être antérieur. ${ }^{189}$

Malgré la présence de trous de garantie dans un contrat basé sur les réclamations, la Cour suprême du Canada précise que c'est en analysant minutieusement chacune des clauses que l'on arrivera à déterminer si le contrat prive injustement l'assuré du bénéfice de la couverture. ${ }^{190}$ Afin de minimiser les désavantages des polices basées sur les réclamations, les assureurs proposent l'ajout de deux types de clauses d'assurance.

\section{d) Les clauses destinées à pallier les trous de garantie}

Conscients des désavantages que procure l'achat d'une police basée sur les réclamations, les assureurs ont mis sur le marché deux types de clauses servant à minimiser les trous de garantie autrement incontournables pour l'assuré. Il s'agit respectivement de la clause de «reprise du passé» et de la clause de «garantie subséquente».

188. Ibid.

189. L'opinion du professeur Bergeron est antérieure à la consécration du régime de protection des droits des tiers lésés en 1994. J.-G. Bergeron, supra note 117 à la p. 283.

190. Reid Crowther Ltd., supra note 162 aux pp. 269-271, Mme la juge McLachlin. 


\section{i) La «reprise du passé inconnu»}

La «reprise du passé» consiste à étendre la garantie d'assurance dans le temps. Normalement, la couverture des polices à base de réclamation s'applique aux sinistres (la réclamation de la victime ou le fait dommageable selon les termes du contrat) qui surviennent pendant que le contrat est en vigueur. L'objectif de la clause de reprise du passé est de permettre à l'assuré d'obtenir une garantie pour les sinistres qui lui sont inconnus et dont la survenance remonte avant la période de validité du contrat.

En d'autres mots, la reprise du passé inconnu consiste à créer une période de rétroactivité qui étend la couverture à des sinistres qui sont exclus de la garantie d'assurance. La protection qu'offre une telle clause se limite généralement à une durée de six mois ou d'un an précédant l'entrée en vigueur du contrat. La période de rétroactivité aura donc pour effet de «valider» les sinistres antérieurs à la prise d'effet d'un contrat.

Prenons l'exemple d'un professionnel couvert par une police hybride. Lorsque ce professionnel assure sa responsabilité pour une année de référence donnée, à supposer que la période débute le $1^{\text {er }}$ janvier 1996 et se termine le 31 décembre 1996, en principe, seuls les sinistres survenus pendant cette période sont couverts par l'assureur. Au moment du renouvellement du contrat pour la période s'étendant du $1^{\mathrm{er}}$ janvier 1997 au 31 décembre 1997, les parties pourront convenir de fixer une date de rétroactivité, supposons le $1^{\mathrm{er}}$ janvier 1996. Ainsi, les sinistres survenus depuis le $1^{\text {er }}$ janvier 1996 pourront être couverts par la nouvelle police d'assurance débutant le $1^{\text {er }}$ janvier 1997, pour autant qu'ils soient inconnus de l'assuré.

Malgré les avantages que procure la clause de reprise du passé à un assuré, la protection offerte par ce genre de clause demeure relative. Cela s'explique par le fait que les contrats d'assurance proposés par le Bureau d'assurance du Canada (B.A.C.) comprennent ordinairement une clause qui permet à l'assureur de modifier la date de rétroactivité.

Ainsi, dans le cas où un assuré souscrit à une première police d'assurance comportant une reprise du passé, Thomas R.M. Davis observe que l'assuré canadien demeure à la merci de l'assureur qui se réserve fréquemment la faculté 
de modifier la date de rétroactivité. Lors du renouvellement de la première police, l'assureur pourrait avancer la date de reprise du passé de manière à la faire correspondre au jour marquant l'entrée en vigueur du contrat renouvelé. ${ }^{191}$ Cela aurait donc pour effet d'annuler la période de rétroactivité projetée. Cependant, à l'occasion des renouvellements ultérieurs, le pouvoir de l'assureur de modifier la date de reprise du passé est limité à des situations particulières. L'assureur ne pourra avancer la date de rétroactivité que «(...) dans les cas de changement d'assureur, d'aggravation du risque, de défaut de l'assuré de fournir les informations voulues ou dans d'autres cas, suite à un accord entre l'assureur et l'assuré». ${ }^{192}$

À la différence de l'assureur canadien, l'assureur américain ne peut avancer la date de rétroactivité d'une première police que dans les cas énumérés dans les contrats standard proposés par le Insurance Services Office, le pendant américain du B.A.C. Ainsi, moyennant que l'assuré y consente et à moins d'un changement d'assureur, d'une aggravation de risque ou d'une déclaration incomplète, fausse ou mensongère de l'assuré, l'assureur américain ne pourra pas modifier la date de rétroactivité d'une première police. ${ }^{193}$

En somme, la protection que procure une clause de reprise du passé inconnu aux assurés canadiens demeure fragile. Outre les possibilités pour un assureur d'avancer la date de rétroactivité, il peut parfois être difficile pour l'assuré de justifier sa bonne foi, advenant une enquête de l'assureur sur la «connaissance» du sinistre. La professeure Lambert-Faivre précise à ce sujet que la bonne foi de l'assuré pourrait être attaquée par l'assureur seulement si ce dernier découvre que l'assuré avait des indices, ou que l'assuré entretenait des rumeurs ou des inquiétudes quant à des dommages pouvant découler d'un fait antérieur à l'entrée en vigueur du contrat. ${ }^{194}$

Le caractère incertain de la protection d'une clause de reprise du passé entraîne des incidences sur le recours direct du tiers lésé. En effet, il se peut que le tiers lésé ne puisse pas toucher le montant de l'indemnité auquel il a droit parce

191. T. R. M. Davis, supra note 156 aux pp. 85-86.

192. R. Moreau, supra note 114 à la p. 450.

193. T. R. M. Davis, supra note 156 à la p. 86.

194. Y. Lambert-Faivre, supra note 142 à la p. 16. 
que la clause de reprise du passé n'élimine pas complètement les trous de garantie. Nous constaterons que la clause de garantie subséquente ne sécurise pas davantage le tiers lésé qui entend exercer l'action directe contre l'assureur de l'auteur du préjudice.

\section{ii) La «garantie subséquente»}

L'assuré qui bénéficie d'une «garantie subséquente» se voit accorder un délai supplémentaire pour déclarer les sinistres à l'assureur après l'expiration du contrat. La garantie subséquente permet donc de modifier la condition du contrat selon laquelle les sinistres doivent être déclarés à l'assureur depuis la date de rétroactivité, s'il y a lieu, jusqu'à l'expiration de la police d'assurance. ${ }^{195}$

La clause de garantie subséquente se distingue de la clause de reprise du passé en ce qu'elle se rapporte à la déclaration du sinistre faite à l'assureur plutôt qu'à la survenance du sinistre. Même en présence d'une garantie subséquente, les réclamations faites à l'assureur après l'expiration du contrat doivent donc se rapporter à des sinistres survenus pendant que le contrat est en vigueur (incluant la période de rétroactivité). ${ }^{196}$

Il existe trois types de garanties subséquentes définies en fonction de leur durée respective. Les plus courtes durent soixante jours et les plus longues peuvent durer cinq ans. Certaines périodes de prolongation possèdent une durée illimitée. ${ }^{197}$ Contrairement à la clause de reprise du passé inconnu qui peut être modifiée par l'assureur aux termes des contrats proposés par le B.A.C., ${ }^{198}$ seul le non-paiement de la prime permet à l'assureur de priver l'assuré de la garantie subséquente.

Afin d'illustrer l'effet d'une garantie subséquente, reprenons l'exemple du professionnel dont la responsabilité est couverte pour la période du $1^{\text {er }}$ janvier 1996 au 31 décembre 1996. Supposons que l'assuré bénéficie d'une garantie subséquente d'une durée de soixante jours qui entrera en vigueur à la fin du

195. R. Moreau, supra note 114 aux pp. 450-451.

196. T. R. M. Davis, supra note 156 à la p. 86 .

197. R. Moreau, supra note 114 aux pp. 450-451.

198. Supra notes 192-193. 
contrat. Après l'expiration du contrat, soit dès le $1^{\text {er }}$ janvier 1997, la clause de garantie subséquente permettra à l'assuré de déclarer les sinistres à l'assureur pendant soixante jours additionnels. Cependant, seuls les sinistres survenus pendant la période d'assurance qui débute le $1^{\text {er }}$ janvier 1996 et se termine le 31 décembre 1996 pourront donner lieu à une réclamation couverte par l'assureur. Advenant que l'assuré bénéficie d'une reprise du passé inconnu combinée à une garantie subséquente, les sinistres survenus pendant la reprise du passé et qui sont déclarés durant la période de garantie subséquente seront également couverts. ${ }^{199}$

Rémi Moreau est d'avis que la «(...) combinaison d'une police fondée sur la date des réclamations et d'un avenant de garantie subséquente d'une durée illimitée permet une couverture d'assurance similaire à celle que procure une police à base d'événement (...)». ${ }^{200}$ Il est certain que l'ajout d'une garantie subséquente illimitée avantage l'assuré. ${ }^{201}$ Cependant, l'assuré doit comprendre qu'en principe, la période de garantie subséquente ne s'applique qu'aux

199. La figure suivante illustre les effets que créent la reprise du passé et la garantie subséquente sur l'étendue de la couverture d'une police à base de réclamation :

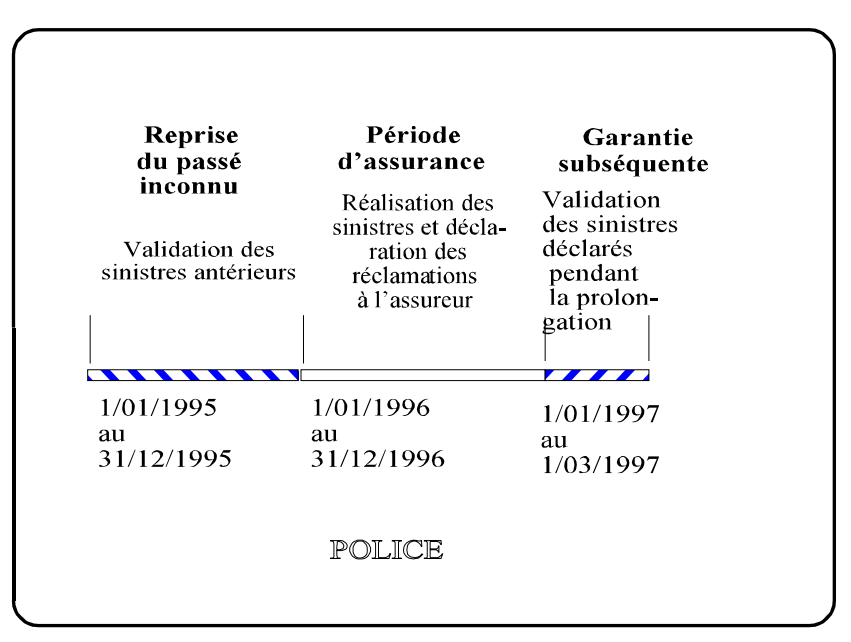

200. R. Moreau, supra note 114 à la p. 451 .

201. Thomas R. M. Davis rapporte qu'une prime supplémentaire peut s'élever à $200 \%$ du coût de la prime de base afin que l'assuré puisse bénéficier d'une telle garantie. T. R. M. Davis, supra note 156 à la p. 86. 
réclamations déclarées à l'assureur et qui se réfèrent à un sinistre survenu pendant que le contrat est en vigueur. ${ }^{202}$

À cet égard, la clause de prolongation ${ }^{203}$ de la police d'assurance responsabilité professionnelle du Barreau du Québec se distingue des clauses de garantie subséquente selon lesquelles la période de garantie additionnelle débute après l'expiration de la police, limitant ainsi la couverture aux seules réclamations rattachées à un sinistre survenu pendant que le contrat est en vigueur. Mme Chantale Thouin, avocate au Fonds d'assurance de responsabilité du Barreau du Québec, nous expliquait, lors d'un entretien téléphonique, que la clause de prolongation a pour effet de repousser la date d'expiration de la police de façon illimitée dans le temps. Ainsi, la réclamation déclarée à l'assureur pendant la période de prolongation se trouve à être déclarée pendant la période d'assurance. Cependant, la clause de prolongation du Barreau du Québec peut présenter des trous de garantie relativement aux services professionnels rendus avant la «période d'assurance», ${ }^{204}$ soit avant l'entrée en vigueur du régime d'assurance de responsabilité professionnelle obligatoire en mai 1988.

202. G. Hilliker résume le contenu d'une garantie subséquente illimitée, tel que le Bureau d'assurance du Canada la présente dans les polices CGL : «(c) Unlimited Tail : For an additional premium, coverage may be purchased with respect to any claims which may result in the future from occurences which took place during the policy period. In short, this endorsment converts the claims-made policy into an occurrence policy. The extendend reporting period endorsment may be purchased generally or for specific accidents, products, or locations.» G. Hilliker, supra note 129 à la p. 136.

203. La clause 3.12 de la police d'assurance-responsabilité professionnelle du Barreau du Québec pour la période 1996-1997 se lit ainsi : "Si l'Assuré désigné vient à mourir, est radié ou cesse de façon définitive ou pour une période limitée d'exercer sa profession ou poursuit l'exercice de sa profession tout en bénéficiant d'une exemption de souscrire au Fonds d'assurance, la garantie restera en vigueur indéfiniment et sans coût additionnel pour l'Assuré tant que le Fonds d'assurance existera, mais elle ne s'appliquera qu'aux seuls Services professionnels rendus ou qui auraient dî être rendus durant la Période d'assurance et avant le décès, la radiation, la cessation d'exercice ou le moment de l'exemption.»

204. Il importe de préciser qu'en présence de renouvellements sans interruption, la «période d'assurance», telle que définie à la clause 1.06 de la police d'assurance responsabilité professionnelle du Barreau du Québec, s'étend à toute période d'assurance antérieure consécutive et ininterrompue auprès de l'assureur. Les services rendus pendant les périodes d'assurances antérieures, consécutives et ininterrompues auprès du Barreau du Québec sont donc couverts par la clause de prolongation. 
De façon générale, la clause de reprise du passé et la clause de garantie subséquente ont pour effet de diminuer les trous de garantie autrement inévitables dans une police à base de réclamation. Néanmoins, l'assuré qui souscrit à ce genre de police doit être conscient que la reprise du passé et la garantie subséquente ne procurent qu'une protection relative parce que de telles clauses n'éliminent pas entièrement les trous de garantie.

La possibilité d'être privé ou non du bénéfice de la garantie au cours d'un contrat désavantage aussi le tiers lésé. L'action directe devient un recours incertain et fragile s'il s'avère que le contrat comporte des trous de garantie. Le tiers lésé devra donc agir avec circonspection s'il entend poursuivre directement un assureur lié par un contrat basé sur les réclamations.

Par exemple, si l'assureur modifie la date de rétroactivité (reprise du passé inconnu) à l'occasion du renouvellement du contrat ou si l'expiration de la période de garantie subséquente est de trop courte durée, le tiers lésé peut détenir une créance de responsabilité qui n'est pas encore prescrite. Cependant, il sera empêché de faire valoir sa créance directe auprès de l'assureur en raison de l'expiration de la période d'assurance. Cela nous conduit à nous interroger sur la validité des clauses liant la garantie à la réclamation de la victime en fonction du caractère impératif de l'action directe du tiers lésé.

\section{\$2. Le caractère prépondérant de l'action directe du tiers lésé sur les clauses à base de réclamation}

La consécration de l'action directe du tiers lésé en un droit substantiel, lequel droit est protégé par un régime de protection d'ordre public en assurance de responsabilité, implique une remise en question des clauses d'assurance qui peuvent diminuer les droits des tiers lésés. On se rappellera que, dans les contrats à base de réclamation, le jour du sinistre n'a pas pour effet de déclencher la garantie d'assurance, ce qui engendre des trous de garantie pouvant préjudicier l'assuré. Nous verrons que les problèmes de couverture particuliers aux polices à base de réclamation sont aussi défavorables pour les tiers lésés. Il n'est pas certain que les clauses d'assurance basées sur le concept de réclamation soient valides depuis l'affirmation de l'action directe du tiers lésé en assurance de responsabilité. 


\section{A. La protection de l'action directe en réparation du tiers lésé}

Le droit direct du tiers lésé n'est plus un droit d'exception. Le Code civil $d u$ Québec reconnaît que l'action en responsabilité civile de la victime et l'action directe du tiers lésé constituent deux recours autonomes et distincts l'un de l'autre.

\section{a) La consécration du droit direct}

Même si le Code civil du Québec reconnaît que le tiers lésé possède un droit direct fondé sur le droit à réparation de son préjudice, le droit direct est doté d'un caractère exorbitant. En effet, le droit direct autorise, en quelque sorte, le tiers lésé à exiger de l'assureur l'exécution d'une obligation contractuelle conclue avec une autre personne, soit l'assuré. Avant 1994, cette particularité de l'action directe en faisait une exception au principe de la relativité des conventions.

Cependant, depuis l'affirmation du caractère substantiel de l'action directe, le droit du tiers lésé constitue désormais une règle de droit générale. L'action directe du tiers lésé ne doit donc plus être interprétée de façon limitative comme s'il s'agissait d'un droit d'exception. Le respect du droit direct du tiers lésé est d'ailleurs assuré par le caractère d'ordre public du régime de protection des droits des tiers lésés en assurance de responsabilité.

Le droit du tiers lésé ne constitue plus un aspect du droit de l'assuré, ${ }^{205}$ malgré le fait que l'exercice de l'action directe du tiers lésé dépend de l'existence du contrat d'assurance. À ce propos, nous trouvons intéressant de remarquer que le libellé de l'article 2501 C.c.Q., ${ }^{206}$ qui consacre le droit direct du tiers lésé, est le même que celui de l'ancien article 2603 C.c.B.-C., alors que la jurisprudence

205. Les auteurs A. Létourneau, A.T. Hewitt, P.-A. Melançon, F.C. Meagher et B. Faribault étaient d'avis que l'article 2603 ne créait aucun droit. Selon eux, le législateur ne faisait que transférer, au profit de la victime, le droit de poursuivre l'assureur aux lieu et place de l'assuré. Cet extrait tiré d'un article d' A.T. Hewitt, exprime bien leur pensée : «The question which may be asked is : did the authors of Article 2603 intend more than the natural meaning of the words? If the answer is no, then does the article do more than enable the victim to name the insurer in place of the insured as a party to the action and pursue the same right of action against the insurer? No right is abrogated and no new cause if action is created; an existing right is transferred.» A.T. Hewitt, supra note 49 à la p. 67. 
de la Cour d'appel refusait d'attribuer à l'action directe tous les attributs d'un droit substantiel ${ }^{207}$ L'affirmation du caractère substantiel du droit direct procure donc au tiers lésé un recours additionnel lui permettant d'être indemnisé par l'assureur de responsabilité de l'auteur du préjudice.

\section{b) L'autonomie du droit direct}

Lorsque l'auteur d'un préjudice a assuré les conséquences de sa responsabilité civile, la victime dispose d'un droit à réparation direct contre l'assureur de ce même auteur. La relation «victime-responsable» prend ainsi une configuration triangulaire en matière d'assurance de responsabilité. ${ }^{208}$ La présence d'un contrat d'assurance n'annihile pas pour autant la relation de «débiteurcréancier» qui existe entre le responsable et la victime. ${ }^{209}$

La victime pourra toujours choisir de réclamer sa créance de responsabilité contre le responsable. En effet, le tiers lésé peut exercer son recours direct de manière à canaliser le montant de l'assurance dans son patrimoine sans perdre le droit de faire valoir sa créance de responsabilité contre l'auteur du préjudice. ${ }^{210}$

La possibilité de cumuler l'action en responsabilité avec l'action directe et l'absence de renonciation conséquente au choix d'exercer une action plutôt que l'autre exprime bien l'intention du législateur de donner au recours direct une existence juridique propre et autonome. ${ }^{211}$ Si la prohibition du cumul prévalait encore, cela signifierait que la victime ne ferait valoir qu'un seul droit, soit le droit de l'assuré, lorsqu'elle poursuit directement l'assureur. ${ }^{212}$

207. Mutuelle des Bois-Francs, supra note 14 aux pp. 475, 476, M. le juge Mayrand; Aetna, supra note 49 à la p. 1802, M. le juge Brossard.

208. «C'est cet objet particulier qui donne à l'assurance de responsabilité sa physionomie spéciale, car elle implique nécessairement l'existence, en dehors de l'assureur et de l'assuré, d'une troisième personne, à savoir la victime créancière de l'assuré responsable.» $\mathrm{M}$. Picard et A. Besson, supra note 130 à la p. 520, n 351.

209. Supra note 100.

210. Supra pp. 24-25.

211. Voir J.-G.Bergeron, supra note 52 à la p. 397

212. Dans l'affaire Mutuelle des Bois-Francs, la Cour d'appel s'est limitée à une analyse grammaticale du mot «ou» pour fonder le rejet du cumul, sans toutefois préciser ce en quoi la possibilité de cumuler le recours direct avec l'action en responsabilité contreviendrait à 
Depuis 1994, le droit direct du tiers lésé est un droit autonome qui se détache de la créance de responsabilité de la victime, une fois que les conditions de la responsabilité civile sont réunies et après que le risque prévu au contrat d'assurance s'est réalisé. ${ }^{213}$ De plus, le droit direct du tiers lésé est protégé par un régime de protection d'ordre public, ce qui suppose que les droits des victimes ne peuvent être diminués. Sur la base de ces principes, nous remettrons en cause l'utilisation des clauses basées sur les réclamations.

\section{B. La critique des clauses à base de réclamation}

L'exercice de l'action directe du tiers lésé nécessite l'application du contrat d'assurance de l'auteur du préjudice. Or, les clauses d'assurance à base de réclamation limitent l'étendue de la garantie d'assurance dans le temps, ce qui entraîne des effets sur les délais pendant lesquels l'action directe du tiers lésé peut être exercée.

\section{a) La perte du bénéfice de la prescription}

Précédemment, on a établi qu'en présence d'un contrat à base de réclamation, la couverture est déclenchée par la réclamation logée contre l'assureur au cours du contrat. On a aussi observé que les clauses à base de réclamation peuvent priver l'assuré du bénéfice de la garantie (trous de garantie) malgré le fait que la dette de responsabilité de ce même assuré soit née au cours du contrat et que la police soit renouvelée avec l'assureur. ${ }^{214}$ Il s'ensuit que le tiers lésé perd tout intérêt juridique à faire valoir son recours direct contre l'assureur de l'auteur du préjudice si la couverture ne peut être mise en jeu en raison de trous de garantie.

Le tiers lésé perd également tout intérêt à exercer son action directe contre l'assureur de l'auteur du préjudice après l'expiration du contrat d'assurance qui dure généralement un an. Or, la créance de réparation directe du tiers lésé se prescrit selon un délai de trois ans ou de dix ans, selon la nature du droit

la procédure. Mutuelle des Bois-Francs, supra note 14 aux pp. 475 et 477, M. le juge Mayrand.

213. Supra note 92.

214. Voir sous-section 1, B. c) du présent chapitre. 
revendiqué par la victime. ${ }^{215}$ Les clauses limitant la garantie de l'assureur à la réclamation soumettent donc indirectement les tiers lésés à la durée de la période d'assurance.

La période d'assurance devient en quelque sorte le «délai de prescription» que le tiers lésé doit respecter s'il entend faire valoir sa créance de réparation directe. Le déclenchement particulier de la garantie des polices d'assurance à base de réclamation a donc pour conséquence de dissocier «(...) la durée d'une responsabilité qui se prolonge jusqu'à la prescription de l'action de la victime, de la garantie d'assurance qui cesse à la résiliation du contrat». ${ }^{216}$

L'ajout d'une clause de garantie subséquente ne diminue pas vraiment le problème de dissociation entre la durée de la responsabilité civile et la durée de la garantie d'assurance. On se rappellera que la période de garantie subséquente est souvent d'une durée inférieure aux délais de prescription triennale ou décennale prévus au Code civil. Ainsi, même en présence d'une clause de prolongation de garantie, le tiers lésé peut être astreint à des délais de plus courte durée que ceux prévus au Code civil, sans quoi son droit de faire valoir sa créance directe demeurera purement théorique.

La consécration de l'action directe du tiers lésé en assurance de responsabilité doit servir les intérêts des victimes en leur permettant de faire valoir leur droit direct en tout temps depuis la naissance de leur créance de réparation jusqu'à leur extinction. Les clauses d'assurance à base de réclamation se concilient donc difficilement avec la volonté du législateur d'assurer la protection des droits des tiers lésés en assurance de responsabilité. C'est pourquoi nous nous sommes intéressés aux conséquences de la création du régime de protection des droits des tiers lésés sur les clauses à base de réclamation.

\section{b) La dérogation à l'ordre public}

Depuis 1994, la finalité de l'assurance de responsabilité se réalise tant par l'indemnisation des victimes que par la sécurité patrimoniale de l'assuré. ${ }^{217}$

215. Infra notes 416-418.

216. Y. Lambert-Faivre, supra note 84 à la p. $418, n^{\circ} 646$.

217. O. Jobin-Laberge et L. Plamondon, supra note 95 à la p. 1161, n ${ }^{\circ} 254$. 
Par exemple, le droit direct du tiers lésé de toucher en exclusivité le montant de l'assurance, l'inopposabilité des moyens postérieurs au sinistre et le cumul des recours en faveur du tiers lésé constituent des dispositions d'ordre public qui traduisent la volonté du législateur de faire de l'indemnisation des victimes un des objectifs de l'assurance de responsabilité.

Cependant, comme nous le rappelle madame Jobin-Laberge, la portée de l'article 2414 C.c.Q., qui consacre le caractère d'ordre public du droit direct, n'empêche pas l'assureur «(...) d'inclure au contrat des dispositions qui limitent les garanties offertes ou qui circonscrivent les risques assumés par lui ou encore, sur les sujets qui ne sont pas spécifiquement régis par le code». ${ }^{218}$ L'assureur possède donc la liberté de limiter sa garantie, mais nous pensons qu'il doit considérer la durée de la responsabilité civile lorsqu'il détermine la durée de la période de couverture d'une police à base de réclamation, sans quoi les droits des tiers lésés peuvent être diminués.

L'utilisation des clauses liant la garantie d'assurance à la réclamation de la victime nous paraît contestable depuis l'institution du régime de protection des droits des tiers lésés en 1994. Par l'adoption de l'article 2414 C.c.Q., ${ }^{219}$ l'ensemble des dispositions du chapitre «Des assurances» sont consacrées d'ordre public. Ainsi, le législateur interdit aux parties de déroger par contrat aux règles relatives à la protection des droits des tiers lésés. Par conséquent, les principes énoncés aux articles 2500 à 2502 C.c. Q, qui traitent de l'exercice de l'action directe, constituent plus qu'un minimum accordé aux tiers lésés; ils représentent un absolu immuable. Les règles spécifiques à la protection des droits des tiers lésés doivent donc être respectées, sous peine de nullité.

L'utilisation des clauses basées sur les réclamations est d'autant plus critiquable dans le domaine de l'assurance de responsabilité professionnelle obligatoire. Dans ce cas particulier, l'assurance couvrant la responsabilité professionnelle a notamment comme mission de protéger le public en plus d'assurer la protection de l'assuré. À titre d'illustration, l'assurance de responsabilité professionnelle du Barreau du Québec est une assurance obligatoire qui s'inscrit

218. Ibid. aux pp. 1123-1124, $\mathrm{n}^{\mathrm{o}} 103$.

219. Supra note 78. 
dans la mission de l'Office des professions «de veiller à ce que chaque corporation assure la protection $d u$ public $\gg .{ }^{220}$ Le respect des droits des tiers lésés est donc capital en présence d'une assurance obligatoire.

Somme toute, les clauses d'assurance basées sur le concept de réclamation privent le tiers lésé du bénéfice de la prescription applicable à la responsabilité civile. Nous pensons qu'en raison du régime de protection des droits des tiers lésés en assurance de responsabilité, la jurisprudence n'hésitera pas à déclarer de telles clauses d'assurance nulles lorsque les droits des tiers lésés sont diminués. La France a d'ailleurs longuement discuté la légalité des clauses basées sur les réclamations avant d'adopter une position ferme à leur égard. Voyons ce que le droit français nous enseigne à ce sujet.

220. Code des professions, L.R.Q. c. C-26, art. 94. Voir art. 1.10, par. 2 de la police d'assurance responsabilité professionnelle obligatoire du Barreau du Québec. 


\section{§3. Le caractère impératif des droits des tiers lésés en droit français}

En France, le problème découlant de l'interprétation des clauses basées sur les réclamations des victimes n'est pas récent. Picard et Besson évoquaient déjà, en 1943, le problème d'interprétation des clauses limitatives de garantie qui dissociaient la durée de la période de garantie de la durée de la responsabilité civile. ${ }^{221}$ Après avoir expliqué les difficultés qu'éprouvait la Cour de cassation à interpréter de telles clauses, ${ }^{222}$ Picard et Besson souhaitaient que la loi lie la durée de la responsabilité civile à celle de la période de garantie. ${ }^{223}$ En 1978, le législateur a effectivement lié ces durées, mais en matière d'assurance de construction seulement. ${ }^{224}$

Dans les autres domaines de la responsabilité civile, la liberté contractuelle justifiait les parties de limiter la garantie selon l'espace et le temps. En conséquence, les clauses liant la garantie à la réclamation étaient opposables à la victime «(...) au motif que le droit de celle-ci contre l'assureur prend sa source et trouve sa mesure dans le contrat d'assurance et qu'il ne peut porter que sur l'indemnité d'assurance telle qu'elle a été stipulée, définie et limitée par ce contrat». ${ }^{225}$

Mais voilà qu'en janvier 1985, une polémique s'est engagée dans la jurisprudence au regard de la légalité des clauses d'assurance basées sur les réclamations. Le débat a d'abord porté sur l'analyse d'une clause d'exclusion

221. M. Picard et A. Besson, supra note 46 à la p. 609, n 256.

222. Cass. civ. $1^{\text {re }}, 28$ mars 1939, R.G.A.T. 1939.286, D.H. 1939.I.68; Cass. civ. $1^{\text {re }}, 26$ mars 1941, R.G.A.T. 1941.301.

223. «En réalité, du point de vue législatif, tout en réduisant le délai de la prescription de l'action de la victime contre l'assuré, il faudrait surtout lier, au point de vue de la prescription, l'action directe à l'action de l'assuré contre l'assureur.» M. Picard et A. Besson, supra note 46 à la p. 609, no 256.

224. Article L. 241-1, al. 3, C. ass. Le libellé de ce texte de loi se lit ainsi : «Tout contrat d'assurance est, nonobstant toute stipulation contraire, réputé comporter une clause assurant le maintien de la garantie pour la durée de la responsabilité pesant sur la personne assujettie à l'obligation d'assurance.» (Voir L. 4 janv. 1978.)

225. H. Groutel, note sous Cass. civ. $3^{\mathrm{e}}, 8$ avril 1987, D. 1988.somm.153. Voir Cass. civ. $1^{\text {re }}, 28$ octobre 1974, D. 1975.Jur..269 (note Besson); Cass. civ. $1^{\text {re }}$, 19 juillet 1978, D.1979.I.r.194 (note Cl.-J. Berr et H. Groutel). 
exigeant la survenance de la réclamation de la victime au cours du contrat. La jurisprudence française a mis plusieurs années avant de clore le débat.

\section{a) Le premier courant prononçant l'inopposabilité des clauses basées sur les réclamations}

Dans l'affaire de la Société Bati Technique, ${ }^{226}$ la Cour de cassation a procédé à l'analyse d'une clause d'un contrat d'assurance de responsabilitéconstruction selon laquelle l'assureur excluait les sinistres (définis comme étant les réclamations des victimes) survenus après l'expiration du contrat. Les faits en l'espèce portaient sur l'achat de tuiles par la compagnie de construction S.C.I. auprès de la Société Bati Technique, en vertu d'un contrat signé en 1965. Des malfaçons sont apparues en 1970 en raison de tuiles défectueuses. Même si la réclamation de la victime est survenue après l'expiration du contrat, la Cour de Versailles a décidé, en 1983, de condamner l'assureur à indemniser la S.C.I., tierce lésée, ${ }^{227}$ parce que les dommages sont apparus pendant que le contrat était en vigueur.

La compagnie d'assurances Eagle Star demande la cassation du jugement. Toutefois, le 22 janvier 1985, la $1^{\text {re }}$ chambre civile de la Cour de cassation confirme la décision de la Cour de Versailles au motif que le dommage dont la tierce lésée se plaint est apparu alors que la garantie de l'assuré était acquise. La Cour de cassation reconnaît que l'assuré a fait naître une créance d'indemnité dans le patrimoine de la victime. Par conséquent, la Cour conclut que les clauses basées sur les réclamations sont inopposables aux victimes, ${ }^{228}$ ce qui suppose que ces mêmes clauses demeurent valides entre l'assureur et l'assuré. Le lendemain, la $3^{\mathrm{e}}$ chambre civile emprunte la même direction que la $1^{\text {re }}$ chambre et décide qu'une clause limitant la garantie aux réclamations que les victimes présentent pendant la durée du contrat est inopposable au tiers lésé dans la mesure où les dommages se sont révélés au cours de la période d'assurance. ${ }^{229}$ Une telle

226. Cass. civ. $1^{\text {re }}, 22$ janvier 1985, D. 1985.Jur.216 (note Y. J).

227. Versailles, 12 juillet 1983.

228. Supra note 226. La Cour de cassation a statué dans le même sens le lendemain, le 23 janvier 1985 : Cass. civ. $1^{\text {re }}, 23$ janvvier 1985, J.C.P. 1985.II.20509 (note Durry).

229. Cass. civ. $3^{\mathrm{e}}$, 14 mai 1985, D. 1985.Jur..507. 
clause était donc opposable au tiers lésé lorsque les dommages apparaissaient après l'expiration du contrat.

La jurisprudence de la Cour de cassation, qui déclare l'inopposabilité aux victimes des clauses à base de réclamation, fut largement contestée parce qu'elle suppose qu'une clause d'exclusion est inopposable comme s'il s'agissait d'une déchéance. Sur ce point, le professeur Hubert Groutel considère que l'inopposabilité est injustifiable puisque «(...) le tiers lésé n'a certainement pas plus de droit que l'assuré lui-même quant à l'objet de la garantie». ${ }^{230}$ Il qualifie d'ailleurs d' «hérésie» le raisonnement de la $3^{\mathrm{e}}$ chambre civile qui a conclu à l'inopposabilité. ${ }^{231}$ Le professeur Groutel précise que l'article L.124-1 du Code des assurances, ${ }^{232}$ relatif à la garantie de l'assureur, oblige ce dernier à exécuter la garantie lorsque le tiers lésé présente une réclamation «à l'assuré» et non pas à l'assureur. Selon H. Groutel, si le texte de loi à la base du litige dans l'affaire de la S.C.I. est l'article L.124-1 C. ass., la Cour n'avait qu'à rechercher si une réclamation était survenue au cours du contrat.

La professeure Yvonne Lambert-Faivre dénonce aussi la jurisprudence de la Cour de cassation selon laquelle les clauses basées sur les réclamations sont inopposables aux victimes. D'après l'auteure, cette décision témoigne d'une double erreur parce que «(...) la déchéance sanctionne une faute de l'assuré inopposable à la victime, or ici la date de la réclamation est celle faite par la victime elle-même... Mais surtout la déchéance suppose qu'au moment de la réalisation du dommage, la garantie prévue dans le contrat préexiste donc au dommage dont elle détermine les conditions de réparation». ${ }^{233}$

Selon les professeurs Groutel et Lambert-Faivre, la Cour de cassation aurait mieux fait de se fier à la rigueur du courant dégagé par la $1^{\text {re }}$ chambre civile à la fin des années soixante-dix en refusant d'analyser la clause basée sur les réclamations des victimes comme une déchéance, mais en la rangeant plutôt dans la catégorie des exclusions. ${ }^{234}$ C'est d'ailleurs ce que la Cour de cassation a fait

230. H. Groutel, supra note 225 à la p. 153.

231. Ibid.

232. Supra note 130.

233. Y. Lambert-Faivre, supra note 84 à la p. 419, n 647.

234. Cass. civ. $1^{\text {re }}, 7$ novembre 1978, D. 1979.I.r.194 (note Cl.-J. Berr et H. Groutel). 
en 1990 lorsqu'elle a condamné l'utilisation des clauses limitatives de garantie qui se fondent sur les réclamations des victimes.

\section{b) Le renversement jurisprudentiel déclarant la nullité des clauses dites «claims-made»}

Le 19 décembre 1990, la Cour de cassation opère un revirement jurisprudentiel important. Elle statue sur sept espèces ${ }^{235}$ qui remettaient en cause la validité des clauses d'assurance définissant le sinistre par la réclamation du tiers lésé et limitant la couverture aux seules réclamations que les victimes présentaient au cours de la période d'assurance. D'abord, la Cour affirme que la police est «dénaturée» lorsque le sinistre est défini comme étant la réclamation du tiers lésé présentée au cours du contrat. Elle prononce ensuite un attendu de principe selon lequel la garantie d'assurance s'applique à tout fait survenu pendant la période d'assurance du moment que ce fait engage la responsabilité civile de l'assuré.

La Cour de cassation refuse d'admettre la validité des clauses basées sur les réclamations. D'après la jurisprudence de la Cour de cassation, les trous de garantie des contrats à base de réclamation privent l'assuré du bénéfice de l'assurance en raison d'un fait qui n'est pas imputable à ce même assuré. La Cour déclare donc la nullité des clauses liant la garantie d'assurance à la réclamation. Elle s'exprime en ces termes :

«Mais attendu que le versement des primes pour la période qui se situe entre la prise d'effet du contrat d'assurance et son expiration a pour contrepartie nécessaire la garantie des dommages qui trouvent leur origine dans un fait qui s'est produit pendant cette période; que la stipulation de la police, selon laquelle le dommage n'est garanti que si la réclamation de la victime, en tout état de cause nécessaire aux termes de l'article L.124-1 du Code des assurances à la mise en oeuvre de l'assurance de responsabilité, a été formulée au cours de la période

235. Cass. civ. $1^{\text {re }}, 19$ décembre 1990, Resp. civ. et assur. 1991.13-15.comm.81. Les sept espèces réunies sont les suivantes : Girard c. Caisse d'assurance mutuelle du bâtiment; Mutuelle Générale Française Accidents c. Epx Hardouin; Sté Anaro c. Gelis; Concorde c. Sté Les grandes tuileries de Roumazières; UAP c. Epx Mitais; Cie Commercial Union c. Small; Baumgartner c. Cie Commercial Union Northern. 
de validité du contrat, aboutit à priver l'assuré du bénéfice de l'assurance en raison d'un fait qui ne lui est pas imputable et à créer un avantage illicite comme dépourvu de cause et par conséquent contraire aux dispositions de l'article 1131 du Code civil, au profit du seul assureur, qui aurait alors perçu des primes sans contrepartie; que cette stipulation doit, en conséquence, être réputée non écri$t e ;(\ldots) . »^{236}$

Mme Lambert-Faivre observe que la jurisprudence de la Cour de cassation ne précise pas la nature du fait qui est à l'origine des dommages. Selon elle, «(...) il faut bien comprendre que c'est la réalisation du dommage donc le "fait dommageable" qui fait naître la dette de responsabilité de l'assuré et la garantie de l'assureur en assurance de responsabilité; celle-ci doit se situer pendant la validité du contrat». ${ }^{237}$

Récemment, la Cour de cassation a précisé que la notion de «fait à l'origine des dommages», dont traitaient les arrêts de décembre 1990, se définit par le fait générateur, c'est-à-dire à l'événement qui est la cause génératrice du dommage. ${ }^{238}$ La Cour n'a cependant pas clarifié la notion de cause dont faisait état la jurisprudence de décembre 1990 en vertu de laquelle ont été condamnées les clauses claims-made.

La professeure Lambert-Faivre souligne d'ailleurs cette seconde imprécision relativement à la notion de cause. Elle croit que la Cour l'évoquait dans le but de reconnaître la divisibilité des primes d'assurance en cas de résiliation de la police en cours d'exercice. Mme Lambert-Faivre craint que cet argument soit interprété de manière trop générale au risque de «(...) rendre impossible toute détermination de l'objet même du contrat d'assurance. Certes, les "clauses d'exclusion" doivent être soigneusement contrôlées pour ne pas devenir abusives. Leur nullité de principe n'est cependant ni admissible, ni sérieusement envisageable». ${ }^{239}$

236. (Nos caractères gras.) Mutuelle Générale Française Accidents c. Epx Hardouin et autres, supra note 235 à la p. 14.

237. Y. Lambert-Faivre, supra 84 à la p. $420, \mathrm{n}^{\circ} 647$.

238. Supra notes 133-134.

239. Y. Lambert-Faivre, supra note 142 à la p. 17. 
Toutefois, la professeure Lambert-Faivre souhaite que le législateur français étende à toutes les assurances de responsabilité le principe de liaison des durées de la responsabilité civile et de la période de garantie, comme il l'a fait en matière de construction ${ }^{240}$. La loi assurerait ainsi une «(...) triple cohérence entre la durée de la créance d'indemnisation de la victime (prescription de l'action en réparation), la durée d'existence de la dette de réparation du responsable (notamment en cas de pluralité de victimes), et la durée de la garantie du contrat d'assurance de responsabilité». ${ }^{241}$

En ce qui concerne le professeur Groutel, il qualifie d' «inexacte» la motivation à la base des sept arrêts de décembre 1990 selon laquelle la Cour déclare que les assureurs perçoivent des primes sans contrepartie pour des dommages trouvant leur origine dans un fait survenu pendant le contrat. D'après cet auteur, «(...) sauf dans un système fonctionnant en semi-capitalisation comme l'assurance de responsabilité décennale, l'assureur qui accorde une garantie subséquente calcule et perçoit - même si elle n'est pas toujours bien séparée de la prime principale - une prime spéciale à cette garantie. C'est dire, par conséquent, que, en présence d'une clause qui exclut les réclamations postérieures à la résiliation, la garantie de celle-ci n'a pas été rémunérée». ${ }^{242}$ C'est ce qui amène le professeur Groutel à penser que la jurisprudence de décembre 1990 constitue une provocation des tribunaux afin d'inciter la législature à étendre à l'assurance de responsabilité, «(...) un contenu quant à l'étendue de la garantie(... $) »,{ }^{243}$ comme cela a été fait en matière de construction.

Malgré l'importante jurisprudence de la Cour de cassation de décembre 1990, la $3^{\text {e }}$ chambre a continué de déclarer l'inopposabilité des clauses basées sur les réclamations. La $3^{\mathrm{e}}$ chambre considérait donc que l'assuré était en faute lorsque la réclamation de la victime était postérieure à l'expiration du contrat. Cependant, la $3^{\mathrm{e}}$ chambre a fini par se rallier à la décision de la $1^{\mathrm{re}}$ chambre civile

240. Supra note 224.

241. Y. Lambert-Faivre, supra note 84 à la p. $421, \mathrm{n}^{\circ} 647$.

242. H. Groutel, «L'extermination des clauses limitatives dans le temps de la garantie des assurances de responsabilité» Resp. civ. et assur.1991.2.chron.4. Nous ne souscrivons pas à cette opinion du professeur Groutel parce qu'au Canada, l'assureur fixe la prime des contrats d'assurance à un moindre coût compte tenu des avantages que lui procure un contrat à base de réclamation. La garantie est donc rémunérée en conséquence. Supra notes 162-163.

243. H. Groutel, ibid. à la p. 1. 
pour confirmer, une fois pour toutes, la nullité des clauses liant la garantie de l'assureur aux réclamations des victimes.

En effet, le 3 juin $1992,{ }^{244}$ la $3^{\text {e }}$ chambre a reconnu la nullité des clauses d'assurance basées sur le concept de réclamation. La Cour de cassation a d'abord rappelé sa propre jurisprudence de $1939^{245}$ en vertu de laquelle le caractère d'ordre public de l'action directe avait été consacré. Selon cette jurisprudence de la fin des années trente, le délai de prescription de l'action directe a été lié à celui du droit commun dont le caractère impératif était admis. La Cour de cassation décide ensuite que les clauses basées sur les réclamations doivent être déclarées nulles parce qu'elles dérogent à la prescription de droit commun applicable au recours direct du tiers lésé.

Parmi les conséquences relatives à la déclaration de nullité des clauses claims-made, les professeurs Veaux-Fournerie et Veaux observent que les sept arrêts de décembre 1990 remettent en question la validité des clauses de garanties subséquentes. Ces professeurs nous enseignent que la jurisprudence a réputé ces clauses de prolongation de garantie non-écrites au motif que «[1]e versement de primes pour la période qui se situe entre la prise d'effet du contrat d'assurance de responsabilité et son expiration a pour contrepartie nécessaire la garantie des dommages qui trouvent leur origine dans un fait qui s'est produit pendant cette période $(. ..) \gg{ }^{246}$

En d'autres mots, la jurisprudence française considère que la garantie doit s'étendre à la réparation de tous sinistres survenus pendant la période d'assurance, interdisant par conséquent à l'assureur de limiter sa couverture aux seuls sinistres

244. Cass. civ. $3^{\mathrm{e}}, 3$ juin 1992, Resp. civ. et assur. 1992.11.comm.285.

245. Cass. civ., 28 mars 1939, supra note 222 : «Attendu que si l'action de la victime d'un accident contre l'assureur est subordonnée à l'existence d'une convention passée entre ce dernier et l'auteur de l'accident, et ne peut s'exercer que dans ses limites, elle trouve, en vertu de la loi, son fondement dans le droit à la réparation du préjudice causé par l'accident dont l'assuré est reconnu responsable; qu'il suit de là que la prescription édictée par l'art. 25 1, de la loi du 13 juill. 1930 s'applique uniquement dans les rapports de l'assuré et de l'assureur, mais que l'action de la victime contre ce dernier reste soumise à la prescription de droit commun.»

246. J.-cl. resp. civ., supra note 12 fasc. 511-3, n ${ }^{\circ} 29$. Aussi Cass. civ. $1^{\text {re }}, 28$ avril 1993, Resp. civ. et assur., 1993.12.comm. 246; Cass. civ. $1^{\text {re }}, 9$ juin 1993, supra note 132. 
qui lui sont déclarés avant l'expiration de la période de garantie subséquente. ${ }^{247}$ La Cour de cassation n'hésite donc pas à déclarer la nullité des clauses de garanties subséquentes.

En ce qui a trait à la clause de reprise du passé inconnu, le professeur Groutel nous rappelle que «(...) la motivation des arrêts du 19 décembre 1990 repose sur l'existence (...) d'un vice affectant le contrat qui limite l'étendue de la garantie dans le temps. C'est un défaut intrinsèque, indifférent, par conséquent, à la présence d'une reprise du passé dans le contrat suivant». ${ }^{248} \mathrm{Le}$ professeur Groutel comprend difficilement qu'on s'interroge encore sur la validité de la clause de reprise du passé du moment que la jurisprudence de la Cour de cassation de décembre 1990 prévaut. Dès que le fait à l'origine des dommages survient pendant la période d'assurance, le dommage est aussitôt garanti. C'est pourquoi $\mathrm{M}$. Groutel considère que l'on n'a pas à hésiter à réputer la clause de reprise du passé non-écrite. ${ }^{249}$

Il ressort de la jurisprudence de la Cour de cassation que la nullité des clauses basées sur les réclamations ne fait plus aucun doute depuis la jurisprudence de décembre 1990. La Cour de cassation a d'ailleurs maintenu sa décision de principe dans de récents litiges en 1995 et $1996{ }^{250}$ L'analyse de la jurisprudence française confirme le double objectif de l'assurance de responsabilité qui est de veiller à la fois à la protection des intérêts des assurés et à l'indemnisation des victimes.

La jurisprudence de la Cour de cassation est audacieuse. Faut-il se rappeler qu'en droit français, aucun texte de loi n'édicte le droit direct du tiers lésé comme le fait le droit québécois aux termes de l'article 2501 C.c.Q. La jurisprudence française a d'abord déduit le droit direct du tiers lésé de l'article L. 124-3 du Code des assurances. Après quoi la jurisprudence de la Cour de cassation

247. H. Groutel, note sous Cass. civ. $3^{\mathrm{e}}$, 4 novembre 1993, Resp. civ. et assur. 1994.12.comm. 103; H. Groutel, «Propos divers au sujet de l'étendue de la garantie dans le temps», Resp. civ. et assur. 1994.3.chron.18.

248. H. Groutel, note sous Cass. civ. $1^{\text {re }}, 9$ mai 1994 et Civ. $3^{\text {e }}, 11$ mai 1994, Resp. civ. et assur. 1994.13.comm. 307.

249. Ibid.

250. Supra note 134; Civ.1 ${ }^{\text {re }}, 13$ février 1996, Resp. civ. et assur. 1996.16-17.comm.151. 
a consacré le caractère d'ordre public du recours direct pour ensuite conclure à la nullité des clauses à base de réclamation qui éludent la prescription de droit commun applicable à l'action directe du tiers lésé.

Au Québec, le Code civil du Québec a non seulement consacré l'exercice du droit direct du tiers lésé par trois articles de loi (2500 à 2502 C.c.Q.), mais encore le droit québécois a-t-il institué un régime de protection d'ordre public ordonnant la nullité des clauses qui diminuent les droits des tiers lésés. Étant donné la création du régime de protection des droits des tiers lésés en matière d'assurance de responsabilité, nous croyons que le législateur a manifesté sa volonté de condamner les clauses basées sur les réclamations qui réduisent les droits des tiers lésés. ${ }^{251}$

La protection des victimes était autrefois une finalité propre au régime d'assurance de responsabilité automobile des Québécois. Le Code civil $d u$ Québec étend maintenant l'objectif de protection des tiers lésés à tous les domaines de l'assurance de responsabilité. Nous pensons que la doctrine et la jurisprudence québécoises remettront en cause les clauses d'assurance basées sur les réclamations, même si la condamnation de ces clauses peut paraître une conséquence inopinée de la réforme.

Jusqu'à maintenant, l'étude de la nature hybride du droit direct du tiers lésé nous a permis de préciser la double nature de ce droit, tant dans son principe que dans son étendue. À cet égard, nous avons conclu que l'action directe du tiers lésé se fonde sur le droit à réparation de la victime et que cette même action suppose l'application d'un contrat d'assurance. La double nature du droit direct du tiers lésé imprègne aussi l'exercice du recours direct du tiers lésé.

\section{Section 2. Les conditions d'exercice de l'action directe du tiers lésé}

L'action directe du tiers lésé trouve sa source d'autonomie dans la loi mais son exercice demeure soumis à l'application du contrat d'assurance. Le tiers lésé qui choisit de poursuivre directement l'assureur du responsable doit «(...) débattre tant les questions relatives à la responsabilité que celles relatives à l'application

251. Y. Lambert-Faivre, supra note 84 à la p. $418, n^{\circ} 646$. 
$d$ u contrat d'assurance». ${ }^{252}$ Celui à qui est ouverte l'action directe doit donc se soumettre à des conditions d'exercice particulières.

\section{§1. Les personnes pouvant exercer l'action directe}

On se souviendra que la créance de réparation directe naît du droit à réparation du préjudice du tiers lésé. ${ }^{253}$ L'action directe peut donc être exercée par la victime, immédiate ou par ricochet. Dans la mesure où l'action directe est un droit à caractère patrimonial, nous croyons qu'elle peut être transmise aux ayants droit ou aux héritiers successoraux de la victime. ${ }^{254}$

À la suite de la réalisation d'une subrogation légale, d'autres créanciers peuvent exercer l'action directe du tiers lésé. Par exemple, les personnes physiques ou morales légalement subrogées dans les droits de la victime possèdent tous les droits du créancier, le subrogeant. ${ }^{255}$ Attendu que diverses personnes peuvent exercer l'action directe du tiers lésé, nous pensons que cette action n'est pas un recours propre à la personne du débiteur. En raison du fondement du droit direct du tiers lésé dans le droit à réparation du préjudice subi, la personne qui exerce l'action directe doit donc posséder un intérêt juridique dans la créance de réparation de la victime. Il est également essentiel que le demandeur à l'action directe établisse son droit de créance.

\section{\$2. La preuve de la dette de responsabilité de l'assuré}

Lorsque le tiers lésé poursuit directement l'assureur, il ne recherche pas la condamnation de l'assuré puisque ce dernier n'est pas le défendeur à l'action. Cependant, le tiers doit établir de façon contradictoire la responsabilité de l'assuré. La présence de ce dernier dans le cadre de l'action directe est donc utile.

252. J.-G. Bergeron, supra note 52 à la p. 394.

253. Supra note 120.

254. "Le patrimoine est avant tout une notion économique. Il survit au décès de son propriétaire et se transmet à ceux (héritiers, légataires) qui continuent sa personnalité.» J.-L. Baudouin, supra note 6 à la p. $15, \mathrm{n}^{\circ} 22$.

255. Ibid. à la p. 523, $\mathrm{n}^{\circ} 928$. 


\section{A. La mise en cause de l'assuré}

L'objet de la mise en cause est d'obtenir une condamnation de l'assureur et de lui opposer la déclaration de responsabilité de son assuré. ${ }^{256}$ Le but recherché par la mise en cause n'est pas de joindre à l'action directe une action que la victime aurait pu intenter contre le responsable. Par la mise en cause, le tiers lésé possède l'avantage de pouvoir opposer à l'assureur la déclaration de responsabilité de l'assuré en même temps qu'il demande l'exécution du contrat d'assurance. Le jugement portant sur la responsabilité de l'assuré est donc déclaratif de droits. ${ }^{257}$

Le Code civil ne fait pas de la mise en cause de l'assuré une condition d'exercice de l'action directe. Nous jugeons opportun d'observer que l'Avantprojet de Loi portant réforme au Code civil du Québec du droit des obligations ${ }^{258}$ prévoyait la mise en cause obligatoire de l'assuré, à moins que l'assureur n'ait reconnu la responsabilité de son assuré ou encore que l'assignation de ce dernier soit devenue impossible. Le tiers lésé peut donc faire la preuve des éléments de la responsabilité de l'assuré par tous moyens légaux car le Code civil du Québec n'énonce aucune condition d'exercice particulière à l'action directe.

Incidemment, le professeur Bergeron souligne que l'assureur ne peut opposer à la victime une condition préalable à l'exercice de l'action directe contre l'assureur. Par exemple, «(...) la clause interdisant la prise d'action contre l'assureur, antérieurement à l'établissement des dommages par arbitrage ou par jugement rendu contre l'assuré, n'est pas opposable à la victime». ${ }^{259}$ À plus forte raison, ce genre de clause contreviendrait à l'article 2414, al.2 C.c.Q.qui consacre le caractère d'ordre public des droits des tiers lésés en assurance de responsabilité.

256. Y. Lambert-Faivre, supra note 84 à la p. 449, nº 694.

257. Selon le professeur J.-G. Bergeron, cette «(...) procédure ne peut être exercée à fin de condamnation contre l'assuré mais seulement à fin d'opposabilité de la chose jugée». M. Bergeron nous fait remarquer que l'assuré deviendrait alors le défendeur s'il était condamné. J.-G. Bergeron, supra note 52 à la p. 396.

258. Article 2572 de la Loi portant réforme au Code civil du Québec du droit des obligations, supra note 70.

259. J.-G. Bergeron, supra note 52 à la p. 394. 
Même si le Code civil n'exige pas l'intervention forcée de l'assuré, nous croyons qu'en pratique la mise en cause de l'assuré constitue le mode d'intervention le plus commode pour le tiers lésé qui entend opposer la responsabilité de l'assuré à l'assureur. En effet, à moins d'une intervention volontaire de l'assuré ou que la responsabilité de ce dernier soit déjà établie, par jugement ${ }^{260}$ ou en raison d'une reconnaissance de responsabilité, ${ }^{261}$ le tiers lésé ne peut espérer une condamnation de l'assureur sans avoir discuté la responsabilité de l'assuré selon son principe et son étendue. ${ }^{262}$ La présence de l'assuré, lors du déroulement de l'action directe, est donc déterminante pour le tiers lésé qui entend faire la preuve contradictoire de ses dommages.

En France, la mise en cause de l'assuré a été jugée en principe obligatoire même si aucun texte de loi ne l'exige. Dans un jugement du 11 mars 1970, la Cour de cassation a fait de la mise en cause de l'assuré une procédure obligatoire «(...) en dehors de toute reconnaissance de la responsabilité de l'assuré ou de toute condamnation préalablement intervenue contre lui (...)». ${ }^{263}$ La Cour est arrivée à cette conclusion parce que les parties à l'action directe doivent fixer de façon contradictoire l'indemnité qui est due par l'assureur au bénéfice exclusif du tiers lésé.

Picard et Besson affirment au sujet de la procédure de mise en cause qu'à moins que la responsabilité de l'assuré ne soit déjà établie, " [l']assuré doit être

260. Infra, Chapitre, section 2, § 2, B.

261. Lorsque l'assureur reconnaît la responsabilité civile de son assuré, la mise en cause devient inutile. L'article 2572 de l'Avant-projet de loi du Code civil du Québec prévoyait qu'en présence d'une telle admission le tiers lésé n'avait pas à mettre en cause l'assuré. L'assuré ne serait certes pas admis à reconnaître sa propre responsabilité à l'égard du tiers lésé à moins que l'assureur ne prenne part à cette admission. L'article 2504 C.c.Q. précise en effet qu' « [a] ucune transaction conclue sans le consentement de l'assureur ne lui est opposable». L'Avant-projet de loi prévoyait aussi que la mise en cause était inutile lorsque l'assignation de l'auteur du préjudice était devenue impossible.

262. L'assuré mis en cause a tout intérêt à débattre sa responsabilité dans son principe et dans son étendue parce qu'il demeure quand même le principal intéressé. Voir Y. Lambert-Faivre, supra note 84 à la p. $445, \mathrm{n}^{\circ} 689$.

263. Cass. civ. $2^{\mathrm{e}}, 11$ mars 1970, D.1970.somm.153. Voir aussi supra note 12 à la p. 24, nº 103. Le nouveau Code de procédure civile français autorise la mise en cause aux fins de condamnation contre l'auteur du préjudice, mettant ainsi fin au débat sur la responsabilité (art. 331 nouveau C. proc. civ.). 
partie aux débats, parce que, ce que la victime demande à l'assureur, c'est, à concurrence de l'indemnité d'assurance, l'indemnité dont l'assuré responsable est redevable envers elle. Comment concevoir la détermination de la responsabilité à l'encontre de l'assureur seul, étranger au fait dommageable et en l'absence du principal intéressé? Cette responsabilité est le support de l'action directe». ${ }^{264}$

Au Québec, il est tout aussi difficile d'imaginer comment le tiers lésé peut arriver à débattre de manière contradictoire les éléments de la responsabilité de l'assuré sans que ce dernier soit présent aux débats. Comme le rappelle Madame Lambert-Faivre, "(...) il ne faut jamais oublier que l'objet de la garantie de l'assureur est la dette de responsabilité de l'assuré». ${ }^{265}$ En définitive, la présence de l'assuré est essentielle ${ }^{266}$ afin que le tiers lésé puisse opposer à l'assureur la déclaration de la responsabilité de l'auteur du préjudice.

Si utile soit-elle, la mise en cause n'est pas une condition de recevabilité de l'action directe car le tiers lésé ne recherche pas la condamnation de l'assuré. En effet, le tiers lésé ne devrait pas être débouté de son action directe s'il lui est impossible d'assigner l'assuré car aucun texte de loi n'impose l'intervention forcée de ce dernier. Le tiers lésé pourrait donc mettre l'assuré en cause à l'expiration du délai de prescription de l'action directe sans pouvoir se faire opposer la prescription de son action.

En France, la Cour de cassation a pourtant fait de la mise en cause une condition de recevabilité de l'action directe. La Cour a jugé irrecevable une action directe dont l'assuré avait été mis en cause à l'expiration de la prescription du recours du tiers lésé. ${ }^{267}$ Toutefois, cette décision demeure sévèrement critiquée. Le professeur Groutel considère à cet égard que la Cour de cassation n'aurait pas dû faire de la mise en cause une condition de recevabilité de l'action directe car «[1] a position de la Cour revient à dire que l'action directe contre l'as-

264. M. Picard et A. Besson, supra note 130 à la p. 576, $\mathrm{n}^{\circ} 387$.

265. Y. Lambert-Faivre, supra note 84 à la p. $445, \mathrm{n}^{\circ} 689$.

266. Voir A. Nadeau, Traité pratique de la responsabilité civile délictuelle, Montréal, Wilson \& Lafleur, 1971 aux pp. 595-611, $\mathrm{n}^{\text {os }}$ 635-656.

267. Cass. civ. $3^{\mathrm{e}}, 23$ janvier 1991, Resp. civ. et assur. 1991.11.comm. 114. 
sureur est subordonnée à la réussite d'une action en paiement distincte dirigée contre l'assuré, action antérieure ou concomitante». ${ }^{268}$

Le professeur Groutel rappelle que le droit français n'oblige pas le tiers lésé à intenter une action en responsabilité civile contre le responsable lorsqu'il décide d'exercer son action directe. Selon le professeur Groutel, l'action directe doit être jugée recevable dès qu'elle «(...) est exercée avant l'expiration du délai dans lequel, en l'absence d'assurance, l'action de la victime contre l'assuré eût été enfermée (...).». ${ }^{269}$ Nous pensons que l'enseignement de cet auteur pourrait s'appliquer, par analogie, en droit québécois étant donné la reconnaissance du caractère autonome du recours direct du tiers lésé en assurance de responsabilité.

Il va sans dire que la procédure de mise en cause constitue un moyen efficace permettant au tiers lésé de faire la preuve de la dette de responsabilité de l'assuré. Par ailleurs, d'autres moyens de preuve sont ouverts au tiers lésé afin d'établir la dette de responsabilité de l'auteur de son préjudice, notamment lorsqu'un premier jugement a reconnu la responsabilité de l'auteur du préjudice.

\section{B. La preuve de la responsabilité de l'assuré au moyen de l'«exception de la chose jugée»}

Lorsque la responsabilité de l'auteur du préjudice a déjà été établie par jugement, le tiers lésé doit-il refaire la preuve de la dette de responsabilité de l'assuré lorsqu'il poursuit directement l'assureur de ce dernier? Sans pour autant faire autorité de chose jugée, nous verrons que le jugement qui a reconnu la responsabilité de l'auteur du préjudice peut faciliter la preuve que doit établir le tiers lésé.

Dans le passé, les tribunaux québécois ont reconnu que la condamnation de l'auteur du préjudice prononcée dans une action principale intentée par la victime n'a pas autorité de chose jugée à l'égard de l'assureur du responsable lors d'une

268. H. Groutel, «La double nature de l'action directe contre l'assureur de responsabilité», Resp. civ. et assur. 1991.2-3.chron.8.

269. Ibid. 
saisie-arrêt. ${ }^{270}$ Plus récemment, la Cour supérieure confirmait, dans l'affaire American Home Insurance Company c. Rapid Transport Terminal Ltd., ${ }^{271}$ que le jugement rendu dans le cadre d'une action en garantie n'avait pas autorité de chose jugée à l'égard de l'assureur lors d'une saisie-arrêt. La victime devait donc refaire la preuve de la responsabilité de l'auteur du préjudice lorsqu'elle voulait saisir-arrêter l'indemnité d'assurance contre l'assureur du responsable.

Par analogie avec la jurisprudence en matière de saisie-arrêt, nous sommes d'avis que le jugement rendu dans l'action en responsabilité dirigée contre l'auteur du préjudice n'a pas autorité de chose jugée à l'égard de l'assureur qui est directement poursuivi par le tiers lésé. D'abord, les parties en litige sont différentes. Les objets sont peut-être identiques, ${ }^{272}$ mais la cause d'action n'est pas la même. L'action en responsabilité est en effet un recours extracontractuel, tandis que le recours direct du tiers lésé se fonde à la fois sur la responsabilité civile et sur le contrat d'assurance. En somme, le jugement rendu sur la responsabilité de l'auteur du préjudice ne fait pas autorité de chose jugée lors de l'exercice subséquent de l'action directe du tiers lésé.

Néanmoins, nous pensons que le jugement qui a établi la responsabilité de l'auteur du préjudice possède une certaine autorité à l'égard de l'assureur qui est directement poursuivi par le tiers lésé. Par exemple, l'assureur qui a pris fait et cause de son assuré est généralement informé des éléments qui lui permettent de savoir si sa garantie est effective. En effet, l'assureur qui a assumé la défense de l'assuré a pu débattre de façon contradictoire les éléments de la responsabilité de ce dernier.

270. Bercovici c. Guardian Insurance Company(1941), 71 B.R. 267; Stevenson c. Brique Champlain Ltée, [1943] B.R. 196; London Assurance c. Miron, [1957] B.R. 183; Canadian Fire Insurance Company c. Di Nunno., [1962] C.S. 242; Punger c. Héritiers de feu Ernio Serega dit Radicione., [1962] C.S. 702; Coronation Foods Corp. c. Lasalle Warehousing, [1967] C.S. 93.

271. American Home Insurance Company c. Rapid Transport Terminal Ltd., [1992] R.R.A. 723 (C.S.).

272. Les articles 1457 et 2396 C.c.Q. expriment bien l'objet commun à la responsabilité civile et à l'assurance de responsabilité, soit l'indemnisation de la victime. Voir: Groupe Commerce, compagnie d'assurances c. Compagnie Sherbrooke Trust (20 février 1989), Montréal 50009-001302-884 (C.A.) aux pp. 3-4. 
Nous souhaitons rappeler à cet égard qu'aux termes de la jurisprudence en matière de saisie-arrêt, ${ }^{273}$ l'assureur qui ne s'est pas réservé le droit de discuter la responsabilité de l'assuré doit être conséquent avec la décision du tribunal qui a condamné l'auteur du préjudice et admettre la dette de responsabilité de l'assuré. Compte tenu de cette jurisprudence, nous sommes d'avis que le tiers lésé peut opposer le jugement sur la responsabilité de l'auteur du préjudice à l'assureur qui a pris le fait et cause de l'assuré sans faire de réserve.

Le droit français admet d'ailleurs l'opposabilité à l'assureur du jugement qui a reconnu la responsabilité de l'auteur du préjudice, que cet assureur fasse l'objet d'une saisie-arrêt ou qu'il soit directement poursuivi par le tiers lésé. L'opposabilité du jugement sur la responsabilité de l'assuré se fonde sur une interprétation jurisprudentielle qui consiste à créer une exception à l'autorité de la chose jugée. En interprétant de façon extensive l'autorité de chose jugée, ${ }^{274}$ le droit français faisait une brèche au principe de chose jugée pour éviter que l'assureur conteste de façon abusive la responsabilité de l'assuré lorsque ce même assureur a dirigé le procès et qu'il a pu émettre des réserves à l'égard de la responsabilité de l'auteur du préjudice.

Pour fonder sa décision admettant l'opposabilité du jugement qui a établi la responsabilité de l'assuré, la Cour de cassation a d'abord considéré que l'assureur «(...) renonce tacitement à contester la décision intervenue (...)» ${ }^{275}$ parce qu'en assumant la défense de l'assuré sans réserve, l'assureur dirige en quelque sorte le procès de l'auteur du préjudice. Nous pensons que l'interprétation extensive de la chose jugée peut également s'appliquer en droit québécois, puisque cette interprétation va dans le même sens que la jurisprudence qui conclut à l'opposabilité à l'assureur du jugement sur la responsabilité de l'auteur du préjudice lorsque cet assureur n'a pas fait de réserve.

273. Supra note 270.

274. Juris-classeur responsabilité civile, fasc. 224-1, par C. Giraudel, $\mathrm{n}^{\circ} 33$ [ci-après J.-cl. resp. civ.]; J.-cl. resp. civ., supra. note 12 fasc. 511-3, $\mathrm{n}^{\text {os }} 58-60$.

275. Y. Lambert-Faivre, supra note 84 à la p. 434, nº 670. Voir Cass. civ. $2^{\mathrm{e}}, 6$ mai 1981, Rev. trim. dr. civ. 1981.644. (note Durry); D. 1983.i.r.214 (note Cl.-J. Berr et H. Groutel); R.G.A.T. 1982.189 (note A. Besson). 
Incidemment, il est intéressant de préciser qu'avec le temps, la France a adopté une approche plus audacieuse qui consiste à opposer de plein droit à l'assureur le jugement qui établit la responsabilité de l'auteur du préjudice. ${ }^{276}$ Cette opposabilité se fonde sur le fait que le jugement sur la responsabilité de l'assuré constitue la preuve officielle du sinistre. ${ }^{277}$ La jurisprudence de la Cour de cassation attribue d'autres conséquences au jugement ayant établi la responsabilité de l'auteur du préjudice. Ces effets se rapportent à la preuve de la garantie d'assurance. ${ }^{278}$ Nous vérifierons l'applicabilité de ces conséquences au droit québécois en examinant la preuve du contrat d'assurance.

\section{§3. La preuve du contrat d'assurance}

Aussi réelle l'autonomie de l'action directe du tiers lésé soit-elle, la réussite du recours direct ne repose pas uniquement sur la preuve de la responsabilité de l'assuré. Le tiers lésé doit aussi démontrer que l'assureur est tenu d'exécuter son obligation de garantie. Il importe donc que le tiers lésé fasse la preuve de l'application du contrat d'assurance.

\section{A. L'existence du contrat d'assurance}

En principe, la preuve de l'application du contrat d'assurance «(...) repose sur les épaules de celui qui invoque le contrat ou une de ses dispositions (...)». ${ }^{279}$ La preuve du contrat d'assurance et de ses dispositions suit le régime général de

276. Y. Lambert-Faivre, supra note 84 à la p. $434, n^{\circ} 670$.

277. Cass. civ. $1^{\text {re }}, 12$ juin 1968,. J.C.P. 68, éd. G.II.15584 (concl. Lindon); D. 1969.Jur..249 (note A. Besson); Cass. civ. $2^{\mathrm{e}}$, 6 mai 1981, supra note 275. Les moyens de défense pouvant être soulevés par l'assureur varieront selon qu'il a pris le fait et cause de son assuré ou qu'il a laissé l'assuré se défendre seul. Si l'assureur dirige le procès, il ne sera pas admis à contester la décision qui établit la responsabilité de l'assuré à moins qu'il ait pris le soin d'invoquer l'exception de non-garantie et qu'il ait avisé l'assuré de ses réserves (Civ. $1^{\text {re }}, 15$ oct. 1991, Resp. civ. et assur.comm.439, $2^{\mathrm{e}}$ esp.). Si l'assureur laisse l'auteur du préjudice diriger sa défense, il ne pourra contester l'opposabilité du jugement sur la responsabilité de l'assuré qu'en invoquant son ignorance du litige ou la collusion entre la victime et l'assuré (Cass. civ. $1^{\text {re }}, 31$ mai 1983, Bull. civ. 1983.I, $n^{\circ} 162$ ) .

278. Cass. civ. $1^{\text {re }}, 11$ mars 1947, R.G.A.T.1947.173.

279. D. Lluelles, Précis des assurances terrestres, Montréal, Thémis, 1994 à la p. 86. 
preuve des obligations, ${ }^{280}$ sous réserve des règles particulières à l'assurance. ${ }^{281}$ Le tiers lésé doit donc invoquer le bénéfice du contrat d'assurance lorsqu'il exerce son action directe. Il nous semble toutefois exagéré que le tiers lésé doive faire la preuve du contenu de la police d'assurance puisqu'il n'est pas partie au contrat.

Récemment, dans l'affaire Champagne, ${ }^{282}$ la Cour d'appel a d'ailleurs obligé l'assureur à produire une copie du contrat d'assurance à la demande du tiers lésé. La Cour s'interrogeait en particulier sur le droit du tiers lésé de contraindre l'assuré à lui divulguer le nom de l'assureur et à lui remettre copie du contrat d'assurance lors de l'exercice de l'action directe.

La Cour a rejeté l'argument des appelants selon lequel le nom de l'assureur et le contenu de la police étaient de nature confidentielle. Cependant, la Cour d'appel a spécifié que l'assureur peut «(...) demander au tribunal d'expurger le contrat d'assurance de certaines parties non essentielles au débat, compte tenu de leur nature privilégiée (...)», ${ }^{283}$ tel le montant de la prime. Le juge Brossard affirme qu'à moins d'être en présence de dommages punitifs, ${ }^{284}$ les limites monétaires des protections fournies par l'assureur, ce qui équivaut à la «mesure de la solvabilité» de l'assureur selon l'expression du juge, devraient être enlevées par le tribunal, à la demande de l'assureur, avant que la police ne soit remise au tiers lésé. ${ }^{285}$ À cet égard, le juge Forget adopte une opinion plus élargie ${ }^{286}$ et permet la remise de la copie du contrat d'assurance afin que le juge, présidant l'action directe, puisse vérifier le type de responsabilité couvert par le contrat ainsi que les termes et conditions de la garantie.

Nous trouvons pertinent d'observer que la France a adopté une position qui facilite la preuve de l'application du contrat d'assurance pour le tiers lésé. La jurisprudence française reconnaît le principe selon lequel le tiers lésé n'a qu'à prouver l'existence du contrat d'assurance, après quoi un renversement du fardeau

280. Ibid. aux pp. 87-88. Voir art. 2859-2874 C.c.Q.

281. Art. 2404-2405, 2413 C.c.Q.

282. Champagne c. CEGEP de Jonquière (3 septembre 1996), Québec 200-09-000775-962 (C.A.), MM. les juges Lebel, Brossard et Forget.

283. Ibid. aux pp. 6-7, 9,12-13, M. le juge Forget.

284. Article 1621 C.c.Q.

285. CEGEP de Jonquière, supra note 282 aux pp. 2-3, M. le juge Brossard.

286. Ibid. aux pp. 9-10, M. le juge Forget. 
de preuve s'opère du côté de l'assureur. La Cour de cassation considère ainsi $\mathrm{qu}^{\prime} \ll(. .$.$) il incombe à l'assureur [l'assureur du responsable] de démontrer, en$ versant la police aux débats, qu'il ne doit pas sa garantie pour le sinistre objet du litige». ${ }^{287}$

À l'instar de l'interprétation jurisprudentielle de droit français portant sur la preuve de l'existence du contrat d'assurance, nous sommes enclins à reconnaître que le renversement du fardeau de preuve puisse s'opérer en droit québécois. Certes, le tiers lésé doit d'abord prouver l'existence du contrat d'assurance pour que le renversement s'opère. Rappelons-nous que l'article 2396 C.c.Q., qui définit l'objet de l'assurance de responsabilité, oblige l'assureur à garantir la dette de responsabilité de l'auteur du préjudice. Or, le tiers lésé fournit la preuve de cette même dette lorsqu'il établit la responsabilité de l'assuré et l'existence du contrat d'assurance. Il appartiendrait alors à l'assureur de produire le contrat (ou les extraits pertinents) pour contester l'application de sa couverture ou encore d'invoquer la nullité de la police. Le renversement du fardeau de preuve serait conforme à l'article 2803 C.c.Q. selon lequel celui qui prétend qu'un droit est nul, modifié ou éteint doit prouver les faits sur lesquels se fonde sa prétention.

Le renversement du fardeau de preuve obligeant l'assureur à prouver qu'il ne doit pas sa garantie n'a peut-être pas encore été analysé par le droit québécois, mais la jurisprudence québécoise a eu l'occasion de reconnaître que le jugement qui a établi la responsabilité de l'auteur du préjudice suppose que l'assureur est tenu d'exécuter son obligation de garantie.

\section{B. La preuve de la garantie d'assurance au moyen de l'«exception de la chose jugée»}

Lorsque l'assureur conteste l'application de sa garantie, le tiers lésé dispose d'un moyen de preuve lui permettant de démontrer le déclenchement de l'obligation de couverture. On se rappellera que le jugement qui a préalablement établi la responsabilité de l'auteur du préjudice peut être opposé à l'assureur afin

287. J.-cl. resp. civ., supra note 12 fasc. 511-3, $\mathrm{n}^{\circ} 86,2$; Cass. civ. $1^{\text {re }}, 22$ avril 1992, Resp. civ. et assur. 1992.10-11.comm.281. 
que le tiers lésé fasse la preuve de la dette de responsabilité de l'assuré. ${ }^{288}$ L'exception de l'autorité de la chose jugée permet aussi d'opposer le jugement portant sur la responsabilité de l'auteur du préjudice dans le but de prouver le déclenchement de la garantie d'assurance.

\section{a) L'application de l' «exception de la chose jugée» aux fins de prouver le sinistre}

Il s'agit d'une seconde application de l'interprétation extensive de l'autorité de la chose jugée ${ }^{289}$ selon laquelle la décision judiciaire qui condamne l'auteur du préjudice apporte la preuve du sinistre. Cette interprétation, issue de la jurisprudence de la Cour de cassation, se fonde sur le principe que «(...) la condamnation intervenue constitue la réalisation du risque prévu au contrat, sauf fraude (aveu, collusion avec la victime)». ${ }^{290}$ Le droit français rappelle que l'assureur s'est engagé à garantir la dette de responsabilité de l'assuré et que le jugement obtenu constate cette dette car il «(...) apporterait en quelque sorte la "preuve officielle du sinistre" ». ${ }^{291}$ La France admet donc que le jugement qui établit la responsabilité de l'assuré consacre le sinistre et, par conséquent, réalise le risque prévu au contrat.

Au Québec, l'affaire Miron c. Demers ${ }^{292}$ s'est appuyée sur cette interprétation jurisprudentielle de droit français pour appliquer, de façon extensive, l'autorité de la chose jugée en matière d'assurance de responsabilité. En l'espèce, la Cour supérieure avait condamné Demers pour avoir blessé le demandeur Miron avec sa motocyclette. La compagnie d'assurances avait assumé la défense de son assuré sur la foi d'une déclaration signée par ce dernier, tout en avisant l'assuré qu'elle refuserait de le payer si la déclaration s'avérait être fausse. Par la suite, le demandeur Miron a procédé à une saisie-arrêt contre The London Assurance, l'assureur de l'auteur de son préjudice. La compagnie a refusé d'indemniser la victime au motif que l'assuré avait fait une fausse déclaration, malgré le fait que

288. Supra notes 273 et 276.

289. Supra note 274.

290. Y. Lambert-Faivre, supra note 84 à la p. 446, $\mathrm{n}^{\circ}$ 690. Aussi : Cass. civ. $1^{\text {re }}, 12$ juin 1968 , supra note 277; J.-cl. resp. civ., supra note 12 fasc. 511-3, $\mathrm{n}^{\text {os }} 54-82$.

291. J.-cl. resp. civ., supra note $274, \mathrm{n}^{\circ} 32$.

292. Miron c. Demers (4 janvier 1954), Montréal 309.938 (C.S.), M. le juge Marier. 
le premier juge ait établi la responsabilité de Demers et convenu que la fausseté de la déclaration n'a pas été prouvée.

En Cour du Banc de la Reine, la compagnie d'assurances The London Assurance objectait «(...) que le demandeur, en pratiquant la saisie-arrêt, reconnaît implicitement le bien-fondé du jugement dont il poursuit l'exécution et que, dès lors, il ne saurait être admis à prétendre que ce jugement l'a condamné à tort». ${ }^{293}$ L'objection de la tierce-saisie est rejetée au motif que cette dernière méconnaît la véritable obligation d'un assureur. Selon le juge, l'assureur doit verser l'indemnité lorsque l'assuré est «légalement tenu responsable» aux termes du contrat d'assurance. Étant donné qu'il n'a pas été prouvé que le premier juge a erré en droit, l'assureur doit donc indemniser la victime même s'il croit toujours que l'assuré a fait une fausse déclaration. Le juge présente son raisonnement de la façon suivante :

«Il suffit que l'assuré soit légalement responsable pour que l'assureur puisse être contraint de l'indemniser.

Or, lorsque l'assuréa été condamnéà payer en raison de la survenance du risque prévu dans le contrat, sa responsabilité légale existe, même si le jugement prononcé contre lui est mal fondé.

D'où il suit que, contrairement à la prétention de la tierce-saisie, l'assuré qui, à la suite du jugement prononcé contre lui en faveur de la victime, demande à son assureur de l'indemniser, ne reconnaît pas par là le bien-fondé de ce jugement : il ne fait que réclamer ce à quoi l'assurance lui donne droit. ${ }^{294}$

La Cour précise que son raisonnement se fonde sur la doctrine de Picard et Besson selon laquelle le jugement obtenu contre l'auteur du préjudice n'a pas autorité de chose jugée à l'égard de l'assureur, mais ce même jugement démontre

293. London Assurance c. Miron, supra note 270 à la p. 186, M. le juge Pratte.

294. Ibid. aux pp. 186-187, M. le juge Pratte. Les juges Bissonnette et Owen souscrivent à l'opinion du juge Pratte et recommandent l'application de l'exception de la chose jugée développée en droit français. 
que le risque s'est réalisé. ${ }^{295}$ La Cour du Banc de la Reine conclut que la victime peut opposer à l'assureur le jugement qui a établi la responsabilité de l'auteur du préjudice, lorsque cette même victime pratique une saisie-arrêt contre l'assureur du responsable. Le même raisonnement semble s'appliquer au recours direct du tiers lésé.

\section{b) L'application de l' «exception de la chose jugée» à l'action directe du tiers lésé}

En 1993, dans l'arrêt Compagnie d'assurances Continental du Canada c. Compagnie d'assurances Générale Dominion du Canada, ${ }^{296}$ la Cour d'appel a décidé que le jugement rendu dans l'action en garantie de l'assuré pouvait être opposé à l'assureur qui en appelle du jugement de la Cour du Québec ayant rejeté son action en remboursement des frais encourus dans un dossier où l'assureur croit que l'intimé, un second assureur, devait prendre son fait et cause. Selon la Cour, ce premier jugement a «autorité de chose jugée» à l'égard de l'assureur qui est directement poursuivi par l'assureur subrogé.

Le litige portait sur l'interprétation d'une entente qui prévalait entre un entrepreneur et un sous-traitant. Aux termes de l'entente, le sous-traitant s'est engagé à prendre le fait et cause de l'entrepreneur et à le défendre à ses frais. La responsabilité du sous-traitant a été reconnue dans l'action en garantie intentée par l'entrepreneur principal. Par la suite, l'assureur de ce même entrepreneur a directement poursuivi l'assureur du sous-traitant, sur la base de l'entente.

En Cour d'appel, le juge Gendreau estime qu'il n'est pas nécessaire de refaire la preuve de la responsabilité du sous-traitant, non plus la preuve que le contrat d'assurance couvre le dommage réclamé. Selon le juge, l'action en garantie fait «autorité de chose jugée» relativement à ces deux aspects. Le juge Gendreau s'exprime en ces mots :

295. Comme le soulignent Picard et Besson : «Sans doute le jugement obtenu n'a pas autorité de chose jugée à l'égard de l'assureur (...); mais il démontre la réalisation du risque et, à ce titre, permet à la victime de mettre en jeu la garantie par l'action directe sans mettre en cause l'assuré.» M. Picard et A. Besson, supra note 46 à la p. 456, nº 196.

296. Continental du Canada, compagnie d'assurances c. Générale Dominion du Canada, compagnie d'assurances, [1993] R.R.A. 145 (C.A.) [ci-après Continental du Canada]. 
«Lorsqu'un demandeur veut poursuivre un assureur directement, il lui faut établir, outre la responsabilité de l'assuré, que le contrat d'assurance couvre le dommage réclamé.

En l'espèce, nous n'avons pas le contrat mais, lorsque le juge de la Cour supérieure a maintenu l'action en garantie de Walsh \& Brais contre Dominion sur la base de la clause XIII [l'entente] du contrat de sous-traitance, il a répondu à cette question. Ce jugement a maintenant l'autorité de chose jugée en raison du désistement d'appel de Dominion. C'est sans doute pour cette raison que les parties n'ont pas débattu de cette question en première instance et devant nous.» ${ }^{297}$

D'après nous, lorsque le juge Gendreau affirme que le jugement obtenu dans l'action en garantie de Walsh \& Brais a «autorité de chose jugée», il applique l'interprétation de la jurisprudence française selon laquelle ce premier jugement apporte la preuve officielle du sinistre. Avec égards, le juge Gendreau n'aurait pas dû utiliser l'expression «autorité de chose jugée» parce que la règle des trois identités n'est pas respectée. ${ }^{298}$

À la lumière de la décision du juge Pratte dans l'arrêt Miron ${ }^{299}$ et de celle du juge Gendreau dans l'arrêt La Dominion, ${ }^{300}$ nous sommes forts de constater que les tribunaux québécois sont enclins à opposer à l'assureur le jugement qui a antérieurement établi la responsabilité de l'auteur du préjudice afin de prouver la consécration du sinistre. Le tiers lésé serait alors en mesure de démontrer que le risque prévu au contrat d'assurance s'est réalisé et que l'assureur est tenu d'exécuter sa garantie.

297. (Nos caractères gras.) Ibid. à la p. 148, M. le juge Gendreau. Le juge Beauregard, dissident, a refusé de reconnaître qu'il y avait chose jugée entre l'action en garantie et l'action directe, mais pour des raisons différentes de celles de son collègue. D'après le juge Beauregard, l'absence de chose jugée tient au fait que la question des frais extrajudiciaires n'avait pas été discutée lors de l'appel en garantie. Ibid. à la p. 146, M. le juge Beauregard.

298. Coronation Foods Corp. c. Lasalle Ware Housing and Transfer Ltd., supra note 270 aux pp. 98-99, M. le juge Tellier.

299. Supra note 293.

300. Continental du Canada, supra note 296 à la p. 145. 
Cette seconde application découlant de l'interprétation extensive de l'autorité de la chose jugée fait ressortir le caractère hybride de l'action directe en ce qu'elle permet d'apporter à la fois la preuve de la dette de responsabilité de l'auteur du préjudice ${ }^{301}$ et la preuve officielle du sinistre.

Malgré la double nature du droit direct du tiers lésé, ce droit demeure autonome puisqu'il se détache de la créance de responsabilité civile. ${ }^{302}$ Nous constaterons que l'affirmation de l'autonomie de l'action directe du tiers lésé a des conséquences sur les droits qui permettent à un assureur subrogé de recouvrer contre certaines personnes le montant de l'indemnité qu'il a versée. L'autonomie de l'action directe du tiers lésé entraîne aussi des conséquences sur l'extinction de ce même recours.

\section{CHAPITRE 2 :}

LES CONSÉQUENCES DE L'AUTONOMIE DE L'ACTION DIRECTE DU TIERS LÉSÉ

L'affirmation et la protection de l'action directe du tiers lésé n'ont pas que des conséquences sur les droits des tiers lésés qui sont en présence de parties détenant une police basée sur les réclamations des victimes. Il est intéressant de faire apparaître les incidences de l'autonomie de l'action directe sur les droits dont dispose l'assureur subrogé pour recouvrer, contre certains tiers, l'indemnité qu'il a payée en vertu de son contrat. Nous vérifierons notamment s'il y a lieu d'appliquer les limites imposées à l'exercice du recours subrogatoire de l'assureur lorsque ce même assureur entend se faire rembourser le montant de l'indemnité par l'assureur d'un tiers responsable faisant partie de la maison de l'assuré.

L'affirmation de l'autonomie de l'action directe a aussi pour conséquence de modifier l'extinction de la créance directe. Nous verrons que, dans certaines circonstances, la durée de l'action directe se distingue de celle de l'action en responsabilité civile.

301. Supra notes 276-277.

302. Supra note 92. 


\section{\$1. Le caractère autonome de l'action directe en réparation du tiers lésé}

Une des conséquences de l'autonomie de l'action directe du tiers lésé consiste à reconnaître la possibilité d'une subrogation de la créance directe. À la suite de la réalisation de la subrogation légale, l'assureur qui a payé son assuré et qui désire faire valoir la créance directe doit le faire dans les limites que le Code civil impose à l'exercice du recours subrogatoire.

\section{A. Le recours subrogatoire de l'assureur}

La subrogation légale revêt toute son importance dans le cadre de l'analyse de l'action directe du tiers lésé. C'est en vertu de la subrogation que la créance directe du tiers lésé est transférée dans le patrimoine de l'assureur qui a indemnisé ce même tiers.

\section{a) Le principe de la subrogation}

Selon la codification de 1866, le lien juridique unissant l'assureur du tiers lésé au responsable était fondé sur une cession de droits. ${ }^{303}$ Seule la cession de créance dûment signifiée pouvait autoriser l'assureur à poursuivre l'auteur du préjudice. $^{304}$

En 1974, le législateur a adopté l'article 2576 C.c.B.-C. dans le but d'instituer la subrogation légale en faveur de l'assureur. Dans l'arrêt Trépanier c. Plamondon, ${ }^{305}$ les juges Lebel et Rothman, au nom de la majorité, ont établi que la subrogation se réalise de plein droit par le seul effet du paiement reçu par

303. Avant 1974, l'article 2584 C.c.B.-C. accordait à l'assureur la possibilité de poursuivre l'auteur du préjudice au moyen d'une cession légale des droits de l'assuré. L'article 2584 C.c.B.-C. se lit ainsi : "L'assureur, en payant l'indemnité, a droit à la cession des droits de l'assuré contre ceux qui ont causé le feu ou la perte.»

304. Voir C.-A. Bertrand, «Effets des subrogations et des transports aux assureurs», (1953) 7 R. du B. aux pp. 285-299. Le juge analyse la nature des droits transmis à l'assureur avant la réforme de 1974.

305. Trépanier c. Plamondon, [1985] C.A. 242. 
l'assuré. ${ }^{306}$ Le transfert des droits de l'assuré s'effectue donc automatiquement au profit de l'assureur, sans aucune formalité. ${ }^{307}$

Lorsque la subrogation légale se réalise, elle assure le transfert des droits à la base de l'indemnisation de la victime. Ainsi, l'assureur ne peut instituer ni continuer l'action sous le nom de l'assuré car celui-ci ne possède pas l'intérêt requis par l'article 59 C.p.c. La subrogation légale constitue donc la source de transmission de la créance de l'assuré envers son assureur. ${ }^{308}$ Dans la mesure où la subrogation légale est le fondement ${ }^{309}$ du recours «en remboursement» de l'assureur contre les tiers, l'assureur ayant indemnisé la victime dispose-t-il de l'action directe du tiers lésé?

\section{b) La subrogation de la créance de réparation directe du tiers lésé}

Le Code civil du Québec n'affirme pas expressément que l'action directe peut faire l'objet d'une subrogation en faveur de l'assureur qui a payé l'indemnité d'assurance au tiers lésé. Par contre, il consacre d'ordre public les règles relatives à la subrogation établies par le droit commun ainsi que celles en matière d'assurance. ${ }^{310}$ Selon le droit commun, la subrogation opère une mutation de la créance du subrogeant. En d'autres mots, l'assureur devient «(...) créancier $d u$ débiteur au même titre et avec les mêmes garanties, droits et privilèges que ceux que détenait le créancier subrogeant. (...) Il y a identité parfaite entre l'ancien lien d'obligation qui existait entre le créancier subrogeant et le débiteur, et le nouveau lien d'obligation qui s'est formé entre le solvens subrogé et le débiteur».311

306. Ibid. à la p. 248, M. le juge Lebel et à la p. 250, M. le juge Rothman.

307. Ibid.

308. Selon une récente doctrine, il serait encore possible pour l'assureur d'obtenir une cession conventionnelle de droits en vue de se faire transmettre le droit de poursuivre l'auteur du préjudice : O. Jobin-Laberge, supra note 95 à la p. 1114, nº 65.

309. J.-L. Baudouin, supra note 6 aux pp. 532-533, n ${ }^{\circ} 950$.

310. Ibid. Le lecteur peut également se référer aux articles 1402 et 2414 C.c.Q.

311. J.-L. Baudouin, ibid. 
À partir du principe que le Code civil du Québec a institué deux actions distinctes et autonomes ${ }^{312}$ en faveur du tiers lésé, l'assureur du responsable qui a indemnisé ce tiers lésé se voit transmettre à la fois la créance de responsabilité civile et la créance de réparation directe. L'assureur investi des droits de la victime bénéficie donc du choix de recours établi en faveur du tiers lésé sous l'article 2501 C.c.Q.

Avant 1994, la question de savoir si l'action directe pouvait faire l'objet d'une subrogation n'a pas été vraiment débattue. Il importait, d'abord et avant tout, d'identifier la nature de l'action directe selon qu'elle relevait de la procédure ou du droit substantiel. Néanmoins, une certaine doctrine reconnaissait déjà que l'action directe du tiers lésé était transmise à l'assureur par l'opération juridique de la subrogation légale. ${ }^{313}$

La Cour d'appel a également eu l'occasion de reconnaître, avant 1994, que le droit direct de la victime pouvait être transmis à l'assureur subrogé qui a versé l'indemnité d'assurance. Dans l'arrêt Dominion, ${ }^{314}$ l'intimée soutenait que le recours direct institué selon l'article 2603 C.c.B.-C. ne pouvait pas bénéficier à l'assureur. L'intimée faisait valoir que l'action directe s'adresse spécifiquement au tiers lésé, soit la victime en tant que telle. En Cour d'appel, les juges Gendreau et Baudouin ont estimé que l'assureur subrogé dans les droits du tiers lésé pouvait assigner directement l'assureur de l'auteur du préjudice «(...) dans la mesure où bien sûr cet assureur est tenu par son contrat d'assurance de couvrir ce dommage». ${ }^{315}$

312. Supra note 73.

313. Selon le professeur Bergeron : «(...) quand l'assureur est subrogé dans les droits de son assuré contre le tiers responsable, cet assureur est nécessairement investi de l'option donnée par l'article 2603 C.c., d'exercer le droit d'action de son assuré contre le responsable ou contre son assureur. L'assuré ne peut retenir sur lui l'exercice de son droit d'action contre l'assureur du responsable.» J.-G. Bergeron, supra note 117 à la p. 447. Voir J.-L. Baudouin, Les obligations, Cowansville, Yvon Blais, 1989 aux pp. 145 et 268, n 655.

314. Continental du Canada, supra note 296 à la p. 145.

315. Ibid. à la p. 148, M. le juge Gendreau. Voir : Albany Insurance Company c. Reliable Cartage Ltd., [1992] R.J.Q. 2594 aux pp. 2597-2598. 
En France, il ne fait pas de doute que l'action directe peut être subrogée en raison du caractère impératif du droit direct du tiers lésé. ${ }^{316}$ D'après Picard et Besson, une fois que l'assureur a indemnisé la victime, il est subrogé dans les droits de celle-ci et dispose, par conséquent, de l'action directe. ${ }^{317}$ Le professeur Hubert Groutel abonde dans le même sens en affirmant que "[l]orsque la subrogation joue au profit de l'assureur de la victime, celui-ci reçoit les deux actions [action en responsabilité et action directe] dans la mesure de l'indemnisation qu'il a procurée à son assuré». 318

Même si l'assurance de choses ne crée pas d'action directe, la jurisprudence de la Cour de cassation reconnaît que l'assureur de choses peut être subrogé dans les droits de son assuré et poursuivre l'assureur de responsabilité de l'auteur du préjudice. Ce principe découle d'une décision de la Cour de cassation de 1889 en vertu de laquelle il fut décidé qu' "[à] concurrence des sommes qu'il a versées à son assuré, l'assureur de choses peut donc, pour se faire rembourser, exercer contre l'assureur de responsabilité de l'auteur du dommage, l'action directe qui appartenait à son assuré, en sa qualité de victime». ${ }^{319}$ De plus, dans les cas où la victime ne possède pas la qualité d' «assuré», la Cour de cassation considère qu'en dépit du libellé de l'article L. 121-12 C. ass. selon lequel l'assureur est subrogé dans les droits de l' «assuré», la subrogation légale confère à l'assureur du responsable qui paie l'indemnité à la victime les droits de celle-ci contre les co-responsables et contre les tiers responsables pour lesquels l'assureur est tenu. ${ }^{320}$

316. Cass. civ. $1^{\text {re }}, 5$ avril 1978, Bull. civ. 1978.I.114 à la p. 571, nº 384.

317. M. Picard et A. Besson, supra note 130 à la p. 571, $\mathrm{n}^{\circ} 384$.

318. Cass. civ. $1^{\text {re }}, 13$ janvier 1987, D. 1987.397 (note H. Groutel).

319. J.-cl. resp. civ., supra note 12, no 68; Cass. civ. 20 février 1889, J.O., 20 fév. 1889; S. 89.législ.549. Cette décision se fonde sur le principe indemnitaire selon lequel la victime ne peut cumuler l'indemnité de son assureur à celle que doit l'assureur de responsabilité de l'auteur du préjudice.

320. Cass. civ. $1^{\text {re }}, 7$ avril 1987, Bull. civ. 1987.I.92, $n^{\circ} 121$; D. 1988.somm.151, obs.H. Groutel. La jurisprudence française considère que les problèmes d'interprétation de l'article L. 121-12 C. ass. qui subroge l'assureur dans les droits de l'assuré, résultent du fait que le texte a été écrit pour les assurances de choses où l'assuré et la victime constituent une seule et même personne. L'intérêt de la question de la subrogation dans les droits de la victime plutôt que dans les droits de l'assuré tient à l'efficacité du recours de la victime sur le plan de la prescription. 
Par analogie avec la jurisprudence française, forte de soixante-cinq années de débats portant sur l'action directe, nous croyons que l'assureur qui a indemnisé son assuré peut poursuivre directement l'assureur de responsabilité de l'auteur du préjudice. Nous croyons également que l'assureur qui a indemnisé un tiers lésé qui n'a pas la qualité d' «assuré» est légalement subrogé dans les droits de ce tiers, bénéficiaire exclusif de l'indemnité d'assurance. Refuser la subrogation du recours direct en faveur de l'assureur serait admettre que la subrogation transforme et modifie la créance subrogée de manière à créer de nouveaux liens à l'égard des tiers. ${ }^{321}$

Suivant le principe que la subrogation légale opère une mutation de la créance du subrogeant, l'assureur qui a indemnisé le tiers lésé est nécessairement investi de la créance de réparation directe de ce même tiers. Il appartient à cet assureur de choisir l'action qu'il lui convient d'exercer comme le lui permet l'article 2501 C.c.Q. Somme toute, le caractère autonome de l'action directe du tiers lésé implique la transmission du droit direct dans le patrimoine de l'assureur qui, après avoir payé l'indemnité, est investi des droits du tiers lésé par l'effet de la subrogation légale. L'assureur peut ensuite faire valoir la créance de réparation directe dans les limites de l'exercice de son recours subrogatoire.

\section{B. Les exceptions au recours subrogatoire de l'assureur}

En 1974, l'article 2576 C.c.B.-C. ${ }^{322}$ créait une exception au recours subrogatoire afin d'empêcher l'assureur de poursuivre les tiers responsables faisant partie de la maison de l'assuré. Des considérations d'ordre moral et juridique sont à la base de l'adoption de l'interdiction légale en matière de subrogation.

\section{a) Les considérations morales}

Les considérations morales constituent sans nul doute la première finalité qui nous vient à l'esprit lors de l'analyse du libellé de l'interdiction de subrogation

321. J.-L. Baudouin, supra note 6 à la p. 534, ${ }^{\text {os }}$ 951-952.

322. L'article 2576 C.c.B.-C. correspond maintenant à l'article 2474 C.c.Q. 
de l'article 2474, al. 2 C.c.Q. D'un point de vue moral, il est peu probable qu'un assureur poursuive un proche que l'assuré n'aurait pas poursuivi. ${ }^{323}$

En tenant compte des liens familiaux qui unissent l'assuré aux personnes faisant partie de sa maison, l'on comprendra que l'assuré préfère ne pas diriger d'action en responsabilité contre ces personnes. ${ }^{324}$ La suppression du recours subrogatoire de l'assuré à l'égard des personnes de la maison crée en quelque sorte une immunité. ${ }^{325}$ Le législateur a donc choisi d'empêcher l'assureur d'exercer une action que l'assuré n'aurait pas exercée lui-même. ${ }^{326}$

La jurisprudence s'est interrogée sur le sens de l'expression «personnes de la maison» afin d'identifier les personnes qui ne peuvent être poursuivies par l'assureur subrogé. Avant 1974, les personnes de la maison regroupaient les membres de la famille de l'assuré, ses serviteurs et préposés qui avaient coutume d'habiter chez lui. ${ }^{327} \mathrm{Au}$ fil du temps, la jurisprudence a interprété l'expression «personnes de la maison» dans son sens libéral. ${ }^{328}$ Les tribunaux ont alors étendu la notion à des personnes qui, sans nécessairement résider chezl'assuré, entretiennent avec lui des liens privilégiés ou des liens de préposition, même sporadiques. ${ }^{329}$

Comme nous le rappelle le juge Gendreau dans l'affaire Duquette, ${ }^{330}$ l'élargissement à outrance de l'expression n'est pas souhaitable. Selon lui, la

323. Gagné c. Le Groupe La Laurentienne, [1990] R.J.Q. 1819 aux pp. 1821-1822, M. le juge Bisson et à la p. 1824, M. le juge Chouinard (C.A.).

324. D. Lluelles, supra note 75 à la p. 328.

325. J.-G. Bergeron, supra note 117 à la p. 441. Voir Y. Lambert-Faivre, supra note 84 aux pp. 384-385, n 609.

326. Ibid. aux pp. 435-436. Le professeur Bergeron observe que l'assuré a peut-être souscrit à une police d'assurance avec l'intention de ne pas ennuyer ses proches.

327. J.-G. Bergeron, ibid. aux pp. 432-441.

328. Ibid.

329. Groupe La Laurentienne, supra note 323 aux pp. 1820-1824, M. le juge Bisson (La Cour suprême a rejeté la requête pour autorisation de pourvoi dans l'affaire Groupe La Laurentienne (C.S.C. 22105 - 1991 - IRCS); General Accident Compagnie d'assurances du Canada c. Legault, [1986] R.J.Q. 311 (C.S.); Groupe Desjardins Assurances Générales c. Simard, [1987] R.R.A. 151 (C.S.); Groupe Desjardins Assurances Générales c. DorionMcCoubrey, J.E. 89-643 (C.S.).

330. Compagnie d'assurances Missisquoi c. Duquette, [1996] R.J.Q. 1479 à la p. 1485, M. le juge Gendreau. 
jurisprudence devrait suivre l'interprétation libérale mais modérée de la dissidence du juge Bisson dans l'affaire Gagné, ${ }^{331}$ ce que la Cour supérieure avait d'ailleurs rappelé récemment dans l'affaire Martel. ${ }^{332}$ Cette interprétation se rapproche davantage de l'expression «household» qui est utilisée dans la version anglaise de l'article 2576 C.c.B.-C. et reprise sous le libellé de l'article 2474 C.c.Q.. ${ }^{333}$

Selon l'expression «household», une relation étroite doit exister entre l'assuré et le responsable afin que celui-ci fasse «partie de la maison» du souscripteur. À défaut d'y retrouver un tel lien, l'interprétation trop large $\mathrm{e}^{334} \mathrm{de}$ la notion devient équivoque. Les tribunaux doivent alors jauger à la fois la symbolique du «foyer familial» avec le concept de «maître de maison» et l'importance de sauvegarder des relations de «bon voisinage» ou encore de «bonne camaraderie».

En France, le Code des assurances contient une disposition similaire à celle de l'article 2474 al. 2 C.c.Q. qui consiste à supprimer le recours subrogatoire de l'assureur envers les proches de l'assuré. Le recours subrogatoire de l'assureur est cependant permis dans le cas de malveillance commise par le responsable. ${ }^{335}$

Selon Picard et Besson, «[o]n a voulu seulement empêcher l'exercice par l'assureur d'une action que, sans l'assurance, l'intéressé n'aurait pas lui-même

331. Gagné c. Groupe La Laurentienne, supra note 323 aux pp. 1820-1824, M. le juge Bisson.

332. Groupe Commerce c. Martel (31 mars 1995), Québec 200-05-004018-912 (C.S.) aux pp. 35, M. le juge Marquis.

333. L'expression anglaise traduit davantage l'idée de la maisonnée et du ménage domestique. Voir Cassell's Dictionary, London, Brooke Crutchley, University Printer, 1974 à la p. 244.

334. Gagné c. Groupe La Laurentienne, supra note 323 aux pp. 1823-1824, M. le juge Bernier et aux pp. 1824-1825, M. le juge Chouinard. Les juges Bernier et Chouinard ont interprété l'expression «personnes de la maison» de manière à sauvegarder les relations de bon voisinage.

335. L'article L. 121.12, al. 3 C. ass. se décrit comme suit : «Par dérogation aux dispositions précédentes, l'assureurn'a aucun recours contre les enfants, descendants, ascendants, alliés en ligne directe, préposés, employés, ouvriers ou domestiques, et généralement toute personne vivant habituellement au foyer de l'assuré, sauf le cas de malveillance commise par une de ces personnes.» En dépit du caractère limitatif découlant de l'énumération de l'article L. 121-12 du Code des assurances, la jurisprudence française a interprété cet article dans un sens libéral en raison de l'expression «et généralement». De plus, la Cour de cassation a considéré que la résidence n'était pas un facteur essentiel ni limitatif. Cass. civ. 28 octobre 1947, D. 1948.13 (note P.L.P.). 
exercée, à raison du lien l'unissant au responsable : la disposition légale repose ainsi sur l'intention probable des contractants». ${ }^{336}$ Là aussi, la finalité de l'interdiction légale fait foi du respect des considérations morales unissant l'assuré aux personnes faisant partie de sa maison. Chose certaine, en France, " [1] e droit ne veut pas aller ici contre le pardon». ${ }^{337}$

Il ne fait aucun doute que les considérations morales servent de fondement à l'interdiction de subrogation de l'article 2474 al. 2 C.c.Q. en faveur des personnes de la maison de l'assuré. La doctrine soulève une seconde raison dite «juridique» afin de justifier l'absence de subrogation contre ces personnes.

\section{b) Les raisons juridiques}

Les raisons juridiques à la base de l'interdiction de subrogation de l'assureur s'analysent en fonction du contrat d'assurance et du Code civil. Ces motifs mettent en cause la définition d' «assuré» couramment utilisée dans une police d'assurance de responsabilité traditionnelle ainsi que l'application du principe selon lequel l'assureur ne répète pas contre son propre assuré.

Règle générale, les proches de l'assuré sont aussi couverts par la police d'assurance de responsabilité du souscripteur. ${ }^{338}$ Ainsi, le terme «assuré» comprendra ordinairement le conjoint, les membres de la famille du souscripteur, les membres de la famille de son conjoint, les personnes âgées de moins de 21 ans à sa garde ou à la garde des autres personnes faisant l'objet de l'énumération. ${ }^{339}$ Les assureurs ont pris l'habitude d'étendre la notion d' «assuré» aux personnes de la maison parce qu'il est clair que le souscripteur désire aussi protéger ses proches des conséquences de leur responsabilité civile. ${ }^{340}$

En étendant la définition d' «assuré» aux personnes de la maison, l'assureur ne peut recouvrer «(...) d'une main ce qu'il doit couvrir de l'autre

336. M. Picard et A. Besson, supra note 130 à la p. 505, $\mathrm{n}^{\circ} 346$.

337. Cass. civ. $1^{\text {re }}, 8$ décembre 1993, D. 1993.235 (note B. Beignier).

338. J.-G. Bergeron, supra note 117 aux pp. 81-82.

339. Extrait de la définition d' «assuré» dans la police d'assurance-habitation des Assurances générales Desjardins.

340. J.-G. Bergeron, supra note 117 aux pp. 443-444. 
main». ${ }^{341}$ L'interdiction de subrogation empêche donc l'assureur de répéter le montant de l'assurance contre une personne de la maison qui est également couverte par la police d'assurance de l'assuré principal.

Dans le même ordre d'idée, nous pensons que l'interdiction de subrogation de l'article 2474, al. 2 C.c.Q. empêche l'assureur de répéter l'indemnité d'assurance contre les proches de l'assuré parce que ce dernier en est civilement responsable. ${ }^{32}$ À ce sujet, Picard et Besson étaient d'opinion que «(...) si on permettait à l'assureur d'agir contre ces personnes et si celles-ci étaient insolvables, l'action rejaillirait sur l'assuré lui-même, en qualité de civilement responsable; et ainsi, par la subrogation, l'assureur pourrait reprendre à l'assuré le montant de l'indemnité. Ces conséquences ne pouvaient être admises». ${ }^{343}$

L'article 2474 al. 2 du Code civil du Québec, qui interdit la subrogation de l'assureur envers les personnes de la maison, empêche donc à l'assureur de répéter l'indemnité d'assurance contre ces personnes qui ont aussi la qualité d' «assuré» aux termes du contrat. L'interdiction de subrogation empêche également l'assureur de répéter contre son propre assuré qui possède la qualité de «civilement responsable». ${ }^{344}$ De plus, l'assureur est le garant légal des personnes dont l'assuré est responsable. ${ }^{345}$ Comment l'assureur pourrait-il s'acquitter valablement de cette obligation s'il lui est possible d'exercer par la suite une action subrogatoire contre les personnes de la maison?

Selon nous, l'argument dit «juridique» est empreint d'un caractère économique puisqu'il veille au respect et à la sauvegarde des intérêts pécuniaires de la famille

341. Ibid. à la p. 448.

342. Articles 1459-1464 C.c.Q.

343. M. Picard et A. Besson, supra note 130 à la p. 502, n ${ }^{\circ} 344$.

344. O. Jobin-Laberge, «La subrogation légale de l'assureur», dans La responsabilité et les assurances, Cowansville, Yvon Blais, 1990 aux pp. 25 et 34; Y. Lambert-Faivre, supra note 84 aux pp. 383-384, n 608; B. Beignier, supra note 337 à la p. 235.

345. Art. 2464, al 2 C.c.Q. À l'origine de la codification, en 1866, l'assureur était aussi responsable de la faute des serviteurs résidant chez l'assuré en vertu de l'article 2979 C.c.B.-C. : "L'assureur est aussi responsable des dommages causés par la faute des serviteurs de l'assuré hors de la connaissance et sans le consentement de ce dernier.» Voir É. Lefebvre De Bellefeuille, Le Code Civil annoté étant le Code civil du Bas-Canada, Montréal, C.O. Beauchemin \& Fils, 1889 à la p. 754. 
et des préposés de l'assuré. ${ }^{346}$ En somme, la protection des relations que l'assuré entretient avec sa famille et ses préposés constitue un objectif majeur sur lequel se fonde l'interdiction de subrogation de l'article 2474 al. 2 C.c.Q.

Dans certaines circonstances, il peut arriver que les «personnes de la maison» de l'assuré soient couvertes par une police d'assurance de responsabilité distincte de celle de l'assuré. Cette situation risque de se présenter de plus en plus fréquemment étant donné l'interprétation élargie de la notion de «personnes de la maison» développée par la jurisprudence. ${ }^{347}$ En pareil cas, doit-on opposer l'interdiction de subrogation à l'assureur qui, après avoir versé l'indemnité, désire poursuivre directement l'assureur du responsable faisant partie de la maison de l'assuré?

\section{\$2. Le caractère prédominant de l'action directe du tiers lésé sur les exceptions à la subrogation de l'article 2474 C.c.Q.}

L'affirmation du droit direct du tiers lésé en assurance de responsabilité modifie les droits de l'assureur subrogé qui a payé l'indemnité garantie. Des suites du paiement de l'indemnité au tiers lésé, l'assureur est effectivement investi d'un droit substantiel qui lui permet de faire valoir la créance de réparation directe.

En privant de son recours subrogatoire contre les «personnes de la maison» l'assureur qui a versé l'indemnité, le législateur entendait-il interdire à cet assureur de poursuivre directement le second assureur qui peut aussi couvrir la responsabilité des personnes de la maison? La doctrine a soulevé la question et propose deux interprétations distinctes. La solution que nous privilégions découle de l'affirmation de l'action directe du tiers lésé en assurance de responsabilité et s'appuie sur le caractère d'exception de l'interdiction de subrogation de l'article 2474 C.c.Q.

346. Supra note 340.

347. Supra notes 323, 329, 330, 332. 


\section{A. L'inapplication des fondements de l'interdiction de subrogation à l'assureur}

L'assuré, on le sait, n'hésiterait pas à poursuivre l'assureur de l'auteur du préjudice en raison de l'absence de considération morale. À partir de ce principe, il nous semble encore plus évident que deux assureurs peuvent se poursuivre entre eux. Cependant, l'assureur qui a effectué le paiement de l'indemnité est-il en droit de recouvrer la valeur de son paiement en poursuivant l'assureur d'une personne de la maison de l'assuré?

\section{a) L'absence de liens moraux entre assureurs}

On comprend facilement que l'argument moral, qui est à la base de l'institution de l'interdiction légale, tombe lorsque deux assureurs se poursuivent entre eux. Les considérations morales ne sont pas opposables à l'assureur parce que seules les personnes physiques peuvent éprouver du repentir envers un proche ou encore le besoin profond de respecter l'esprit de famille.

Par exemple, avant 1994, la jurisprudence a analysé l'applicabilité de l'interdiction de subrogation de l'article 2576 C.c.B.-C. aux personnes morales. Dans l'affaire Laurentienne Générale Compagnie d'assurances c. De Wolfe, ${ }^{348}$ une maison résidentielle, propriété d'une personne morale, avait été assurée par cette dernière. Un incendie a dévasté la chambre de la défenderesse De Wolfe dont le père détenait la compagnie. Pour s'opposer au recours subrogatoire de l'assureur, Josée De Wolfe invoquait contre l'assureur l'interdiction de subrogation qui bénéficie aux personnes de la maison de l'assuré.

La Cour du Québec a cependant refusé d'appliquer l'interdiction de subrogation parce que l'assurée, propriétaire de la maison partiellement incendiée, était une personne morale. La Cour précise $\mathrm{qu}^{\prime} «(. .$.$) une compagnie$ 
ne peut avoir de sentiment ni de préférence». ${ }^{349}$ Selon le juge Verdy, il est nécessaire que l'assuré soit capable de sentiments et doté d'émotions pour que l'on oppose l'interdiction de subrogation de l'ancien article 2576 C.c.B.-C. ${ }^{350}$ à l'assureur.

Certes, la moralité ne constitue pas un motif pouvant être soulevé entre assureurs. Picard et Besson sont d'ailleurs d'avis que «[c]e motif n'est pas valable pour le recours contre l'assureur du responsable, car la victime n'hésiterait pas à agir contre ce dernier si elle n'était pas assurée personnellement.». ${ }^{351}$ De plus, Picard et Besson reconnaissent à l'assureur le droit de poursuivre directement l'assureur de responsabilité des personnes de la maison, même en dehors du cas de malveillance. ${ }^{352}$

Afin d'illustrer l'absence de liens moraux entre assureurs, nous jugeons opportun de rapporter l'exemple que livre le professeur français Bernard Beignier en parlant d'un fils qui a la possibilité d'indemniser son père sans être ruiné grâce à l'assurance. Le professeur Beignier s'exprime de la façon suivante :

«Mais si le fils peut indemniser son père sans être ruiné, précisément parce qu'il est assuré, une telle considération ne vaut plus. Le coupable ne risque plus rien. Il serait même scandaleux qu'au bout du compte ce soit la victime, indemnisée par son assureur, qui en vienne à supporter les conséquences de la situation par une possible augmentation de sa prime si son assureur ne peut se dédommager par ailleurs.» ${ }^{353}$

Tout compte fait, l'interdiction légale de l'article 2474 al. 2 C.c.Q. a pour objet d'éviter que l'assureur poursuive une personne que l'assuré n'aurait pas poursuivie. Les assureurs ne sont donc pas justifiés d'invoquer des considérations morales entre eux. Il reste à savoir si les motifs juridiques, justifiant la suppression de l'action subrogatoire contre les personnes de la maison de

349. Ibid. à la p. 444.

350. Ibid. à la p. 443.

351. M. Picard et A. Besson, supra note 130 à la p. 505, $\mathrm{n}^{\circ} 346$.

352. Ibid.

353. B. Beignier, supra note 337 à la p. 236. 
l'assuré, empêchent l'assureur, qui est investi de l'action directe, de poursuivre l'assureur d'un tiers responsable faisant partie de la maison de l'assuré.

\section{b) L'absence de raison juridique}

En général, les proches de l'assuré sont aussi couverts par la définition d' «assuré» dans une police d'assurance de responsabilité traditionnelle. ${ }^{354}$ Compte tenu de cette définition et de l'interprétation élargie ${ }^{355}$ de l'expression «personnes de la maison», il se peut qu'un membre de la famille soit aussi couvert par une police d'assurance distincte de celle de l'assuré principal. Il en est de même à l'égard des employés de maison qui peuvent être désignés sous le vocable d' «assuré». Considérant cette possibilité qu'un second assureur couvre aussi la responsabilité des proches et préposés d'un assuré, l'assureur qui a payé l'indemnité répète-t-il contre son propre assuré s'il poursuit directement l'assureur des personnes de la maison de l'assuré?

Dans l'arrêt Wawanessa, ${ }^{356}$ la Cour suprême du Canada a fait des personnes de la maison de véritables assurées possédant un intérêt d'assurance substantiel dans l'ensemble de la maison. Sur la base de ce principe développé par la jurisprudence de la Cour suprême, peut-on soutenir que l'assureur qui a versé l'indemnité fait indirectement ce que la loi lui interdit de faire directement, soit de répéter contre son propre assuré lorsqu'il poursuit l'assureur de responsabilité des personnes de la maison qui sont également des assurées?

D'après nous, les personnes de la maison ne possèdent pas un véritable statut de créancier de l'obligation de garantie de l'assureur, ce qui les distinguent

354. Supra notes 338-339.

355. Supra note 330.

356. Cecil Scott c. Wawanessa Insurance Company, [1989] 1 R.C.S. 1445. Voir : AgnewSurpass Shoe Store Ltd. c. Cummer-Yonge Investments Ltd., [1976] 2 R.C.S. 221; Commonwealth Construction c. Imperial Oil Ltd., [1978] 1 R.C.S. 317. La jurisprudence de la Cour suprême a reconnu un intérêt d'assurance commun dans un ensemble à des coassurés et assurés conjoints avec la conséquence que l'assureur était privé de subrogation puisqu'il ne pouvait pas répéter l'indemnité contre son propre assuré. Cependant, dans les affaires Commonwealth Construction et Agnew-Surpass Shoe Store Ltd., contrairement à l'arrêt Wawanessa, la police d'assurance comportait une stipulation pour autrui «pour le compte» d'autres assurés. 
de l'assuré principal. L'assuré souscripteur est le véritable créancier de l'obligation contractuelle de l'assureur. Par exemple, c'est l'assuré qui doit payer la prime, déclarer les aggravations de risque ainsi que le sinistre. Les personnes de la maison ne sont aucunement liées par de telles obligations envers l'assureur. Leur statut d' «assuré» n'en fait pas non plus des personnes assimilables à un propriétaire devant veiller à la conservation des lieux, contrairement à l'assuré principal.

Étant donné ces distinctions, nous croyons que les personnes de la maison possèdent un intérêt d'assurance d'une nature différente de celle de l'assuré. Selon l'expression du professeur Bergeron, ${ }^{357}$ les personnes de la maison se voient attribuer la qualité d'«assuré» par commodité. En raison de l'intérêt d'assurance distinct des personnes de la maison, nous sommes d'avis que l'assureur ne répète pas contre son propre assuré lorsqu'il exerce l'action directe contre l'assureur de responsabilité de ces mêmes personnes.

Par ailleurs, on peut ajouter à l'argument fondé sur l'intérêt d'assurance distinct que possèdent les personnes de la maison, l'absence de mandat de représentation entre assureurs et assurés. En conséquence, l'assureur qui a versé le montant de l'indemnité ne risque pas de répéter contre son propre assuré en exigeant un remboursement de l'assureur d'un tiers responsable faisant partie de la maison.

Jusqu'à présent, nous avons démontré qu'aucun argument moral ni juridique ne pouvait être invoqué à l'encontre de l'exercice du recours subrogatoire de l'assureur contre l'assureur du tiers responsable faisant partie de la maison de l'assuré. Toutefois, une décision jurisprudentielle n'est pas favorable à l'exercice de ce recours. La doctrine, quant à elle, est divisée.

\section{B. Le recours direct de l'assureur contre l'assureur du responsable faisant partie de la maison de l'assuré}

Au Québec, la jurisprudence antérieure à 1994 a peu abordé la question de la subrogation de l'assureur qui, après avoir effectué le paiement de 
l'indemnité, désire se faire rembourser par l'assureur d'une personne faisant partie de la maison de l'assuré. Nous verrons que la doctrine alimente davantage la discussion.

\section{a) L'état de la question selon la jurisprudence de la Saint- Maurice}

Dans l'affaire Union Canadienne, Compagnie d'assurances c. SaintMaurice ${ }^{358}$ la Cour supérieure s'est penchée sur la question du recours subrogatoire de l'assureur contre l'assureur de responsabilité d'une personne qui fait partie de la maison de l'assuré. Le juge Moisan a rejeté le recours subrogatoire de l'assureur en raison du caractère strictement procédural de l'action directe. Selon la Cour, la victime ne possède qu'un seul débiteur, l'assuré. Par conséquent, l'assureur ne saurait avoir plus de droits que son assuré. Cette affaire relevait du Code civil du Bas-Canada.

Le juge Moisan précise que si l'on accueillait le recours subrogatoire de l'assureur contre l'assureur d'une personne faisant partie de la maison de l'assuré, cela reviendrait à faire de l'assureur de responsabilité un tiers responsable. ${ }^{359} \mathrm{Le}$ magistrat rejette la notion de tiers responsable parce qu'il est d'avis que l'assureur ne joue pas «(...) un rôle déterminant dans la responsabilité des dommages». ${ }^{360}$ Une certaine doctrine s'inscrit dans le courant de pensée développé par le juge Moisan, ${ }^{361}$ tandis qu'une autre s'y oppose.

\section{b) L'état de la question selon la doctrine québécoise}

La question de la subrogation de l'assureur contre l'assureur de la personne de la maison de l'assuré ne fait pas l'unanimité parmi les auteurs. La thèse favorable au recours de l'assureur se fonde sur les règles de la subrogation,

358. Union canadienne, supra note 15 aux pp. 5-8, M. le juge Moisan.

359. Le professeur Bergeron fait également référence à la notion de tiers responsable lorsqu'il traite la question de la subrogation de l'assureur contre l'assureur d'une personne faisant partie de la maison de l'assuré. Contrairement au juge Moisan, J.-G. Bergeron affirme qu'il n'hésiterait pas à considérer l'assureur comme un tiers responsable pouvant être poursuivi par action directe. J.-G. Bergeron, supra note 117 aux pp. 447-448.

360. Union canadienne, supra note 15 à la p. 6, M. le juge Moisan.

361. O. Jobin-Laberge, supra note 344 à la p. 40. 
tandis que la thèse opposée s'appuie sur des considérations propres à l'assurance de responsabilité.

\section{i) La thèse fondée sur la subrogation}

Le professeur Bergeron est favorable au recours subrogatoire de l'assureur contre l'assureur du responsable faisant partie de la maison de l'assuré. D'abord, ce professeur soutient qu'en vertu de la subrogation légale, l'«(...) assureur est nécessairement investi de l'option donnée par l'article 2603 C.c. (...)». ${ }^{362}$ Selon lui, il ne fait aucun doute que l'action directe est transférée dans le patrimoine de l'assureur, par l'opération juridique de la subrogation légale.

Monsieur Bergeron affirme ensuite que l'interdiction de subrogation qui concerne les personnes de la maison de l'assuré protège exclusivement les «tiers responsables». ${ }^{363}$ À son avis, la subrogation peut donc se réaliser contre l'assureur de responsabilité des personnes faisant partie de la maison de l'assuré. Cet auteur n'hésiterait pas à considérer l'assureur comme un tiers responsable pour permettre la subrogation de l'assureur contre l'assureur de responsabilité d'une personne de la maison. ${ }^{364}$ De plus, le professeur souligne qu'aucune raison morale n'empêche des assureurs de se poursuivre entre eux.

L'essentiel de cette thèse consiste à affirmer qu'au moyen de la réalisation de la subrogation légale, l'assureur est investi de deux actions : l'action en responsabilité et l'action directe. ${ }^{365}$ L'interprétation littérale du libellé de l'interdiction de subrogation et l'absence de moralité entre assureurs justifient l'assureur subrogé, qui a versé l'indemnité, d'exercer l'action directe contre l'assureur des tiers responsables faisant partie de la maison de l'assuré.

362. J.-G. Bergeron, supra note 117 à la p. 447.

363. Ibid.

364. Supra note 359.

365. Supra note 318. 


\section{ii) La thèse fondée sur l'assurance de responsabilité}

La thèse opposée est soutenue par Odette Jobin-Laberge. Selon son interprétation de l'exception de subrogation, l'assureur ne peut être garant du préjudice que l'assuré est tenu de réparer tant que ce dernier n'est pas «légalement tenu de payer» aux termes du contrat d'assurance. ${ }^{366}$ Madame JobinLaberge affirme que «(...) l'assuré ne peut être tenu de payer en réponse à une action subrogatoire puisque l'article 2576 C.c. interdit tout recours contre lui». ${ }^{367}$

O. Jobin-Laberge développe une argumentation similaire à celle qu'a fait valoir le juge Moisan dans l'affaire Saint-Maurice, lorsqu'elle analyse la notion de «tiers responsable» pour contrer l'argumentation inverse. L'auteure refuse donc de considérer l'assureur comme un tiers responsable car l'assureur supporte sa propre dette de garantie. ${ }^{368}$

En résumé, si l'assuré principal n'intente aucune procédure contre une personne faisant partie de sa maison, l'assureur ne saurait être tenu d'exécuter sa garantie. ${ }^{369}$ L'assureur n'a évidemment pas plus de droits que son propre assuré. C'est ce qui conduit Mme Jobin-Laberge à affirmer que l'interdiction de subrogation de l'ancien article 2576 C.c.B.-C. empêche l'assureur d'exercer tout recours subrogatoire contre l'assuré.

Sans pour autant faire de l'assureur un tiers responsable, le droit français a tenté d'apporter une solution à la question de la subrogation de l'assureur contre l'assureur de responsabilité d'un proche de l'assuré. La jurisprudence française a débattu cette question pendant longtemps avant de pouvoir la résoudre.

\footnotetext{
366. O. Jobin-Laberge, supra note 344 à la p. 41.

367. Ibid. à la p. 40.

368. Ibid. Voir Union canadienne, supra note 15 à la p. 6, M. le juge Moisan. Mme JobinLaberge se demande également si l'assureur de choses peut «se transformer» en assureur de responsabilité lorsqu'il recouvre le montant de l'indemnité versée contre l'assureur de responsabilité du tiers. Ibid. à la p. 43. 


\section{c) Les hésitations de la jurisprudence française}

Dès $1947,{ }^{370}$ la jurisprudence française s'est interrogée sur la question de l'exercice de l'action directe par l'assureur subrogé contre l'assureur de responsabilité d'un proche ou d'un préposé de l'assuré. Le débat se situait tantôt du côté de la thèse de l'assurance de responsabilité qui niait le recours de l'assureur, tantôt du côté de la thèse de la subrogation qui, à l'inverse de la première, était favorable à la subrogation de l'assureur. La jurisprudence de la Cour de cassation est demeurée ambivalente pendant près de cinquante ans.

\section{i) Le premier courant rejetant le recours subrogatoire de l'as- sureur}

Vers 1950, la Cour de cassation a rejeté le recours subrogatoire de l'assureur de choses contre l'assureur de responsabilité au motif que l'interdiction de subrogation de l'article L. 121-12, al. 3 du Code des assurances ${ }^{371}$ s'appliquait également à l'assureur. La Cour déclarait qu' «(...) à défaut d'une attribution légale de l'indemnité due au responsable, l'assureur de choses n'est investi d'aucun droit propre contre son assureur (...)». ${ }^{372}$

À la suite de cet arrêt, la jurisprudence française a longtemps affirmé que l'assureur subrogé n'a pas plus de droits contre l'assureur du responsable qu'il peut en avoir contre le responsable lui-même. Afin de motiver sa décision, la Cour reconnaissait que tant que l'auteur du préjudice n'était pas soumis aux conséquences de sa responsabilité civile, son assureur n'avait pas plus à l'être. ${ }^{373}$ La Cour de cassation faisait aussi valoir que l'interdiction légale en matière de subrogation devait s'étendre à l'assureur étant donné son caractère d'ordre public. ${ }^{374}$ Ce n'est qu'au début des années quatre-vingts que la jurisprudence a remis en question sa position.

370. Cass. civ., 28 octobre 1947, supra, note 335.

371. Art. L. 121-12, al. 3 C. assur., supra note 335.

372. H. Groutel, «La boucle est bouclée (À propos des immunités contre un recours subrogatoire)», Resp. civ. et assur.1993.3.chron.3.

373. Supra note 318 aux pp. 397-398.

374. Ibid. 


\section{ii) Le revirement de la jurisprudence française à l'égard des Caisses de Sécurité sociale}

La thèse défavorable au recours de l'assureur a prévalu en France jusqu'en 1983 où la Cour de cassation a changé de point de vue. ${ }^{375}$ Le tribunal a alors accueilli le recours subrogatoire d'une Caisse de Sécurité sociale contre l'assureur du responsable d'un accident de la circulation. Cette décision de la Cour de cassation a été fortement critiquée en raison de l'immunité de responsabilité qui bénéficie aux membres d'une même famille dans le domaine des assurances sociales. ${ }^{376}$

Pour contester ce revirement de la jurisprudence française, on invoquait également l'absence de préjudice des organismes de sécurité sociale qui ne font qu'exécuter leur obligation légale en versant à la victime leurs prestations à caractère statutaire plutôt qu'indemnitaire. ${ }^{377}$ La professeure Yvonne LambertFaivre observe à ce sujet : "Les caisses de sécurité sociale sont certes victimes... de leur déficit financier : on n'ose croire que ce soit la vraie raison d'un tel détournement juridique de garantie! ${ }^{378}$

En France, le courant développé du point de vue de l'assurance de responsabilité a pris une importance considérable en raison des immunités qui prévalent entre un employeur et ses préposés ainsi qu'à l'égard des membres d'une même famille. À la différence du Québec, le droit commun de la responsabilité en France immunise l'employeur contre une action en responsabilité civile dirigée par ses préposés et vice-versa. ${ }^{379} \mathrm{Il}$ en est de même dans le domaine $\mathrm{du}$ droit des assurances sociales où «(...) l'unité économique du foyer et la communauté de vie entre époux ne permet pas de considérer le conjoint responsable comme un "tiers" ${ }^{380}$

375. Cass. civ. Ass. plén., 3 juin 1983, Bull. civ. 1983 Ass. plén., nº 6 à la p. 9, D.1983.Jur.537. (concl.Cabannes).

376. Art. L. 282 Code des assurances sociales.

377. Y. Lambert-Faivre, «De la dégradation juridique des concepts de "responsable" et de "victime"», D. 1984.chron.51 à la p. 54.

378. Ibid. à la p. 54 .

379. Art. L. 451-1 Code de la sécurité sociale.

380. P. Jourdain, «Obligations et contrats spéciaux» Rev. trim. dr. civ. 1989.335. 
$\mathrm{Au}$ Québec, notre système de droit ne prévoit aucune immunité de responsabilité entre commettants et préposés ni entre les membres d'une même famille, encore moins une exonération de responsabilité. Au contraire, en ce qui concerne les préposés, le Code civil du Québec prévoit expressément qu'un commettant possède un recours récursoire contre son préposé. ${ }^{381}$ D'ailleurs, avant 1994, la jurisprudence a eu l'occasion de reconnaître que l'employeur avait toujours le droit de poursuivre ses employés. ${ }^{382}$ C'est ce qui explique pourquoi une certaine doctrine n'étend pas l'expression «personnes de la maison» aux préposés. ${ }^{383}$ En ce qui concerne les membres d'une même famille, la jurisprudence québécoise n'a jamais exclu que des parents en ligne directe ou collatérale puissent se poursuivre entre eux. ${ }^{384}$

Étant donné cette particularité du droit français qui consiste à créer des immunités de responsabilité, la jurisprudence de la Cour de cassation a cherché à savoir si ces mêmes immunités emportaient l'irresponsabilité des personnes visées par l'interdiction de subrogation de l'article L. 121-12, al. 3 C. ass. En 1983, la Cour de cassation a répondu à cette question en affirmant que les immunités de droit commun n'entraînaient pas l'irresponsabilité ${ }^{385}$ des personnes soumises à l'interdiction. L'assureur était donc admis à poursuivre directement

381. Art. 1463 C.c.Q.

382. Lister c. Romford Ice and Cold Storage Ltd., [1956] 2 B.R. 180.

383. O. Jobin-Laberge, supra note 344 aux pp. 37-39.

384. L'arrêt Fidelty \& Casualty of New York c. Marchand est sans doute une des premières affaires rencontrées où un tribunal s'est interrogé sur la moralité du recours civil intenté par un fils contre son père. Les propos du juge Mignault sont très évocateurs : «Before this case was submitted, I may frankly say that I never heard of a civil action by or on behalf of a minor child against his father or mother, claiming damages for injuries caused by negligence of the latter. (...) In the absence of authority to the contrary, the question really is whether an exception founded on family relationship can be admitted in view of the general rule of liability contained in article 1053 of the civil code. This rule is in as wide terms as possible and renders every person capable of distinguishing right from wrong responsible for damage caused by his fault to another. There is here no limitation, no exception of persons, and the class of those to whom compensation is due is as wide as that of the persons on whom liability is imposed. It seems, therefore, sufficient to say "lex non distinguit", however repugnant it may seem that a minor child should sue his father, although it would propably be equally repugnant that a child injured by his father's negligent act, perhaps maimed for his life, should have no redress for the damage he has suffered.» Fidelty \& Casualty Company of New York c. Marchand, [1924] R.C.S. 86 à la p. 97, M. le juge Mignault.

385. Cass. civ. Ass. plén., 3 juin 1983, supra note 375. 
l'assureur du responsable faisant partie de la maison de l'assuré pour se faire rembourser le montant de l'indemnité versée. Malgré cette prise de position de la Cour de cassation, la jurisprudence a fait volte-face en $1988 .{ }^{386}$

\section{iii) Le retour au premier courant}

Le revirement de la Cour de cassation intervient dans le cadre de l'application de la Loi de Badinter de 1985. ${ }^{387}$ La Cour rejette le recours subrogatoire d'un assureur envers l'assureur de responsabilité des membres d'une même famille.

La Cour conclut à la nullité du recours subrogatoire de l'assureur dirigé contre l'assureur de responsabilité des personnes de la maison de l'assuré. Le raisonnement du tribunal consiste à affirmer que le recours subrogatoire priverait l'accidenté de la route de l'intégralité de l'indemnité d'assurance. En effet, la Cour considère que bien que des parents puissent être auteurs d'un accident de la circulation ayant causé la mort de leur enfant, ces parents ont droit à la réparation de leur préjudice découlant du fait du décès de la victime. Or, le recours subrogatoire de l'assureur priverait les parents de l'indemnisation complète qui leur est attribuée pour le décès de leur enfant.

Mais voilà qu'en 1992, la Cour de cassation prend une orientation opposée. Elle accueille le recours subrogatoire de l'assureur contre l'assureur d'un responsable faisant partie de la maison de l'assuré.

386. Cass. civ. 2 $2^{\mathrm{e}}, 13$ janvier 1988 et 17 février 1988, D. 1988.Jur.293 (note Groutel).

387. La Loi de Badinter est une loi à caractère social visant à réformer les principes de responsabilité civile en matière d'accidents de la circulation ainsi qu'à réglementer l'indemnisation des victimes de tels accidents. 


\section{iv) La jurisprudence française change encore d'optique}

En janvier 1992, dans une affaire mettant en présence un accidenté de la route, la Cour de cassation accueille le recours subrogatoire de l'assureur d'un coauteur de l'accident contre l'assureur du coauteur du préjudice. Cette fois-ci, la Cour décide que «(...) si le recours d'un coauteur d'un accident de la circulation contre un coauteur non assuré et parent de la victime peut avoir pour effet de priver directement ou indirectement celle-ci de la réparation intégrale de son dommage, le recours contre l'assureur d'un coauteur, parent de la victime, ne porte aucun préjudice à celle-ci». ${ }^{388}$

Ces revirements successifs de la jurisprudence de la Cour de cassation démontrent jusqu'à quel point le droit français est longtemps demeuré impuissant à résoudre la question de la subrogation de l'assureur contre l'assureur d'un responsable faisant partie de la maison de l'assuré. Tour à tour, les thèses fondées sur la subrogation et sur l'assurance de responsabilité se sont succédé sans que la jurisprudence n'établisse de faille déterminante dans l'un ou l'autre des raisonnements.

Les thèses développées par la jurisprudence française sont intéressantes. En effet, les deux courants jurisprudentiels qui ont été longuement débattus en France correspondent en substance aux thèses soutenues au Québec par le professeur J.-G. Bergeron et par madame O. Jobin-Laberge. Cette comparaison entre le droit français et québécois est d'autant plus intéressante depuis que la France a réussi à se sortir de l'impasse en abordant la question différemment.

388. Cass. civ. $2^{\mathrm{e}}, 8$ janvier 1992, Resp. civ. et assur. 1992.comm.96. Voir G. Viney, L'indemnisation des victimes d'accidents de la circulation, Paris, L.G.D.J., 1992 aux pp. 80$83, \mathrm{n}^{\text {os }} 59-60$. 


\section{d) La solution française s'appuyant sur le caractère d'exception de l'interdiction de subrogation}

Malgré le renversement jurisprudentiel de janvier 1992, par lequel la Cour de cassation a accueilli le recours subrogatoire de l'assureur, ${ }^{389}$ le débat n'était pas pour autant achevé. Ce n'est qu'en décembre 1993 que la première chambre civile mit fin à la controverse qui durait depuis quarante-six ans. La jurisprudence française a alors envisagé selon un nouveau point de vue la question de la subrogation de l'assureur contre l'assureur d'un proche de l'assuré.

L'affaire du 8 décembre $1993^{390}$ a permis à la Cour de cassation de présenter une nouvelle solution à la question de la subrogation de l'assureur contre l'assureur des proches ou préposés de l'assuré. Cette affaire de décembre 1993 concernait un préposé, M. Coutant, qui s'était vu attribuer un logement dans le cadre de l'exercice de ses fonctions. Un incendie est survenu dans l'appartement du préposé et l'assureur de l'employeur a indemnisé M. Coutant. Par la suite, l'assureur a logé une action subrogatoire auprès de la M.G.A., l'assureur du préposé. La Cour a accueilli le recours subrogatoire de l'assureur contre l'assureur du responsable faisant partie de la maison de l'assuré.

Afin de trancher le débat, la Cour de cassation s'est inspirée de la solution apportée au problème d'interprétation des renonciations à recours. Le professeur Groutel note que les développements jurisprudentiels rattachés à l'interprétation des renonciations à recours ${ }^{391}$ ont apporté un éclairage important au problème de la subrogation de l'assureur contre l'assureur d'un proche ou d'un préposé de l'assuré. ${ }^{392}$ Les renonciations à recours ont été interprétées comme un mécanisme d'immunité par lequel «(...) l'auteur de la renonciation désigne les bénéficiaires de l'immunité, et le silence gardé à l'égard de l'assureur du responsable éventuel laisse la possibilité de recourir contre lui». ${ }^{393}$

389. Ibid.

390. Cass. civ $1^{\text {re }}, 8$ décembre 1993, D. 1994.Jur.235.

391. Cass. civ. $1^{\text {re }}, 13$ janvier 1987, R.G.A.T. 1987.44.

392. H. Groutel, supra note 372 à la p. 3.

393. Ibid. Voir Cass. civ. Ass. plén., 23 mai 1973, Bull. civ. 1973. I., no 3; Cass. civ. $1^{\text {re }}, 26$ mai 1993, Resp. civ. et assur. 1993.comm.317; H. Groutel, «L'affirmation d'une doctrine de la Cour de cassation en matière de renonciations à recours» Resp. civ. et assur. 1993.12.chron.30; H. Groutel, «Les recours entre coauteurs (suite - et fin?)», D. 1992.chron.19. 
Considérant le courant suivi en matière de renonciations à recours, la Cour de cassation a décidé, dans l'affaire du 8 décembre 1993, que l'immunité légale en matière de subrogation contre les proches et préposés de l'assuré devait être interprétée de façon restrictive. La Cour a conclu que l'immunité «(...) édictée par le $3^{e}$ al. de l'article L. 121-12 C. ass. ne bénéficie qu'aux personnes visées au texte et ne fait pas obstacle à l'exercice, par l'assureur qui a indemnisé la victime, de son recours subrogatoire contre l'assureur de responsabilité de l'une de ces personnes (...)». ${ }^{394}$

La doctrine française vient préciser que l'interprétation restrictive, mise de l'avant par la jurisprudence, fait en sorte que l'exception de subrogation de l'article L. 121-12, al. 3 C. ass. n'a pas pour effet d'éteindre la dette de responsabilité des personnes énumérées à l'article susmentionné. ${ }^{395}$ Ainsi, si l'on se place du point de vue de l'assuré, l'immunité en matière de subrogation suppose que «le responsable est bien responsable mais n'en supporte pas les conséquences». ${ }^{396}$

À cet égard, le professeur Beignier soutient que l'article L. 121-12, al. 3 C. ass. ne crée pas une «irresponsabilité» de droit mais plutôt une immunité en faveur du responsable alors à l'abri d'une poursuite en responsabilité. ${ }^{397}$ Quant au professeur Groutel, il abonde dans le même sens lorsqu'il affirme que l'interdiction légale de l'article L. 121-12, al. 3 C. ass. paralyse le recours en responsabilité de la victime sans toutefois exonérer le responsable de sa dette de responsabilité. Le professeur Groutel s'exprime en ces mots :

«Au contraire, avec les immunités, le droit à une réparation existe dans son principe et, pour qu'une difficulté se rencontre, il faut même supposer que les conditions en sont réunies. L'action contre le responsable est simplement paralysée, mais rien n'empêche, a priori, de sous-tendre une action contre l'assureur.» ${ }^{398}$

394. H. Groutel, supra note 372.

395. Cette prise de position confirme la théorie française selon laquelle la dette de responsabilité de l'assuré ne naît pas de la réclamation d'un tiers. Supra notes 142-143.

396. B. Beignier, supra note 337 à la p. 236.

397. Ibid.

398. H. Groutel, supra note 393 à la p. 20. 
Nous croyons qu'il est important de préciser que la Cour de cassation n'a pas conclu au caractère d'exception de l'immunité en raison du libellé de l'article L. 121-12, al. 3 C. ass. qui consiste à dresser une énumération des personnes visées. La Cour fonde son interprétation restrictive de l'interdiction de subrogation sur le fait que l'immunité légale est une «(...) exception du droit de la responsabilité civile à un principe du droit des assurances. (...) L'exception $d u$ droit de la responsabilité : c'est cette anomalie qui fait qu'une victime ne poursuit pas le coupable. Le principe du droit des assurances : c'est le recours subrogatoire habituel de l'assureur de la victime contre le tiers responsable ou son assureur». ${ }^{399}$

Au Québec, le recours subrogatoire de l'assureur constitue aussi un principe du droit des assurances et sa suppression, une exception. Par analogie avec le droit français, il y a lieu de s'interroger sur le caractère d'exception de l'interdiction de subrogation de l'article 2474, al. 2 C.c.Q.

\section{e) L'applicabilité de la solution française au Québec}

L'analyse du libellé de l'article 2474 C.c.Q. exprime bien l'intention du législateur d'établir, comme règle générale, la subrogation de l'assureur et, comme exception, la réserve concernant l'interdiction de subrogation contre les personnes de la maison. ${ }^{400}$ Cela signifie-t-il que l'interdiction légale en matière de subrogation doit être interprétée de façon restrictive à l'instar du développement jurisprudentiel français portant sur l'interprétation de l'exception de subrogation?

Aux termes de l'article 2474, al. 2 C.c.Q. l'assureur «(...) ne peut jamais être subrogé contre les personnes qui font partie de la maison de l'assuré». Doit-on déduire de ce principe que les personnes de la maison de l'assuré ne sont plus «tenues de payer» leur dette de responsabilité? D'après nous, les personnes de la maison ne sont pas libérées de leur dette de responsabilité. Seul l'exercice du recours subrogatoire de l'assureur est paralysé contre les personnes de la maison de l'assuré.

399. B. Beignier, supra note 337 à la p. 236. Aussi H. Groutel, supra note 372 à la p. 3.

400. D. Lluelles, supra note 75 aux pp. 328-330. 
À ce sujet, J.-G. Bergeron considère que l'interdiction de l'article 2474, al. 2 C.c.Q. crée une «exemption» ${ }^{401}$ de subrogation en faveur des personnes de la maison de l'assuré. Vu comme une exemption, l'article 2474 C.c.Q. n'établirait qu'une simple interdiction d'agir contre les personnes ou préposés entretenant un lien privilégié avec l'assuré.

Le professeur Groutel précise d'ailleurs qu' «(...) en présence d'une simple interdiction d'agir contre certaines personnes, alors que la dette existe, le sort de leur assureur de responsabilité peut être conditionné par les raisons qui ont fait instituer ou stipuler l'immunité». ${ }^{402}$ Il importe donc de cerner les raisons qui sont à la base de l'interdiction de subrogation de l'article 2474 C.c.Q.

Au Québec, la raison majeure à la base de l'interdiction de l'article 2474, al. 2 C.c.Q. consiste à éviter que l'assureur exerce une action contre un proche de l'assuré alors que ce dernier ne l'aurait pas fait. ${ }^{403}$ Rappelons-nous que ni la moralité, non plus que les règles relatives à la responsabilité du fait d'autrui, ne font obstacle au recours de l'assureur contre l'assureur du responsable faisant partie de la maison de l'assuré. De plus, l'ordre public ne s'oppose pas à ce même recours subrogatoire puisque l'objet de l'interdiction légale est d'éviter qu'une action soit dirigée contre un proche ou préposé de l'assuré. ${ }^{404}$

En interprétant l'article 2474, al. 2C.c.Q. comme une simple interdiction d'agir contre certaines personnes, autrement dit comme une immunité, on admet nécessairement le recours subrogatoire de l'assureur, qui a payé la victime, contre l'assureur du tiers responsable faisant partie de la maison de l'assuré. Le professeur Lluelles semble également d'opinion que l'interdiction légale constitue une immunité à l'égard des tiers responsables que l'assuré n'aurait probablement pas poursuivis. ${ }^{405}$

Selon cette approche inspirée du droit français, il est possible d'éviter les longs débats auxquels peuvent nous conduire les deux thèses respectivement

401. J.-G. Bergeron, supra note 117 à la p. 440 .

402. H. Groutel, supra note 372 à la p. 3.

403. Supra notes 323-324.

404. Ibid.

405. D. Lluelles, supra note 75 aux pp. 328-329. 
fondées sur la subrogation (J.-G.Bergeron) et sur l'assurance de responsabilité (O. Jobin-Laberge). ${ }^{406}$ Compte tenu du but visé par le libellé de l'article 2474, al. 2 C.c.Q., qui est d'éviter que l'assureur ne poursuive un proche de l'assuré, nous sommes d'avis que l'interdiction légale doit recevoir une interprétation restrictive, par analogie avec le droit français.

Le caractère autonome de l'action directe du tiers lésé fonde l'admissibilité du recours direct de l'assureur subrogé qui a versé l'indemnité, contre l'assureur du responsable faisant partie de la maison de l'assuré. En effet, n'eût été l'affirmation de l'autonomie de l'action directe du tiers lésé, l'assureur subrogé ne saurait être investi de cette action pour se faire rembourser le montant de l'indemnité d'assurance. L'action directe se distingue donc nettement de l'action en responsabilité civile depuis la réforme du Code civil.

La doctrine française observe, à ce propos, qu'une distance s'installe entre l'action en responsabilité et l'action directe, ce qui marque de plus en plus leur autonomie respective. ${ }^{407}$ Selon la doctrine française, ce phénomène entraîne la dissociation de deux responsabilités : la responsabilité civile d'une part et la responsabilité en matière d'assurance de l'autre. ${ }^{408}$

Au Québec, depuis la réforme du Code civil en 1994, l'assurance de responsabilité a pris un tournant similaire à celui de l'assurance de responsabilité en France. ${ }^{409}$ Aux termes de l'article 2396 C.c.Q., l'objet de l'assurance de responsabilité est sans nul doute de garantir la dette de responsabilité de l'assuré

406.

Supra notes 366-367.

407. B. Beignier, supra note 337 aux pp. 236-237; H. Groutel, supra note 372 à la p. 3; H. Groutel, «La distance entre l'action directe contre l'assureur de responsabilité et l'action contre le responsable» Resp. civ. et assur. 1992.3.chron.29.

408. B. Beignier, supra note 337 aux pp. 236-237.

409. Selon le professeur Groutel, «(...) il va falloir, peu à peu, revoir l'analyse qui était faite jusqu'à présent, de l'assurance de responsabilité. Il n'y a pas grand chose de commun entre la doctrine affirmée dans l'arrêt du 26 mai 1993 [sur les renonciations à recours] et l'extrait suivant de Picard et Besson: "Les assurances de responsabilité ont pour but de garantir l'assuré contre les recours exercés contre lui par des tiers à raison du préjudice qu'il a pu leur causer et qui engage sa responsabilité; (...) Ce n'est pas le dommage subi par le tiers que l'assureur répare, mais celui que subit l'assuré, du fait qu'il est débiteur envers ce tiers de dommages-intérêts”.» H. Groutel, «L'affirmation d'une doctrine de la Cour de cassation en matière de renonciations à recours», supra note 393 à la p. 1. 
envers les tiers lésés. Toutefois, il se greffe à ce principe une finalité tout aussi importante : la protection des droits des tiers lésés. L'adoption des principes garantissant la protection minimale des droits des tiers lésés dans le domaine de l'assurance de responsabilité en est l'expression majeure. ${ }^{410}$

À la lumière de la nouvelle finalité de l'assurance de responsabilité, nous croyons qu'il faut accorder à la réforme son entière portée. La reconnaissance des conséquences de l'autonomie de l'action directe sur les droits que possède l'assureur subrogé pour recouvrer le montant de l'indemnité versée s'inscrit dans cette perspective.

L'affirmation du caractère autonome de l'action directe du tiers lésé se répercute également sur l'extinction du droit direct du tiers lésé en assurance de responsabilité. À ce sujet, nous verrons que la durée de l'action directe ne coïncide pas nécessairement avec la durée de l'action en responsabilité de la victime.

\section{§3. Le caractère autonome de l'extinction de l'action directe du tiers lésé}

Depuis 1994, l'action directe assure sans nul doute la protection des droits des tiers lésés. ${ }^{411}$ Cette transformation de l'assurance de responsabilité consacre le fondement de la créance directe dans le droit à réparation du préjudice de la victime. Le fondement du droit direct du tiers lésé dans le droit à réparation de la victime suppose qu'en principe, le moment de l'extinction du droit direct du tiers lésé correspond aussi à celui de l'extinction de la créance de responsabilité de la victime.

\section{A. La prescription de l'action directe du tiers lésé}

Avant 1994, la jurisprudence considérait que l'article 2603 C.c.B.-C. n'établissait aucun droit substantiel en faveur du tiers lésé. Suivant ce principe, les tribunaux ont décidé que le délai de prescription de l'action directe ne

410. Supra notes 71 et 73.

411. Supra note 73 à la p. 78. 
pouvait pas correspondre au délai d'un an applicable aux actions fondées sur la responsabilité civile. ${ }^{412}$ Le recours direct du tiers lésé se prescrivait donc selon un délai de trois ans ${ }^{413}$ puisqu'il ne pouvait dériver que du contrat d'assurance. ${ }^{414}$ Depuis 1994, il est clair que le fondement de l'action directe du tiers lésé est issu du droit à réparation de la victime. Cela explique que le délai de prescription du recours direct correspond à celui de l'action en responsabilité. ${ }^{415}$

La prescription de l'action directe variera selon la nature de la créance directe. Si l'action directe fait valoir un droit réel immobilier ou un droit résultant d'un jugement, la prescription sera décennale. ${ }^{416}$ Par contre, si l'action directe se rapporte à un droit personnel ou à un droit réel mobilier, la prescription sera triennale. ${ }^{417}$

Le jour marquant le point de départ de la prescription de l'action directe du tiers lésé est le même que celui de l'action en responsabilité. La computation du délai débutera donc au jour du préjudice ou au jour où le préjudice apparaît pour la première fois, s'il en est un qui se manifeste graduellement ou tardivement. ${ }^{418}$ Quant au dies ad quem, il correspondra au jour où la prescription décennale ou triennale sera acquise selon le droit commun.

Dans l'hypothèse où l'assureur poursuit directement l'assureur de l'auteur du préjudice par suite de la subrogation, le délai de prescription applicable correspondra à celui qui se rapporte aux droits du subrogeant. ${ }^{419}$ Cependant, le dies a quo relatif à la prescription de l'action subrogatoire de l'assureur sera différent de celui des actions directe et en responsabilité. Il en est ainsi parce que «[d]e toute évidence, la prescription d'une action ne saurait commencer à

412. Art. 2262, par. 2 C.c.B.-C.

413. Art. 2495 C.c.B.-C.

414. Supra note 271 à la p. 723; Provinces-Unies, compagnie d'assurances c. Laurentienne Générale, compagnie d'assurances, [1990] R.J.Q. 1304 (C.S.); Albany Insurance Company c. Reliable Cartage Ltd., [1992] R.J.Q. 2594 aux pp. 2597-2598 (C.S.).

415. O. Jobin-Laberge, supra note 95 aux pp. 1160-1161, n 249; D. Lluelles, supra note 75 à la p. 343.

416. Art. 2923 C.c.Q.

417. Art. 2925 C.c.Q.

418. Art. 2926 C.c.Q.

419. Trépanier c. Plamondon, [1985] C.A. 242. 
courir avant que ne soit né le droit d'y recourir». ${ }^{420}$ C'est ce qui explique pourquoi le jour marquant le point de départ du délai de prescription de l'action subrogatoire de l'assureur correspond à la date du paiement de l'indemnité. ${ }^{421}$

Il ne fait aucun doute que l'ancien délai de prescription applicable aux contrats d'assurance n'est plus justifié depuis l'adoption du Code civil $d u$ Québec. Le fondement de la créance directe dans le droit à réparation de la victime sert aussi à déterminer les causes d'extinction du recours direct du tiers lésé.

\section{B. Les modes d'extinction de l'action directe du tiers lésé}

Puisque la créance directe naît du droit à réparation de la victime, ${ }^{422}$ les différentes causes d'extinction de la créance de responsabilité affectent également la créance directe du tiers lésé. L'extinction de la créance de la victime a donc pour effet d'éteindre la créance directe du tiers lésé. Par exemple, la remise de dette, la renonciation, la reconnaissance de dette, la prescription, la compensation et la confusion constituent des modes d'extinction de la créance de la victime et, par voie de conséquence, de la créance directe du tiers lésé.

En France, malgré les causes d'extinction communes à l'action directe et à l'action en responsabilité, une certaine jurisprudence considère que l'extinction de la créance directe se distingue de celle de l'action en responsabilité. ${ }^{423}$ Ce récent développement jurisprudentiel relatif au mode d'extinction qu'est la confusion fait apparaître l'autonomie de l'extinction de l'action directe du tiers lésé.

420. Morin c. Canadian Home Assurance Company, [1970] R.C.S. 561 à la p. 565, M. le juge Fauteux.

421. Transport Indemnity Company c. Paquin, [1972] C.S. 704 à la p. 710, M. le juge Fortin,. conf. par 500-09-00667-72 (C.A.).

422. Supra notes $113,117,120$ et 127.

423. H. Groutel, supra note 268 à la p. 2. 
L'affaire La Paternelle ${ }^{424}$ illustre ce développement de la jurisprudence française portant sur le caractère autonome de l'extinction du droit direct. En l'espèce, mari et femme sont décédés des suites d'un accident d'automobile laissant derrière eux des enfants orphelins. Ces derniers possédaient à la fois les qualités d'héritiers et de demandeurs dans le cadre d'une action directe dirigée contre l'assureur de leurs parents. La Cour de cassation décide que la qualité d'héritiers importe peu puisque les enfants exercent l'action directe. D'après la Cour, le mode d'extinction qu'est la confusion ne prive pas les tiers lésés d'exercer leur créance directe contre l'assureur.

Tel que l'observe le professeur Hubert Groutel, d'ailleurs favorable à cette nouvelle direction, il est nécessaire de mettre quelque distance entre l'action directe et l'action en responsabilité de manière à «(...) occulter en quelque sorte l'action en responsabilité, pour ne plus voir que l'action directe contre l'assureur». ${ }^{425}$ En faisant abstraction de la créance de responsabilité pour ne voir que la créance directe, H. Groutel est d'avis que la victime n'est plus considérée comme créancière de la succession. ${ }^{426}$ Par conséquent, on ne peut plus reprocher à la victime d'être débitrice envers elle-même. Cette solution devient alors avantageuse pour les victimes héritières puisqu'elles peuvent toucher l'indemnité d'assurance.

D'après nous, ce précepte témoigne d'un grand respect de l'autonomie de l'action directe par rapport à l'action en responsabilité car la solution retenue par la jurisprudence française reconnaît que le droit direct du tiers lésé se détache de la créance de responsabilité civile et mène une existence autonome jusqu'à sa propre extinction. Néanmoins, nous croyons qu'il est encore tôt pour que le droit québécois accepte d'occulter l'action en responsabilité, lorsqu'il y a confusion par exemple, pour n'y voir que l'action directe du tiers lésé. Cependant, on ne peut nier l'autonomie de la prescription de l'action directe du tiers lésé depuis 1994.

\section{L'autonomie de la prescription du recours direct du tiers lésé}

424. Cass. civ. $1^{\text {re }}, 25$ mai 1992, Resp. civ. et assur.1992. comm.335.

425. H. Groutel, supra note 398.

426. Ibid. 
L'action directe du tiers lésé se prescrit selon un délai identique à celui de l'action en responsabilité de la victime. Toutefois, la prescription du recours direct suit son propre cours, jusqu'à l'extinction de la créance de réparation directe du tiers lésé. C'est en raison du caractère autonome de l'action directe du tiers lésé que la prescription de l'action directe acquiert toute son autonomie.

\section{a) L'absence d'interruption de prescription}

En raison de l'absence de solidarité entre l'assureur qui est directement poursuivi et l'auteur du préjudice, la prescription de l'action directe n'interrompt pas celle de l'action en responsabilité, et vice-versa. À cet égard, madame Jobin-Laberge considère qu'il serait risqué pour le tiers lésé de laisser prescrire l'une ou l'autre action qu'il n'aura pas choisi d'exercer immédiatement. ${ }^{427}$

Nous croyons également que le tiers lésé devrait se montrer prudent puisqu'il n'existe aucune solidarité entre l'assureur solvens et l'auteur du préjudice. ${ }^{428}$ En effet, la solidarité doit être expressément stipulée par les parties ou par la loi. ${ }^{429}$ Or, les dispositions relatives à l'assurance de responsabilité n'en stipulent aucune. En principe, le dépôt de l'action directe du tiers lésé ne devrait donc pas influencer le sort de la prescription de l'action en responsabilité de la victime.

Néanmoins, aux termes de l'article 2501 C.c.Q. qui consacre le cumul des recours du tiers lésé, une solidarité imparfaite ${ }^{430}$ existe entre l'assureur de l'auteur du préjudice et ce dernier. Cette solidarité imparfaite s'explique par le fait que l'assureur et le responsable, bien qu'ils possèdent leur dette respective, ${ }^{431}$ demeurent tenus à des prestations identiques. L'action en responsabilité ou l'action directe permettent effectivement au tiers lésé d'obtenir l'intégralité de la

427. O. Jobin-Laberge, supra note 95 à la p. 1160, $\mathrm{n}^{\circ} 248$.

428. Art. 2900 C.c.Q. Aussi : Couture c. Halifax Fire Insurance Company, (1938) 64 B.R. 448; Morgan and Company c. North British and Mercantile Insurance Company, (1940), 69 B.R. 511; Brosseau c. Choinière, [1976] C.S. 950.

429. Art. 1525 C.c.Q.

430. "L'obligation in solidum implique (...) que chaque débiteur doit (...) une chose identique à celle à laquelle [son coobligé] est tenu.» M. Tancelin, «Chronique de jurisprudence» (1970) 11 C. de D. 594 à la p. 596.

431. I. Parizeau, supra note 56 à la p. 132; J.-G. Bergeron, supra note 52 à la p. 396. 
réparation de son préjudice. Il y a donc identité d'objets mais différenciation de causes $^{432}$ entre l'action en responsabilité de la victime et l'action directe du tiers lésé.

L'existence d'une obligation in solidum entre l'auteur du préjudice et son assureur de responsabilité implique que chacun d'eux soit obligé au tout. ${ }^{433}$ Par conséquent, le paiement fait par l'un des débiteurs libère l'autre de son obligation. ${ }^{434}$ L'indemnisation complète du tiers lésé par l'assureur éteint donc l'obligation du responsable et la réparation de l'entier préjudice de la victime par le responsable éteint l'obligation de garantie de l'assureur.

Malgré les causes d'extinction et les délais de prescription communs ${ }^{435}$ à l'action en responsabilité et à l'action directe, l'absence de solidarité entre ces deux actions suppose que chacune d'elles possèdent une extinction qui lui est propre. C'est ce qui explique que le déroulement de la prescription de l'action directe du tiers lésé est distinct de celui de l'action en responsabilité de la victime.

432. Y. Lambert-Faivre, supra note 84 à la p. $450, \mathrm{n}^{\circ} 695$.

433. J.-L. Baudouin, supra note 6 aux pp. 493-494, $\mathrm{n}^{\text {os }} 871-872$.

434. Jean Pineau, «Théorie des obligations», dans La réforme du Code civil, Ste-Foy, Presses de l'Université Laval, 1993, aux pp. 9 et 129-133, n ${ }^{\text {os }} 131-132$.

435. Supra, Chapitre 2, § 3, A. et B. 


\section{b) L'étendue de la prescription de l'action directe du tiers lésé}

Le recours direct du tiers lésé est soumis aux mêmes causes d'interruption ou de suspension de prescription que toute autre action civile. Ainsi, le dépôt ${ }^{436}$ de l'action directe, la reconnaissance de dette de l'auteur du préjudice, ${ }^{437}$ l'impossibilité de droit ou de fait de pouvoir agir ${ }^{438}$ peuvent interrompre ou suspendre la prescription de l'action directe, selon le cas. En raison de l'autonomie du recours direct du tiers lésé, les causes d'interruption ou de suspension de la prescription du recours ne sauraient affecter le cours de la prescription de l'action en responsabilité.

Le tiers lésé, on le sait, n'a pas à exercer simultanément le recours direct et l'action en responsabilité. Il est alors possible que le délai de prescription du recours direct soit suspendu indépendamment du déroulement de l'action en responsabilité. L'action directe du tiers lésé pourra donc s'éteindre au-delà du jour marquant l'extinction de l'action en responsabilité. Toutefois, au bout du compte, la durée utile de la prescription du recours direct devrait demeurer triennale ou décennale selon la nature de la créance.

En France, les tribunaux ont ajouté aux phénomènes de suspension et d'interruption des délais de prescription de l'action directe la possibilité de prolonger la durée du recours direct au-delà de la période de prescription normalement prévue par la loi. ${ }^{439}$ La jurisprudence française reconnaît que le délai de prescription de l'action directe se prolongera aussi longtemps que l'assuré peut exercer son recours en garantie contre son assureur.

La théorie française de prolongation de l'action directe du tiers lésé est la conséquence de l'application du principe jurisprudentiel selon lequel «(...) l'action directe de la victime, qui trouve son fondement dans le droit de celle-ci à réparation de son préjudice, peut être exercée contre l'assureur de responsabilité aussi longtemps que celui-ci est exposé au recours de son assu-

436. Art. 2892 C.c.Q.

437. Art. 2898 C.c.Q.

438. Art. 2904 C.c.Q.

439. Cass. civ. $1^{\text {re }}, 1^{\mathrm{er}}$ mars 1986, D. 1987.somm.183 (note H.Groutel); J.-cl. resp. civ., supra note 12, $\mathrm{n}^{\text {os }}$ 53-54; Cass. civ. $1^{\text {re }}, 13$ févier 1996, Resp. civ. et assur.1996.16-17.comm.151. 
ré». ${ }^{440}$ La Cour de cassation a décidé que la prolongation de l'action directe ne peut cependant excéder le délai de deux ans applicable à l'action en garantie. ${ }^{441}$

En d'autres mots, la théorie française portant sur la prolongation de la prescription de l'action directe a été créée par la jurisprudence afin que l'assureur respecte son obligation de conserver efficacement l'indemnité d'assurance au bénéfice exclusif de la victime. ${ }^{442}$ Le droit français permet donc à la victime de contraindre l'assureur à lui verser l'indemnité d'assurance tout au long de la période de prolongation. ${ }^{443}$ Nous pensons que la question de la prolongation du délai de prescription de l'action directe peut également se poser en droit québécois depuis que la loi a consacré l'autonomie du droit direct du tiers lésé afin de garantir une indemnisation efficace à ce dernier.

Le caractère autonome de l'action directe du tiers lésé se reflète à travers le déroulement de la prescription de la créance de réparation directe. En effet, le recours direct du tiers lésé possède ses propres causes de suspension et d'interruption de prescription, indépendamment du cours de la prescription de l'action en responsabilité. Bien que l'action en responsabilité et l'action directe trouvent toutes deux leur fondement dans le droit à réparation de la victime, il demeure qu'elles suivent des voies distinctes jusqu'au jour de leur extinction respective. L'adoption du Code civil du Québec aura donc permis à l'action directe du tiers lésé de se démarquer de l'action en responsabilité dans le but d'assurer la protection des droits des victimes dans le domaine de l'assurance de responsabilité.

440. Cass. civ. $1^{\text {re }}, 17$ février 1993, Resp. civ. et assur. 1993.comm.181.

441. Voir art. L. 114-1 C. ass.; Cass. civ. $3^{\mathrm{e}}$, 22 juillet 1987, D. 1988.somm.151 (note H. Groutel); Cass. civ. $1^{\text {re }}, 13$ février 1996, supra note 439.

442. Ibid.

443. Paris, $8^{\mathrm{e}}$ Ch.B., 20 sept. 1989, Resp. civ. et assur. 1993.Comm.181. 


\section{CONCLUSION}

En principe, l'objet de l'assurance de responsabilité est de garantir la dette de responsabilité de l'assuré. Le Code civil du Québec ajoute un second objectif, soit la protection des droits des tiers lésés. La reconnaissance du caractère autonome du droit direct et la création du régime de protection d'ordre public fournissent d'ailleurs les fondements à la transformation du rôle social de l'assurance de responsabilité. Sur cet aspect, le droit québécois prend une direction similaire à celle de la France lorsqu'il accorde à l'assurance de responsabilité le rôle de garantir la créance d'indemnisation des victimes.

L'affirmation du caractère hybride du droit direct du tiers lésé prend une importance pratique considérable en présence de parties liées par une police à base de réclamation. On a vu qu'en général les droits des tiers lésés sont réduits lorsque l'assureur limite la couverture en fonction de la réclamation de la victime. En effet, les trous de garantie inhérents aux clauses à base de réclamation portent atteinte aux droits des victimes. Celles-ci peuvent être privées d'exercer leur action directe alors que la prescription n'est pas encore acquise.

La consécration de l'action directe du tiers lésé en un droit substantiel, protégé par l'ordre public, remet en question l'étendue de la liberté contractuelle des assureurs. Les assureurs devront à tout le moins apporter une attention particulière aux droits des tiers lésés lors de la rédaction de clauses limitatives de garantie basées sur le concept de la réclamation. L'affirmation du droit direct du tiers lésé a donc pour effet de restreindre les droits des assureurs à l'égard des clauses qui limitent la durée de la garantie dans le temps.

D'un autre point de vue, l'affirmation de l'autonomie du droit direct du tiers lésé élargit les droits de l'assureur. Cela s'explique par le fait que l'assureur subrogé est maintenant investi de la créance directe contre l'auteur du préjudice. Cet élargissement des droits de l'assureur subrogé qui a payé l'indemnité nous a amenés à nous interroger sur l'applicabilité des exceptions au droit de subrogation contre les personnes de la maison de l'assuré. 
À cet égard, nous avons établi que seules les personnes de la maison sont visées par l'interdiction de subrogation étant donné que le caractère d'exception de l'interdiction de subrogation appelle une interprétation restrictive de la suppression du recours subrogatoire de l'assureur. En conséquence, nous avons conclu que l'assureur qui a payé l'indemnité peut, s'il y a lieu, poursuivre directement l'assureur qui garantit aussi la responsabilité des personnes de la maison de l'assuré.

Les conséquences de l'affirmation de l'action directe sur les droits de l'assureur subrogé et la prédominance des droits des tiers lésés en présence de parties liées par une police à base de réclamation constituent deux implications majeures découlant de la nature autonome du droit direct du tiers lésé en assurance de responsabilité. L'action directe n'est plus un droit de procédure. En ayant transformé le droit direct du tiers lésé en un droit substantiel doté d'un caractère impératif, le Code civil du Québec a profondément modifié l'assurance de responsabilité. 